Review

\title{
Channel-Forming Bacterial Toxins in Biosensing and Macromolecule Delivery
}

\section{Philip A. Gurnev ${ }^{1,2}$ and Ekaterina M. Nestorovich ${ }^{3, *}$}

1 Physics Department, University of Massachusetts, Amherst, MA 01003, USA;

E-Mail: gurnev@physics.umass.edu

2 Program in Physical Biology, Eunice Kennedy Shriver National Institute of Child Health and Human Development, National Institutes of Health, Bethesda, MD 20008, USA

3 Department of Biology, the Catholic University of America, Washington, DC 20064, USA

* Author to whom correspondence should be addressed; E-Mail: nestorovich@cua.edu; Tel.: +1-202-319-6723; Fax: +1-202-319-5721.

Received: 2 June 2014; in revised form: 8 August 2014 / Accepted:8 August 2014 / Published: 21 August 2014

\begin{abstract}
To intoxicate cells, pore-forming bacterial toxins are evolved to allow for the transmembrane traffic of different substrates, ranging from small inorganic ions to cell-specific polypeptides. Recent developments in single-channel electrical recordings, $\mathrm{X}$-ray crystallography, protein engineering, and computational methods have generated a large body of knowledge about the basic principles of channel-mediated molecular transport. These discoveries provide a robust framework for expansion of the described principles and methods toward use of biological nanopores in the growing field of nanobiotechnology. This article, written for a special volume on "Intracellular Traffic and Transport of Bacterial Protein Toxins", reviews the current state of applications of pore-forming bacterial toxins in small- and macromolecule-sensing, targeted cancer therapy, and drug delivery. We discuss the electrophysiological studies that explore molecular details of channel-facilitated protein and polymer transport across cellular membranes using both natural and foreign substrates. The review focuses on the structurally and functionally different bacterial toxins: gramicidin A of Bacillus brevis, $\alpha$-hemolysin of Staphylococcus aureus, and binary toxin of Bacillus anthracis, which have found their "second life" in a variety of developing medical and technological applications.
\end{abstract}


Keywords: gramicidin A; $\alpha$-hemolysin; anthrax toxin; biosensing; stochastic sensing; ion channel; biological nanopore; protein translocation; targeted toxins; drug delivery; polymer transport

\section{Introduction: Channel-Forming Bacterial Toxins}

During intoxication or internalization, many bacterial exotoxins form ion-conducting channels in membranes of the targeted cells or intracellular organelles. Channel formation is potentiated by a unique ability of many of these molecules to exist in two states: a stable water-soluble conformation and an integral membrane pore [1]. The resulting channels contribute to the toxin's virulent action either directly or indirectly. Some channel-forming toxins directly kill compromised cells by inducing uncontrollable leaks of ions, water, and/or water-soluble metabolites [2-4]. The toxin-induced membrane perforation allows virulent cells to combat the host defense systems, to mediate escape of invasive bacterial cells into host cytoplasm from encapsulating phagosomes, to provide nutrients for bacteria, and to eliminate or control the competing bacterial cells [4-8]. Membrane-perforating bacterial toxins are often called pore-forming toxins (PFTs).

Distinctively different are the AB-type toxins that employ channel-forming parts for intracellular delivery of specialized catalytic subunits. In contrast to PFTs, AB-type toxins act in the cytosol, targeting specific intracellular substrates. The AB-type toxins are secreted as either single-chain proteins containing at least two functional domains, the receptor binding $\mathrm{B}$ domain and the active/enzymatic A domain, or as two (or three in the case of anthrax toxin) individual non-linked binary toxin subunits, an enzymatic/active A component and a binding/translocation B component [9]. For the AB-type toxin intracellular action, the enzymatic A component has to be delivered across the target cell membrane into the cytosol. Remarkably, the B components of the binary bacterial toxins secreted by several pathogenic species of Bacillus and Clostridium not only provide the binding site for the A components but also mediate the A component intracellular transport [9]. In particular, following the receptor mediated endocytosis, the B components form oligomeric transmembrane channels, that have been suggested to serve as active translocation pathways for the A component transport. The exact role of the B domain in transport of the single-chain AB-type toxins is debated; in particular, it is not always established whether the uptake of these toxins involves formation of ion channels. However, ion channel activity in planar bilayer membranes has been documented for at least two members of the family, namely diphtheria toxin, DT of Corynebacterium diphtheriae [10-12] and botulinum neurotoxin, BoNT of Clostridium botulinum [13,14]. Moreover, even though formation of ion channels in the artificial lipid bilayer systems has been reported for a number of binary bacterial toxin B components [15-17], the traditional pore-facilitated model of anthrax toxin internalization was recently challenged by an alternative "membrane rupturing" scenario [18].

This review is written to discuss several "classical" channel-forming bacterial toxins, which won their "second life" in a variety of developing biotechnological applications. Because the focus of this "Toxins" issue is on intracellular traffic and transport of bacterial protein toxins, we will mostly discuss the questions related to biosensing properties of the channel-forming bacterial toxins. 
More specifically, we highlight the applications where bacterial toxin pores were used to probe mechanisms of molecule detection and macromolecule transport. Remarkably, some of these applications, for instance those that develop the targeted toxin therapies to battle cancer, directly employ the unique ability of these proteins to intoxicate cells, whereas many other approaches use the channel-forming bacterial toxins as suitable tools able to respond to electrical, chemical or mechanical stimuli [19]. Note that the channel-forming proteins play quite distinct roles in the cell intoxication by PFTs and AB-type bacterial toxins. However, for the practical purpose of this review, we will use the term "channel-forming bacterial toxins" when referring to any of these types of toxins.

\section{Biosensing and Polymer Translocation with Nanopores}

The channel-forming toxins, and, more broadly, biological nanopores are molecules of immediate interest for biotechnology [19-22]. The ability of these molecules to generate selective and regulated pathways for water, ions, and water-soluble small and macromolecules in biological and artificial membranes offers exciting possibilities for a variety of medical and technological applications. To be directly examined for these applications, the biological nanopores are often incorporated into model lipid membranes where changes in the channel permeability to ions could be detected directly by applying transmembrane voltage and measuring ion current. The reconstitution methods range from the "classical" planar lipid bilayer and liposomes-based approaches to membranes supported on solid substrates and droplet interface bilayers (reviewed in refs. [19,23]). After gaining momentum from the pioneered studies by Kasianowicz and Bezrukov [24,25] where $\alpha$-hemolysin ( $\alpha \mathrm{HL}$ ) of Staphylococcus aureus was suggested to serve as a "nanoscopic cuvette" to study reaction dynamic some 20 years ago, the field rapidly exploded. Sensing with biological nanopores is based on reversible interruptions of ion current through an assembled pore in the model membrane that are generated by individual analytes, molecular complexes or nanoscale objects. Changes in this current resolved with uttermost precision using low noise feedback-loop operational amplifiers [26] could be used to determine presence, identity, structure, sequence, charged state, and kinetics of the studied objects or phenomena. In a way, this method is a molecular-scaled version of the resistive-pulse sensing technique suggested by William Coulter to count particles suspended in a fluid [27]. Within the reconstituted pore, single molecule binding affects the simultaneous concurrent transport of $\sim 10^{4} \mathrm{~s}^{-1}$ of the small ions, thus providing great electrical amplification of the studied single-molecule process. Pores formed by the membrane-perforating toxins may act as elementary on/off "switches" activated in response to interaction with specific analyte molecules, and as sensors reporting on their membrane surrounding and providing a specific volume for the studied compounds to pass and/or to interact.

\section{GrA, $\alpha \mathrm{HL}$, and $\mathrm{PA}_{63}$ as Nanopores of Choice in Biotechnology}

Among a variety of channel-forming bacterial toxins potentially suitable for the biotechnological applications, one can highlight several dominant toxin molecules that, for a number of reasons, are in the lead of the field. Those are small peptide channel-forming gramicidin A of Bacillus brevis, which induces lesions in cell membranes; $\alpha$-hemolysin of Staphylococcus aureus, a $\beta$-barrel heptameric pore-former, which also perforates cellular membranes; and binary toxin of Bacillus anthracis, in which the channel-forming component mediates delivery of the enzymatic subunits into target cell 
cytoplasm. The small channel-forming peptides, such as gramicidin A, can be chemically modified to serve as ideal on/off switches reacting to different stimuli and sensors of the bilayer membrane physical properties. The large $\beta$-barrel channels, such as $\alpha$-hemolysin, are more suitable for the stochastic resistive-pulse sensing of the entering or passing small and macromolecules. The binary anthrax toxin is a unique tool to investigate the fundamental principles of protein translocation across the membranes and to reengineer the toxin's properties for targeted killing of the cancer cells. In the following sections, we will first briefly review the biological functions of gramicidin A, $\alpha$-hemolysin, and anthrax toxin and then discuss the main current and potential future applications of these three toxins in the growing field of biotechnology.

\subsection{Gramicidin A of Bacillus Brevis}

Antibiotic gramicidin A (GrA) is secreted by soil bacteria Bacillus brevis in a mixture containing closely related peptide compounds [28]. GrA, which is a linear pentadecapeptide composed of 15 alternating L-D amino acids [29-31], is active against many gram-positive and several gram-negative bacteria [32]. Arguably one of the first ever described pore-formers, GrA generates defined and reproducible transmembrane water-filled channels [33] (Figure 1).

Figure 1. (a) Side and end views of the bilayer-spanning gramicidin A (GrA) channel. The energy-minimized structure represents a composite consistent with several NMR structures (PDB 1GRM, 1MAG); (b) GrA channels formed by the transbilayer dimerization of two $\beta$-helical subunits; (c) Single-channel current trace obtained with GrA in diphytanoylphosphatidylcholine bilayer [34]. Reprinted and modified with permission from reference [34].
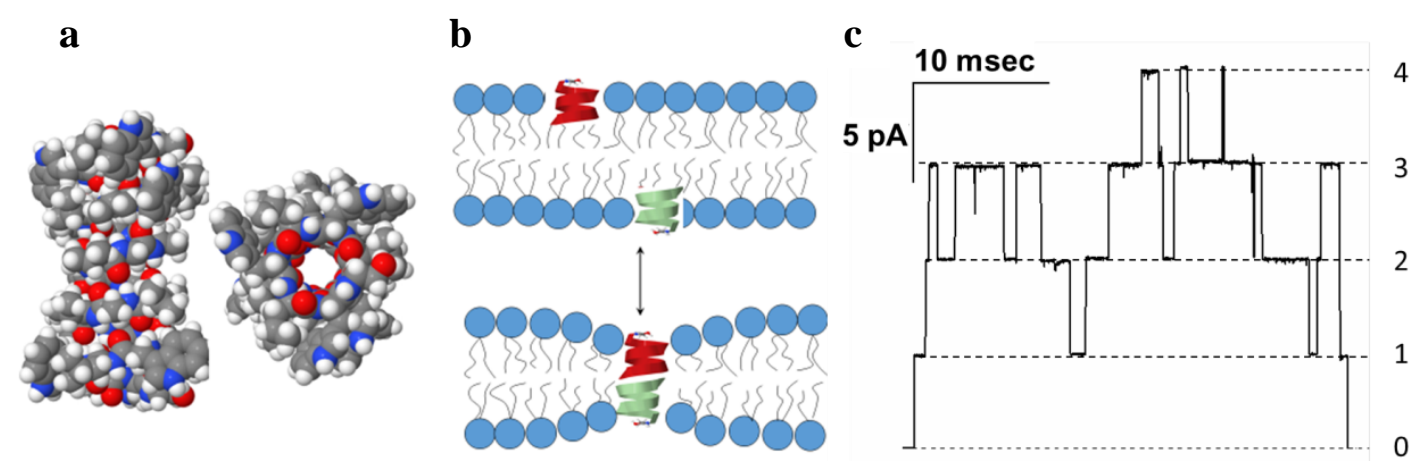

GrA membrane activity has been studied extensively over the last 40 years. Solution and solid-state NMR reveals a dimeric structure of the GrA pore where each molecular monomer adopts $\beta$-helical conformation and interacts with another one through hydrogen bonding between terminal formyl groups [35,36]. The luminal diameter of the pore that is formed by a peptide backbone is $4 \AA$, as determined from the channel's permeability to alkali metal cations, $\mathrm{H}^{+}$, and water [37,38] (Figure 1a). Despite relatively low molecular weight of $\sim 2 \mathrm{kDa}$, GrA creates well-defined and reproducible pores in planar lipid membranes (Figure 1c). The presented ion current recording, obtained under voltage-clamp experimental conditions, demonstrates sharp step-wise increments of the transmembrane current, where each upward "step" corresponds to formation of a GrA conductive dimer in a membrane, and the downward step indicates the dimer dissociation; maximum of four concurrently 
open GrA channels are seen in the record (numbered on the right side of Figure 1c). This type of single-channel recording allows for direct estimation of the major parameters of ion channel activity, current amplitude of the single pore and its average open time. These channels exhibit the structural and functional features typical for complex membrane proteins: defined conductive levels, sharp transitions between open and closed states (i.e., spontaneous gating), and low excess electric noise of the pore open state. The gramicidin channels show an ideal selectivity for monovalent inorganic cations [38], that originates from the side chain dipoles of the peptide backbone facing the channel lumen $[39,40]$. The cation transport across the narrow GrA pore occurs in a single-file fashion through consecutive ion bindings to two specific sites in the pore [41].

The gramicidin channels are specifically interesting because they show a unique sensitivity to the properties of the surrounding lipid bilayer. The length of a pore-forming dimer is only $\sim 26 \AA$, which roughly matches the thickness of the hydrophobic part of the lipid bilayer. Since the hydrophobic thickness of the gramicidin dimer is less than the thickness of the membrane [42,43], pore formation is almost always associated with a local membrane deformation [44,45] (Figure 1b). The energetic cost of that deformation is therefore a primary factor determining the channel's functions. Because of that, the membrane lipid environment is a strong modulator of the GrA channel activity. Subtle changes in membrane properties such as membrane thickness, lipid composition, and ordered state influence parameters of GrA channels. Due to its relative simplicity, gramicidin has been recognized as unique ion channel for modeling and simulation of the fundamental principles of lipid/protein interactions, and membrane protein structure and function. The GrA channels are good candidates for the molecular sensing applications because of the relative simplicity of the peptide, defined characteristics of the ion channel conductance, and unique sensitivity of conductive parameters channel to the membrane structure [46,47]. In the developed applications, GrA is used to study mechanical properties [48] and charged state of membranes [34,49,50], to detect protein-membrane interactions [51], to probe enzyme activity [52] and protein-protein interactions, to create conductive components of bio-inspired diodes [53], and to fabricate components of drug delivery systems in nanomedicine [54].

\section{2. $\alpha$-Hemolysin of Staphylococcus Aureus}

Alpha-hemolysin $(\alpha H L)$ is a water-soluble toxin secreted by the pathogenic bacterium Staphylococcus aureus [55,56]. Released as a 293-amino acid monomeric polypeptide with a molecular mass of $33 \mathrm{kDa}, \alpha \mathrm{HL}$ is believed to bind to membrane protein receptors [57,58] and/or to specific lipids in the susceptible target cells [59,60]. Seven adsorbed monomeric subunits then associate and form a nonlytic prepore complex on the membrane. The subunits further penetrate the membrane to form a lytic pore $[61,62]$. Recent evidence suggests that the lytic pore formation may be not the only way of $\alpha \mathrm{HL}$ toxicity. A specific toxin-induced activation of its putative metalloprotease receptor may trigger activation of intracellular cascades, leading to increased toxicity (for a review see reference [63]). However, the correct assembly of the $\alpha$ HL pores remains a necessary step for its toxic action [64].

The first original study on $\alpha \mathrm{HL}$ channel reconstitution in the model bilayers membranes was performed by Krasilnikov and co-workers over three decades ago [65]. Further electrophysiological studies refined our understanding of an $\alpha \mathrm{HL}$ pore's conductance, geometric, and gating properties [66-77]. 
The pore is weakly anion-selective at neutral $\mathrm{pH}[66]$ and a stable conductance of $\sim 1 \mathrm{nS}$ is observed in $1 \mathrm{M} \mathrm{KCl}$ solution at room temperature (Figure 2a).

Figure 2. (a) Typical recording of a single $\alpha \mathrm{HL}$ channel reconstituted into diphytanoyl-phosphatidylcholine membrane. Applied voltage is $100 \mathrm{mV}$. Channel current corresponds to $\sim 100 \mathrm{pA}$ in $1 \mathrm{M} \mathrm{KCl}, \mathrm{pH} 7.4$; (b) Crystal structure of the $\alpha \mathrm{HL}$ heptamer (top and side views are shown) (PDB 7AHL) [78]. The mushroom-shaped complex is approximately $100 \AA$ tall and up to $100 \AA$ in diameter, and the stem domain measures about $52 \AA$ in height and $26 \AA$ in diameter.

$\mathbf{a}$

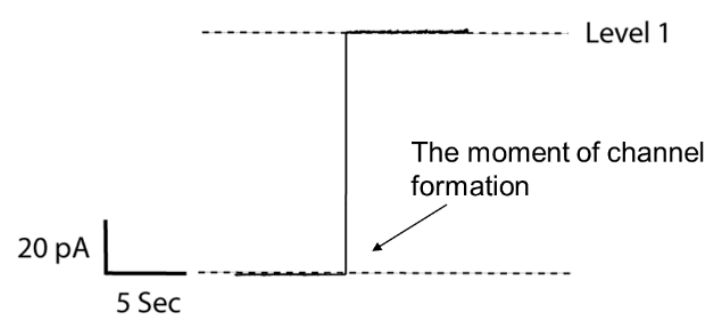

b

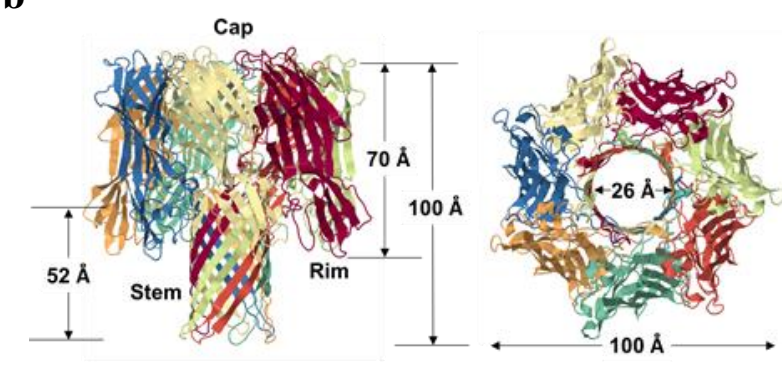

Crystal structure of the $\alpha H L$ pore was solved in 1996 at 1.9- $\AA$ resolution [78] (Figure 2b). The pore heptamer has a hollow mushroom-like shape consisting of the "stem", "cap", and "rim" domains. The cap of the mushroom, which together with the rim forms the core of the protein complex, resides outside the target membrane and is formed by the $\mathrm{N}$ - and $\mathrm{C}$-terminal ends of the monomers; it is composed of a $\beta$-sandwich and has a diameter of $100 \AA$. The stem part is a lytic transmembrane 14 -stranded $\beta$-barrel assembled from seven $\beta$-hairpins, each contributed by an individual monomer. Two apparent constrictions with radii of $0.9 \mathrm{~nm}$ and $0.6-0.7 \mathrm{~nm}$ are located in the channel lumen, with the larger one being closer to the side of the cap. The interior of the $\beta$-barrel is primarily hydrophilic while the exterior has a hydrophobic surface. Molecular dynamic simulations were applied to estimate the diameter of the pore and the permeability of water through its side channels of the mushroom "head" [79]. By applying an electric potential across the pore, the authors were able to calculate the open-channel conductivity and the electrostatic potential along the pore length. Large pore dimensions and structural robustness of the $\alpha \mathrm{HL}$ heptamer permit the wide usage of this bacterial toxin in a variety of developing biotechnological applications.

\section{3. $P A_{63}$ Component of Anthrax Toxin of Bacillus Anthracis}

Bacillus anthracis, the bacterium that causes anthrax, is a large Gram-positive, rod-shaped, aerobic, spore-forming bacterial pathogen. The tripartite exotoxin (anthrax toxin) [80,81] and phagocytosis-inhibiting poly-D-glutamic acid capsule are the main virulence factors of B. anthracis [82]. The deliberate dissemination of $B$. anthracis spores in 2001 via the "anthrax letters" and their fatal consequences led to almost 13 years of continuing political and scientific efforts to develop medical countermeasures to protect humans from anthrax bioterrorism [83]. Because anthrax infections are infrequent, bacterial resistance of $B$. anthracis, even though described [84,85], is not a major focus of ongoing research. The recent efforts to disable the anthrax infection mostly focused on inhibiting the 
tripartite anthrax toxin (reviewed in [86]). Anthrax infection, especially in its inhalational form, is extremely difficult to treat because flu-like symptoms appear only after B. anthracis have multiplied inside the host and started to produce the anthrax exotoxin [87,88]. At this stage, the aggressive antibacterial therapy can inhibit the bacterium growth, but the infection can still be lethal because of the accumulation of the toxin [89]. The recent progress made in understanding of anthrax toxin structure, arrangement, cellular uptake and functions is significant (reviewed in refs. [90-100]). Briefly, the binary anthrax toxin consists of two enzymatically active A moieties: lethal factor (LF) and edema factor (EF), and a single shared binding and translocation moiety: protective antigen (PA). The term "protective antigen" originates from the ability of this protein to stimulate production of the protective antibodies when used in anthrax vaccines. Individually, anthrax toxin's PA, LF and EF components are nontoxic; however, PA combinations with lethal toxin (LT = LF + PA) or with edema toxin $(\mathrm{ET}=\mathrm{EF}+\mathrm{PA})$ are primarily responsible for the anthrax symptoms and lethality.

The internalization process of anthrax toxin involves several stages (Figure 3a).

Figure 3. (a) A schematic model of Bacillus anthracis toxins cell entry; (b) Side and top views of anthrax toxin $\mathrm{PA}_{63}$ component (the symmetric model, PDB:1V36) [101]. The Phe427s are marked because of their importance in the transport properties; (c) Conductance of a single $\mathrm{PA}_{63}$ channel reconstituted into planar lipid membranes demonstrate fast flickering between open and closed states at 1-ms time resolution [102]. Reprinted with permission from references [86,101,102]. Copyright 2011 Wiley, 2012 Elsevier.

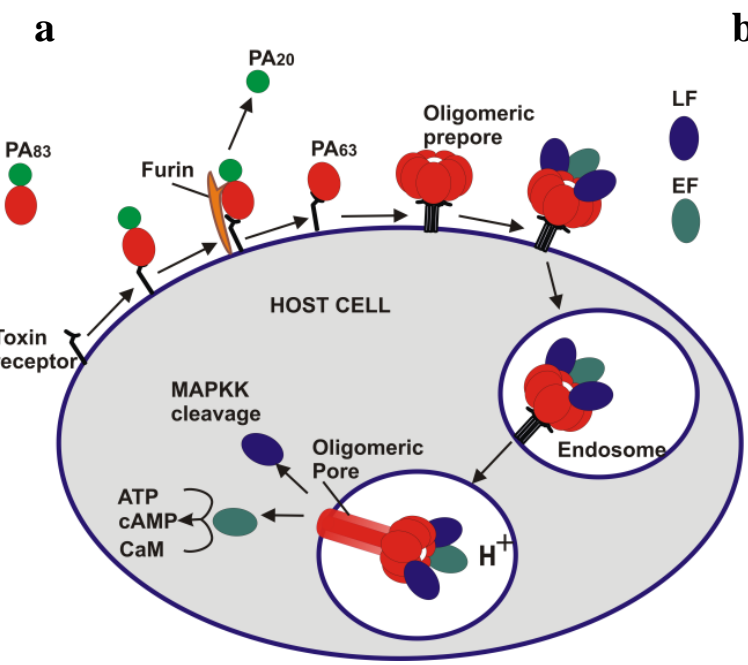

b

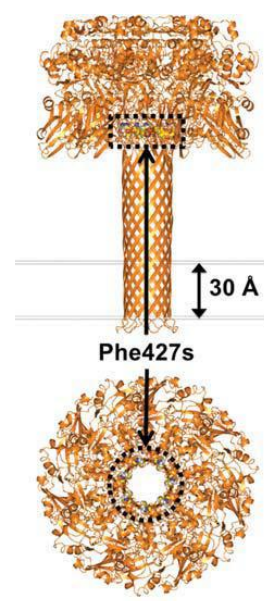

c

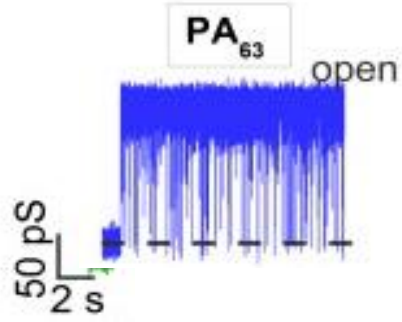

First, full length $\mathrm{PA}_{83}$ binds to the CMG2 and TEM8 receptors [103,104] on a host cell surface and is subsequently cleaved by extracellular furin protease to $\mathrm{PA}_{63}$ [105]. $\mathrm{PA}_{63}$ then undergoes oligomerization, which leads to formation of heptameric, $\left(\mathrm{PA}_{63}\right)_{7}$ [106] and octameric, $\left(\mathrm{PA}_{63}\right)_{8}$ [107] ring-shaped prepores. The formation of $\left(\mathrm{PA}_{63}\right)_{7}$ and $\left(\mathrm{PA}_{63}\right)_{8}$ generates, correspondingly, three [108] and four [107] $\mathrm{LF} / \mathrm{EF}$ binding sites at the interface of two adjacent $\mathrm{PA}_{63}$ molecules and causes receptor-mediated endocytosis of the anthrax toxin tripartite complexes [109]. The oligomeric $\mathrm{PA}_{63}$ prepore then undergoes significant structural changes promoted by the acidic endosomal environment, which results in the formation of a mushroom-shaped ion channel (125 $\AA$ in diameter with $70 \AA$ long cap, and $100 \AA$ long stem [110]) (Figure 3b), preferentially selective to cations [15]. When 
incorporated into the bilayer lipid membranes, $\mathrm{PA}_{63}$ was reported to form ion-permeable cation-selective ion channels $[15,111,112]$ prone to voltage-dependent closures typical for the other $\beta$-barrel channels. The characteristic property of $\mathrm{PA}_{63}$ single channels as well as the channel-forming components of binary clostridial $\mathrm{C} 2$ and iota toxins reconstituted into bilayer membranes is the non-voltage-dependent flickering of ion current between the open and completely closed states [16,17,113-115] (Figure 3c). Interestingly, the current noise of the F427A ( $\phi$-clamp) mutant (see Section 5.2) of $\mathrm{PA}_{63}$ is mostly free of this complex behavior [115]. A PA oligomer then is believed to act as an effective translocase, which unfolds and translocates LF and EF inside the cell using the proton gradient across the endosomal membrane $\left(\mathrm{pH}_{\text {endosome }}<\mathrm{pH}_{\text {cytosol }}\right)$ [116-121]. In an alternative model, the anthrax toxin catalyzes rupture of the endosomal membrane and toxic complexes are released into the cytosol [18]. Once in the cytosol, LF and EF actuate their catalytic actions. LF is a Zn-metalloprotease that cleaves mitogen-activated protein kinase kinases [122,123] and NLrp1 [124], resulting in disturbing host cell signal transduction. EF is a calmodulin-dependent adenylyl cyclase, which increases the cAMP level in the cells, contributing to dissemination of Bacillus anthracis in the host [125]. The key tissue targets responsible for the poisonous effect of LT and ET were recently identified [126]. LT and ET were shown to target the cardiovascular system and liver, respectively.

Anthrax toxin represents a unique arrangement of proteins where intracellular delivery of the enzymatic components is governed by the channel-forming component. Therefore, it provides an exceptional biological tool to study molecular details of protein transport and to rearm this toxin against malignant cells.

\section{Channel Forming Bacterial Toxins for Molecular Sensing}

\subsection{Probing Structure, Charge and Physical State of the Membranes with GrA}

The physical properties of biological membranes, namely membrane composition, lipid content, and asymmetry in lipid distribution between the bilayer leaflets and prevalence of the charged species are among the general factors affecting functions of membrane-embedded proteins. Apart from the specific protein/lipid interactions, the effect of the colligative membrane properties such as bilayer thickness, viscosity, bending rigidity, and the so-called intrinsic curvature [127] on membrane protein functioning is not well understood. The need for molecular probes is well fulfilled by small channel-forming peptide-based toxins, such as gramicidin A, studied in a model systems under controlled conditions. Originally, GrA and its derivatives were used to study membrane mechanics. Andersen and colleagues investigated the correlations between membrane thickness, viscosity, and bending rigidity, and channel lifetime. For details of these studies, we direct the reader to several reviews $[48,128]$.

Apart from their well-recognized application in studying membrane mechanics, small channel-forming peptides have been employed as sensitive probes to monitor surface membrane properties, in particular, membrane electrostatics. For the most part, the phospholipid molecules, which are the building blocks of the cellular membranes, contain zwitterionic or negatively charged headgroups exposed on the membrane/water interface. Distribution of these groups affects combined operation of the membrane-associated molecules, because electrostatic forces are important for many interactions within and between macromolecules. The interaction of proteins, nucleic acids, phospholipids, and 
their supra-molecular assemblies with the membranes affects general system electrostatics. In addition, the membrane surface potential is involved in regulation of membrane transport and cell/cell recognition $[129,130]$. The small channel-forming peptides can serve as the sensitive probes to monitor the properties of their immediate membrane surrounding.

It was established relatively early that the conductance of GrA channels is a strong function of the membrane surface charge [131]. The ion conductance of the bilayer-embedded GrA pore increases with an increase in percentage of the negatively charged surface bilayer groups. The charges on a membrane surface attract counter-ions and reduce the concentration of the co-ions near the entrance of the pore, thus increasing or decreasing a number of the cations, depending on the sign of the surface charge. The effects of the surface charge in GrA conductance are especially strong at low electrolyte concentrations.

Rostovtseva and colleagues analyzed the gramicidin pore conductance varying percentage of the charged lipids in a bilayer composition at different $\mathrm{pH}$ and salt concentrations [50]. Deviations of a single pore conductance from the predictions made using the Gouy-Chapman formalism allowed for estimation of the "intrinsic" pK values of the charged lipids at the surface of the bilayer. Thus, the GrA pore conductance was used to detect minute changes in the membrane surface charge density, supporting the results obtained using different surface charge identifying techniques [129,132]. Borisenko and collaborators [49] attached protonated chemical groups on the gramicidin molecules to create gramicidin-ethylenediamine and gramicidin-histamine peptides (Figure 4a).

Figure 4. (a) Model representation of the engineered GrA-ethylenediamine channel in a lipid bilayer [49]. At both entrances of the channels, an ionizable site (the primary amino group in gram-ethylenediamine; the imidazole group in gramicidin-histamine) is connected to the gramicidin backbone via a carbamate linkage). Representative single-channel currents of gramicidin-ethylenediamine (b) and gramicidin-histamine (c) at different $\mathrm{pH}$ values [49]. The closed channel states are seen as the zero current levels. The currents of the trans $\left(\mathrm{I}_{\mathrm{t}}\right)$ and cis $\left(\mathrm{I}_{\mathrm{c}}\right)$ isomeric states of the channel are indicated. Reprinted and modified with permission from reference [49]. ScienceDirect open archive.

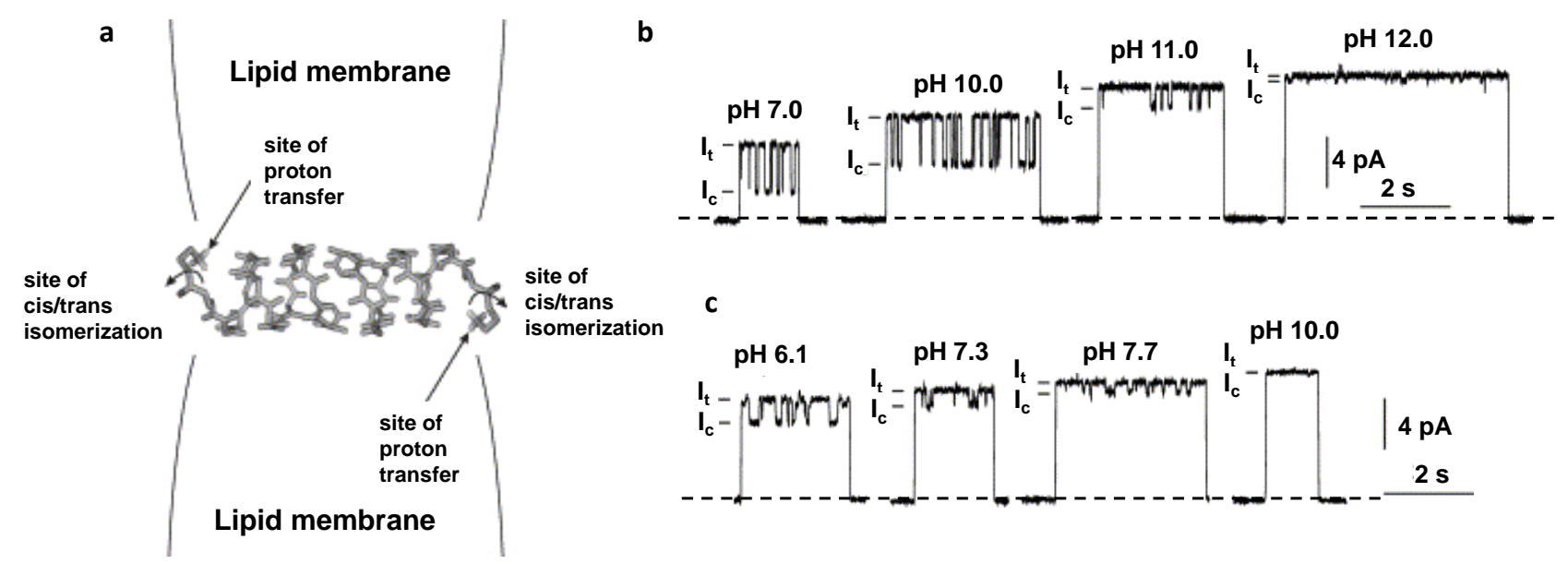

Both GrA variants were able to form single-molecule $\mathrm{pH}$-sensitive pores, by displaying additional current flickering in response to the membrane surface acidity changes (Figure 4b,c). Similarly, 
modified GrA channels with lysine substitution on the C-terminal, allowing for channel activation at the specifically high $\mathrm{pH}$ were recently reported [133].

Sensitivity of the gramicidin channels to the membrane surface properties determined their use in the applications focusing on probing changes in the membrane charged state. Mayer and colleagues [52] used the unmodified GrA to monitor enzymatic activity of the phospholipases D and C (PLD and PLC). These enzymes are cleaving specific phosphodiester bonds in the phospholipid headgroups, resulting in accumulation of charged or non-charged lipid species. Charged state of the membrane surface was changed, which, in the presence of the low electrolyte solution, was expected to influence GrA channel conductance. Indeed, application of PLD to the uncharged phosphatidylcholine membranes significantly increased the unitary GrA channel conductance. This change could be related to a conversion of the phosphatidylcholine lipids into the negatively charged phosphatidic acid, which, in turn, generates an increase in cation concentration at the membrane surface and, thereby, inside the channel (Figure 5).

Figure 5. Monitoring activity of phospholipase D (PLD) in the model lipid bilayers by changes in single channel conductance of GrA pores [52]. (a) As PLD hydrolyzes electrically neutral PC lipids and produces negatively charged PA lipids, the membrane negative charge is generated. It induces accumulation of the cations close to the membrane surface, leading to a significant increase in channel conductance. Negative charges are shown in red, and positive ions are shown in blue; (b) GrA unitary current vs. time recordings before and after addition of PLD. Reprinted with permission from reference [52]. Copyright 2009 American Chemical Society.

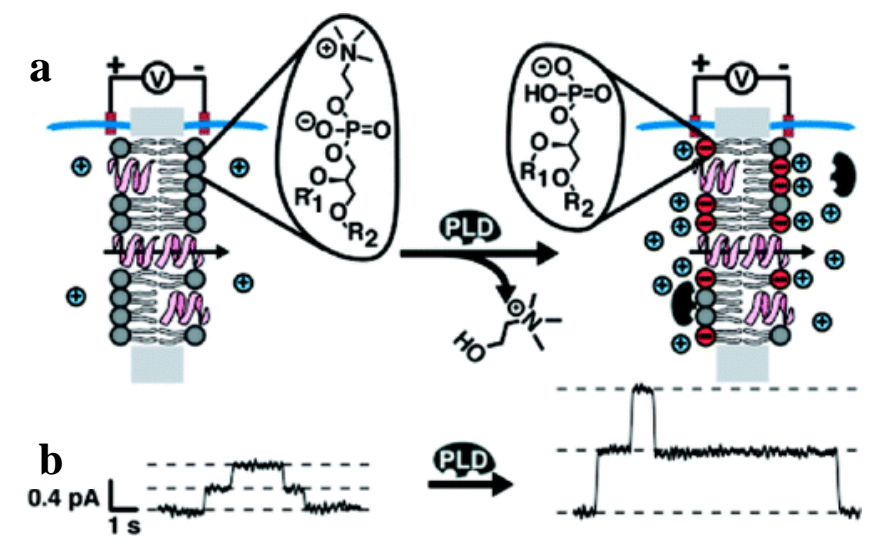

PLC activity in the negatively charged bilayers produces a significant decrease in the GrA conductance, reducing membrane content of the negatively charged phosphatidylinositol. Similarly, picomolar additions of alkaline phosphatase were monitored by attaching an enzyme-cleavable phosphate group on the C-terminal end of the GrA derivative [134]. In this case, cleavage of the negatively charged phosphate group reduces the concentration of cations only in the direct vicinity of the channel opening.

GrA and similar small toxins can be used to probe the electrostatic interactions of charged peptides and counter-ions with the membranes. For example, the membrane surface charge modification induced by adsorption of polyvalent cations and positively charged cargo peptides could be quantitatively detected [34,51]. Similarly, conductance of another small toxin, syringomycin E [135], was used to monitor adsorption of DNA on the positively charged bilayers [136]. 


\subsection{Molecular Sensing with $\alpha H L, P A_{63}$, and GrA}

Accurate and rapid molecular detection is vital for basic research, medicine, technology, and defense. Biological nanopores, including the channel-forming bacterial toxins, are natural single-molecule biosensors evolved to stochastically detect their substrates. In the model lipid bilayers, this detection is often manifested by reversible current fluctuations between open and closed states. The frequency, duration and magnitude of the "on/off" closures are defined by the concentration, size, charge, and other physicochemical characteristics of the substrates and analytes.

Over the past two decades, wild-type and genetically or chemically modified $\alpha \mathrm{HL}$ was extensively investigated as the molecular sensor able to detect a variety of analytes. The ionic species and organic molecules tested include DNA and RNA biopolymers [137], proteins [138], cyclodextrins [73,139,140], divalent metal ions [141-143], phosphate anions [144], trinitrotoluene [145], styryl dyes [146], $\beta$-lactam antibiotics [147,148], heparin [149], chemical warfare agents [150], and neurotransmitters [151].

One of the fascinating examples of the $\alpha \mathrm{HL}$ 's biosensing properties is its ability to reversibly bind $\beta$-cyclodextrin-based ( $\beta C D$ ) molecular adapters. In 1999, Bayley and colleagues equipped a single $\alpha H L$ channel with an internal, non-covalently bound $\beta C D$ that was able to mediate channel blocking by organic analytes, such as adamantanamine hydrochloride, adamantine carboxylic acid, promethazine, and imipramine (Figure 6) [139]. The symmetry match between the heptameric $\alpha$ HL channel and the 7-fold-symmetrical ring-shaped $\beta C D$ as well as a hydrophilic $\beta$-CD's exterior and proper dimensions assure comfortable fit between the single $\beta C D$ and the $\alpha H L$ channel lumen (Figure $6 \mathrm{~b}$ ).

The blockage events were detected when the non-modified cyclodextrins were added to the trans but not cis side of the chamber. Note that 6-fold symmetrical $\alpha \mathrm{CD}$ and 8 -fold symmetrical $\gamma \mathrm{CD}$ were also able to reversibly interact with the channel [139]; $\alpha \mathrm{HL}$ mutants able to bind $\beta C D$ from the cis side were later identified [73]. Because the $\beta C D$-induced current blockage events were partial (64\% of the total current) (Figure 6a, 2nd trace), leaving possibilities for the further current decrease, and because of the known ability of cyclodextrins to host different organic "guest" molecules in their hydrophobic interior, the $\alpha \mathrm{HL} / \beta C D$ system was suggested [139] and further investigated as a stochastic sensor for organic molecules. It turned out that several $\beta C D$ analytes (Figure 6a, 2nd and 3rd traces) were able to further decrease the current through a single $\alpha \mathrm{HL}$ channel, while not affecting the completely open channel. The recorded signals not only were used for the analyte detection but also for their quantification. Moreover, the authors explicitly showed that, when applied in mixtures, the $\alpha \mathrm{HL} / \beta \mathrm{CD}$ "guests" could be stochastically detected and quantified simultaneously by a single sensor element (Figure 6c) [139]. Interestingly, the wild type $\alpha H L$ and various mutants became more anion selective after the $\beta C D$ binding, whereas the negatively charged adapter, hepta-6-sulfato- $\beta C D$ generated selectivity to cations [140]. To understand how $\beta C D$ affects ion selectivity, Roux and colleagues performed molecular dynamic simulations and potential of mean force calculations using $\alpha \mathrm{HL}$ with and without the $\beta C D$ adapter $[152,153]$. The authors demonstrated that the narrow $\beta C D$ adapter increases the anion selectivity of $\alpha \mathrm{HL}$ because it locally reduces the radius of the pore, which results in a decrease in ionic screening and dielectric shielding of the strong electrostatic field induced by a ring of positively charged side chains of $\alpha \mathrm{HL}$ [153]. $\beta C D$ also induces a partial dissolvation of ions and affects the orientation of nearby charged residues [152]. 
Figure 6. (a) Bilayer recordings showing the interaction of a single $\alpha H L$ pore with $\beta$-cyclodextrin and model analytes 2-adamantanamine and 1-adamantanecarboxylic acid; (b) Molecular graphics representation of the interaction between $\alpha \mathrm{HL}$ and cyclodextrin; (c) Analysis of drug molecules by stochastic sensing with $\alpha \mathrm{HL}$ and a $\beta C D$ or $\gamma \mathrm{CD}$ adapter. Reprinted and modified with permission from reference [139]. Copyright 1999 Nature Publishing Group.

$\mathbf{a}$

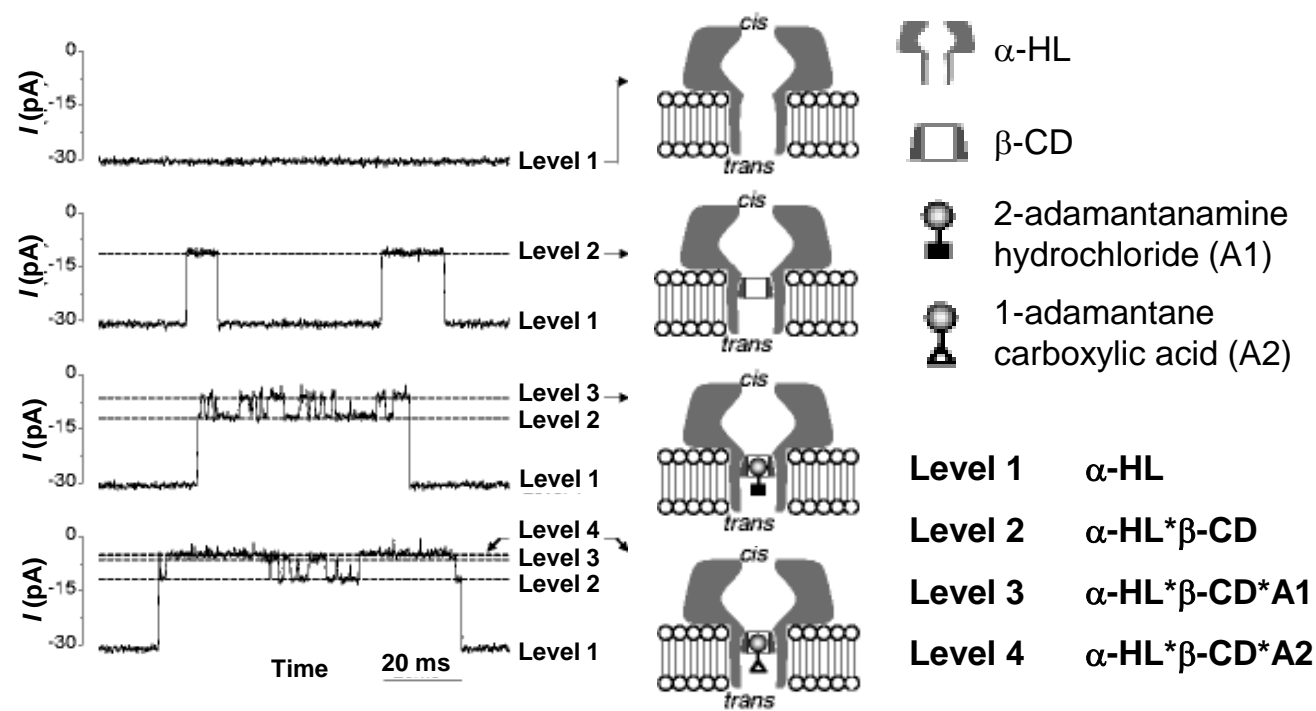

b
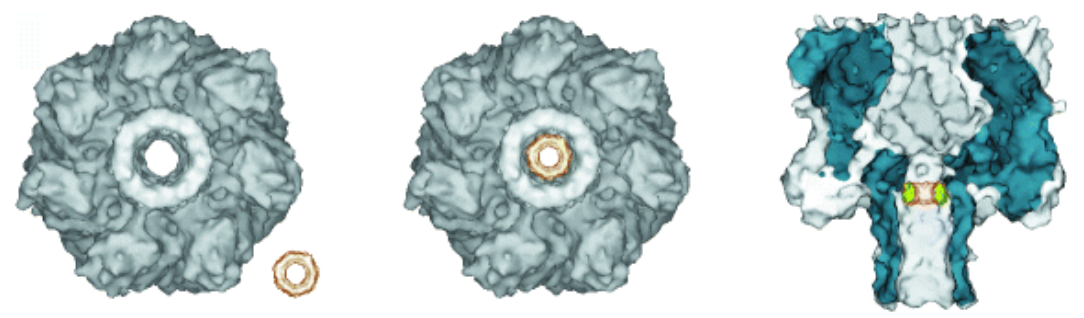

c
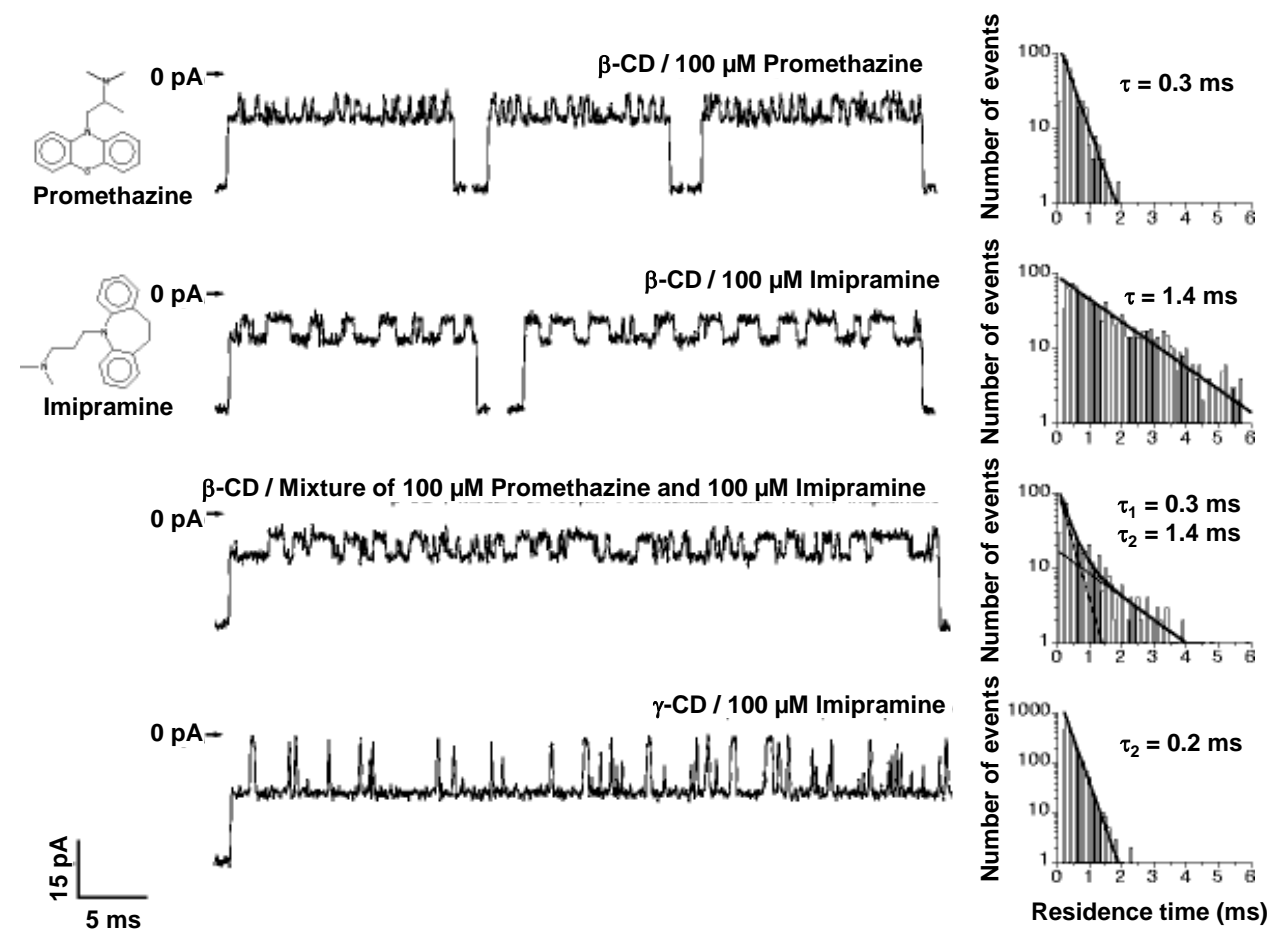
Interaction of $\beta \mathrm{CD}$ with $\alpha \mathrm{HL}$ was shown to be $\mathrm{pH}$ and voltage dependent; the apparent $\beta \mathrm{CD}$ dissociation constant varied from $\sim 3.1 \times 10^{-3}$ to $\sim 2.1 \times 10^{-2} \mathrm{M}$ in $\mathrm{pH} 5-11$ range, and from $\sim 3.1 \times 10^{-3}$ to $\sim 1.4 \times 10^{-2} \mathrm{M}$ with voltage change from $-40 \mathrm{mV}$ to $+40 \mathrm{mV}$ [73]. Moreover, the $\alpha \mathrm{HL}$ mutants that bind the $\beta C D$ adapter $\sim 10^{4}$ times more tightly than the wild type have been designed and investigated both with the planar lipid bilayers and high resolution x-ray crystallography [154]. Clearly, the mutant pores with the extended $\beta C D$ dwell time can serve as improved noncovalent molecular adapters [155], because sensing with molecular adapters would be more effective if the adapter did not frequently dissociate from the channel, leaving $\alpha \mathrm{HL}$ unable to detect analytes [156]. To increase strength of the $\beta \mathrm{CD} / \alpha \mathrm{HL}$ interaction, the authors covalently attached $\beta-\mathrm{CD}$ within the $\alpha-\mathrm{HL}$ pore in two possible molecular orientations by using a specific linker [156]. A modified $\beta C D$-based adapter, where a single oxygen atom in its ring skeleton was replaced by a disulfide unit, was also investigated [157]. A heptameric $\alpha H L$ pore capable to accommodate two different $\beta C D$-based adapters at distinct binding sites was engineered [158]. Non-modified $\beta-\mathrm{CD}$ and hepta-6-sulfato- $\beta C D$ were lodged simultaneously within the lumen of a single $\alpha \mathrm{HL}$ pore that was genetically engineered to accommodate them. The space between the adapters was characterized as $\sim 4400 \AA^{3}$ "nanocavity" for which the adapters served as gates at the cis and trans ends of the cavity [158]. The $\gamma$ CD-based adapters were employed to investigate the dynamic aspects of the Hofmeister effect [159] and to discriminate between the S- and R-enantiomers of the ibuprofen and thalidomide drug molecules [160].

Cyclodextrin's ability to enter a protein pore and reversibly occlude it was explored by a rational design of the channel blocking antitoxins to target both $\alpha \mathrm{HL}$ [161,162] and binary bacterial anthrax, $\mathrm{C} 2$, and iota toxins [102,114,163-170] (recently reviewed in refs. [86,115,171]). Briefly, the idea was to directly obstruct these channels from the physiologically relevant cis-side by compounds of the same symmetry as the target pore [163]. According to the diffusion model of Berezhkovskii and Bezrukov, for the blocking molecule to be therapeutically effective the attraction between the molecule and the channel should be strong enough to allow the molecule to stay in the channel for sufficiently long, thus blocking translocation of other molecules [172,173]. The $\mathrm{PA}_{63}$ prepore internal diameter was estimated to be between 20 and $35 \AA$ [106] with the $\mathrm{PA}_{63}$ pore's constriction region not exceeding $12 \AA[113,174,175]$. This finding guided the choice of the $\sim 15$ - $\AA 7$-fold symmetrical $\beta C D$ s as the potential core structures for blocker design. Because the $\mathrm{PA}_{63}$ channel, the binding component of the anthrax toxin is preferentially selective to cations, $\beta C D$ molecules were rationally modified to incorporate seven rositive charges (amino groups) covalently linked to the cyclodextrin's core by hydrocarbon linkers of different nature and length [163]. Several $7+\beta C D$ s were custom-synthesized and tested in the planar bilayers, in cell assays [102,114,163,168], and in vivo [167]. When a single phenyl group was introduced into each of the seven hydrocarbon linkers, the $\beta C D$ blocker affinity to the pore was enhanced more than 10 times [102,165]. It was suggested that this difference is defined by the additional stabilizing interactions between the introduced aromatic groups and $\phi$-clamp (see Section 5.2). Indeed, two of the tested $\beta C D$ blockers were significantly less potent with the F427A mutant of $\mathrm{PA}_{63}$ [102]. The authors also made a step towards understanding the physical forces responsible for the pore-blocker interactions by analyzing the dependence of interaction strength and underlying kinetics on the salt concentration and applied transmembrane potential [102]. It was shown that in the binding reaction of the $7+\beta C D$ to the channels, salt-concentration independent, short-range forces predominate. In the case of the blockers equipped with the aromatic linkers, the binding was 
further enhanced. At moderate and low salt concentrations, the blockers' residence times were influenced by long-range Coulomb interactions. The increase in the residence time as a function of transmembrane voltage showed the existence of an additional electrostatic component in the blocker/pore interactions.

Aside from $7+\beta C D$ s, $\quad \mathrm{PA}_{63}$ is permeable to a number of small-molecule cationic blockers [111,118,174-176] and some of them, especially those carrying the aromatic fragments [118] bind the channel at the low $\mathrm{nM}$ concentrations. It would be interesting, apart from the therapeutics applications, to explore the ability of the channel to detect positively charged analytes for the biosensing. In a different application, planar lipid bilayer measurements with anthrax toxin components were investigated as a rapid quantitative tool to recognize specific proteins and to screen for anthrax therapeutics [177]. The authors showed that the full-length LF and EF subunits convert the current/voltage relationship of the oligomeric $\mathrm{PA}_{63}$ from slightly non-linear to highly rectifying and diode-like. The pattern represented by the asymmetric blockage of $\mathrm{PA}_{63}$ ion channel with LF and EF provided the basis for the quantitative biosensor allowing one to identify and screen small molecule compounds and antibodies that disrupt anthrax toxin components interaction. Thus, the agents that bind to either $\mathrm{PA}_{63}$ (but do not block the ion current) or LF/EF would inhibit the LF/EF-induced rectification of the current-voltage relationship.

Modified gramicidin was also developed as a key element of a biosensor, composed of a tethered bilayer on a solid support, the a system combining biological recognition mechanism with physical transduction [178-181]. In this application, modified GrA serves as the signal transducer: single molecule binding to its engineered domain modulates ability of the transmembrane pores to dimerize and to pass ion current. Therefore, decrease in the ion flux could be used to detect presence of the analytes and/or their identity.

\subsection{Sequencing of Polynucleotides with $\alpha H L$}

An attractive idea to develop a relatively inexpensive and ultra-fast technique to decipher DNA and RNA polynucleotide sequences surfaced soon after the first reports on time-resolved polymeric molecules translocations across large toxin ion channels. The understanding that charged polymers can be successfully detected as they electrophoretically move through the appropriately narrow aperture of a biological nanopore under externally applied voltage had immediately provoked great interest to this field. The original US patent-awarded concept of the single-molecule sequencer by George Church, David Deamer, Daniel Branton, Richard Baldarelli, and John Kasianowicz [182] describes a nanoscopic channel in an artificial membrane separating two liquid-filled compartments, one of which contains the analyzed polymeric molecule, composed of sequential monomeric residues (Figure 7).

The method is based on detection of changes in the ion current through a single nanopore in the presence of a single polymer molecule that directionally moves, one monomer at a time, through the pore from one electrolyte compartment to another under the influence of an externally applied electric field. At the same time, the different passing polymer units are expected to generate different displacement of the small ions from the pore, and, therefore quite distinct current blockages (Figure $7 \mathrm{~b}$ ). The proposed principle of ion-channel assisted sensing resembles the resistive-pulse Coulter counter method, which detects and counts particles passing through a capillary connecting two 
electrolyte solutions [27]. The channel-based sequencer idea, due to its apparent simplicity and exciting perspectives of the fast and effective nucleic acid sequencing, has attracted multiple research groups to the nanopore-based sequencing field. This idea, if workable, would allow for scanning of polynucleotides with a $\mu$ s per-base rate, making rapid sequencing of a $6 \times 10^{9}$ base pairs of individual genome an achievable task. Moreover, in the originally proposed scheme, the nanopore sequencer idea did not require additional DNA amplification, hybridization and extensive processing, and, therefore, was expected to bring a tremendous improvement in clinical diagnostics and general research.

Figure 7. (a) A scheme of single-stranded DNA characterization with an ion channel. The ion current through a single unoccupied pore (illustrated by the channel at the left) is reduced as a single-stranded DNA molecule begins its passage through the pore (illustrated by the channel at the right) [182]; (b) Schematic representation of DNA sequencing model by the ion channel method. The individual DNA bases (G, A, T, and C) interfere sequentially and differentially with the flow of small ions through the pore which leads to the discrete conductance levels characteristic of the G, A, T, and C bases. The order of appearance of the conductance levels sequentially corresponds to the order of bases in the DNA [182]; (c) Oligomers of poly[U] cause transient blockades in the single $\alpha H L$ channel current [182]. Reprinted and modified with permission from reference [182].

$\mathbf{a}$

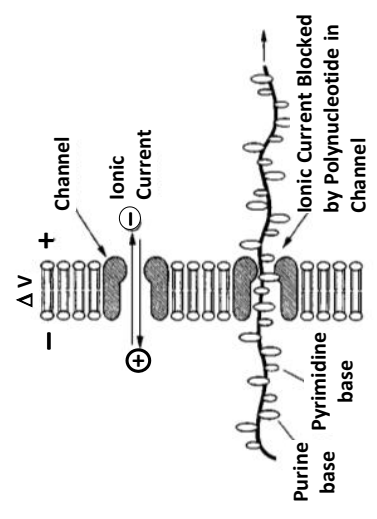

b

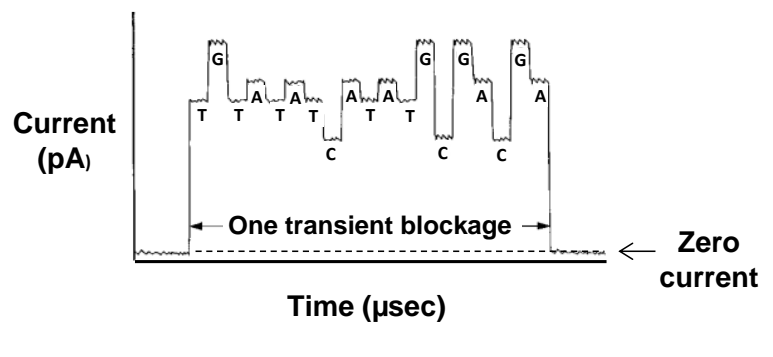

\section{C}

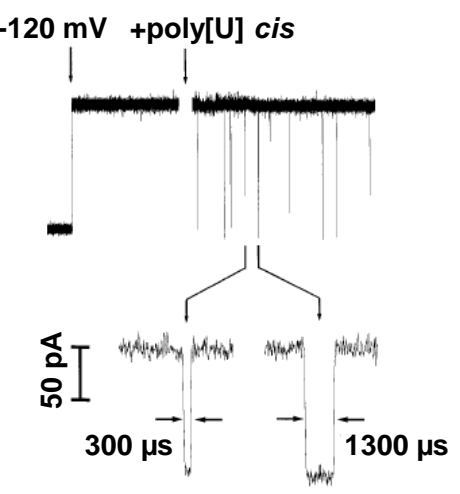

The early proof-of-principle experiments were performed using the wild-type $\alpha \mathrm{HL}$ channel and RNA and single stranded DNA homopolymers, which were believed to be able to pass through the pore. The ion current blockades appeared immediately after polymers such as polyadenylic acid or polyuridylic acid were added to one side of a lipid bilayer containing a single $\alpha \mathrm{HL}$ channel (Figure 7c). To be detected, the current-interruption events required at least $100 \mathrm{mV}$ of applied voltage, positive on the side of the membrane opposite to the nucleic acid addition. These events were from hundreds of $\mu \mathrm{s}$ to several $\mathrm{ms}$ in duration. No channel blockage events were recorded when the polarity was reversed. This fact indicates that anionic nucleic acid molecules are driven through the channel electrophoretically [137]. As expected from the steric parameters of the $\alpha \mathrm{HL}$ pore, the limiting aperture is $1.5 \mathrm{~nm}$ in diameter [78], which allows for a successful passage of only single-stranded DNA molecules, as shown by the quantitative PCR [137]. The additional studies produced even more encouraging results, showing that structurally specific homopolymers of RNA can be detected with reliably measurable differences in both amplitude and duration of the current through the $\alpha \mathrm{HL}$ 
pore [183]. Thus, polyA produced blockades of $\sim 85 \%$, and polyC of $\sim 95 \%$. Dramatic differences were also observed in the average velocity with which the nucleotides traversed the pore at the same applied voltage. PolyC, for instance, passed through at $3 \mu$ s per nucleotide and polyA's rates were $20 \mu$ s per nucleotide.

The concept of protein-pore based nucleotide sequencing has encountered many technical problems and pitfalls, even though all the steps of the original proposal, except for the reliable resolution of single nucleotide bases, had been successfully achieved [184-186]. To achieve a single-base resolution, ionic current through a pore should be affected by exactly one nucleotide at a time, while for $\alpha \mathrm{HL}$ it was found that the pore volume can simultaneously accommodate up to $10-15$ nucleotides $[187,188]$. Interaction of the electric field in the entrance of the pore with the entering nucleotide bases also affects the passing current $[189,190]$. Similarly, formation of the intra-chain intermediate structures in the passing nucleotide may produce blockage irregularities [184,191]. The sufficient rate of one nucleotide per second translocation, needed for a reliable readout, cannot be achieved at the moment, as a nucleotide is moving too fast under the applied electric field [137,192]. Besides, the temporal resolution of the pore current is highly dependent on the random motion of the polynucleotide and on non-specific interactions within the pore [186,188,193]; as a result, the translocation times for two identical molecules can differ by two orders of magnitude.

Despite all these obstacles, great progress in this field had been achieved. The sequence of polynucleotides is now approached not only with the use of ionic channels of biological origin, such as $\alpha$-hemolysin toxin and bacterial porin MspA [194], but also with engineered nanopores made in various synthetic materials, e.g., silicon nitride [186,195]. These studies are not reviewed here and their description is provided elsewhere [185,186,195,196].

The task of individual polynucleotide bases recognition with $\alpha \mathrm{HL}$ can be approached using different strategies. One technique focuses on slowing down the overall transport of a polynuceotide chain across the pore, so only one nucleotide in the chain is affecting the pore current. For instance, the DNA pseudorotaxane species that carry a hairpin structure at one end can be trapped in the process of translocation through the channel [197]. Reproducible current blockages are observed for various nucleotides positioned in the "scanning" constriction of the $\alpha \mathrm{HL}$ pore. Similarly, the polynucleotide immobilization in the pore has been achieved by attaching streptavidin and biotin linkers to the scanned molecule [198,199]. The use of immobilized DNA allowed identification of the two specific regions within the lumen of $\alpha \mathrm{HL}$ that could distinguish individual bases in polynucleotide (Figure 8a).

Another approach employs both rotoxan-additions into DNA chain and specific enzyme complexes (DNA polymerase) that slowly feed a DNA molecule into a pore in a ratchet-like motion, providing an improved signal-to-noise ratio [200-203]. The engineered pores of $\alpha H L$ modified to accommodate a specifically designed molecular adaptor of cyclodextrin also allowed for an improved sensitivity of this pore complex for passing individual nucleotides [199,204]. A combinational method was recently suggested [205]. In particular, the $\alpha H L$ pore, equipped with the permanently attached cyclodextrin adapter was able to electrically recognize single ribonucleoside diphosphates as they were processively cleaved from the analyzed polymer chain by the channel-attached enzyme, processive exoribonuclease (Figure 8b). 
Figure 8. A $\alpha \mathrm{HL}$ nanopore can be used to detect the single nucleotides in single-stranded DNA or RNA molecules. (a) A homopolymeric DNA oligonucleotide (blue circles) can be immobilized inside the $\alpha$ HL pore with a biotin (yellow)/streptavidin (red) linkage [199]; (b) Detection of the individual nucleotides cleaved from a single stranded RNA by polynucleotide phosphorylase [205]. Schematic representation of RNA oligonucleotide (circles) digested by polynucleotide phosphorylase (PNPase, green), one base at a time. The unbound nucleotides (rNDPs) are detected by the mutant M113R $\alpha \mathrm{HL}$ (mutation highlighted in blue) pore equipped with a cyclodextrin adapter (orange). Reprinted with permission from references [199,205].

$\mathbf{a}$

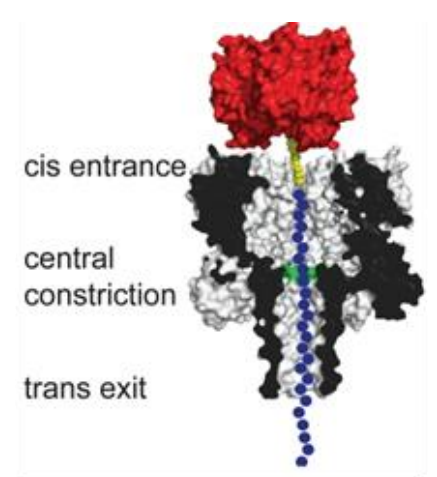

b

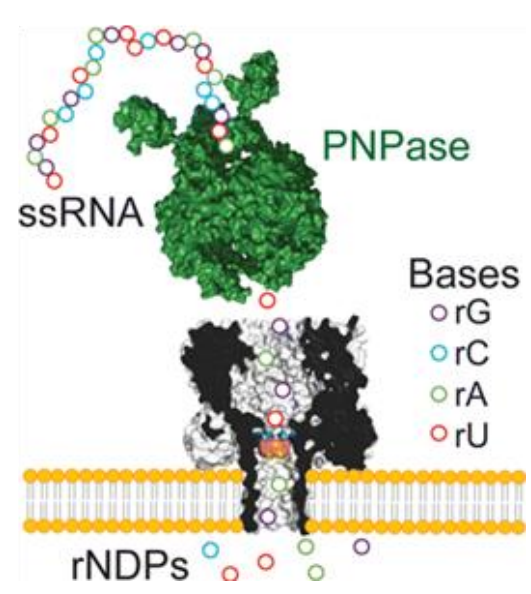

\section{Channel-Forming Bacterial Toxins to Investigate Protein and Other Macromolecule Transport}

Macromolecule transport across bilayer membranes is one of the most fundamental and complex life phenomena. In a recently published book [206], Muthukumar describes the process of macromolecule translocation as an ubiquitous phenomenon where electrically charged polymer molecules move to and from a highly crowded cell environment to make as a thick "Coulomb soup". Comprehensive understanding of principles and regularities involved in the macromolecule transport is lacking and often requires investigation of an isolated translocation process in vitro since many biological translocation processes are too phenomenologically rich and complex for a direct in vivo investigation [206]. One of the powerful methods to probe polymer transport in vitro involves single or multi-molecule nanopore-based translocation experiments performed in the model bilayer lipid membranes. In a number of these studies, channel-forming bacterial toxins were used to exploit the pore-mediated uptake of natural and foreign polymer substrates. To a large degree, these studies were inspired by the successes in the nanopore-based nucleic acid sequencing research that we described above. However, protein translocation studies are believed to be somewhat more complicated [207]. In contrast to the linear homogeneously charged single-stranded DNA homopolymers, proteins contain multiple positively or negatively charged residues and polar and hydrophobic side chains and, therefore, are charged non-homogeneously. Besides, large polypeptides are usually folded into different structures and exist in a variety of transition states and conformations. Therefore, one of the most critical steps for the protein to navigate through the narrow biological pores would be the necessity to undergo substantial conformational transitions, including unfolding. Despite the complexity of the systems, 
several groups have provided essential insight into protein translocation processes using the model lipid bilayer techniques.

\subsection{Studying Polymer and Protein Transport with aHL}

The main body of publications on polymer and protein translocations investigated with the resistive-pulse sensing approach uses single $\alpha \mathrm{HL}$ channels, wild type or variants, reconstituted into the artificial bilayer lipid membranes. In 1992, Krasilnikov and colleagues developed an elegant approach to estimate the effective radius of an ion channel based on the conductivity measurements performed in the presence and in the absence of water-soluble polymers, polyethylene glycols (PEGs) of different molecular weights [208]. The method was later use to determine the geometry of different ion channels, including the pores of $\alpha \mathrm{HL}$ [71] and $\mathrm{PA}_{63}$ [209], discussed here. The approach was further refined to allow not only for determining the size of channel openings but also to detect the presence, size, and apparent localization of structural constrictions inside the pore [71]. The method was based on the effect of asymmetrical addition of PEG on the channel conductance.

An approach for covalent attachment of the single PEG molecules within the lumen of the $\alpha \mathrm{HL}$ pore has been described [210]. When the polymer was functionalized by a covalently attached biotin molecule, the tethered polymer was detected on both the cis and trans sides of the membrane using genetically engineered streptavidin mutants with a weakened binding affinity [211]. Such a covalently attached and functionalized "moving arm" is designed to move across the bilayer from one opening of the pore to another and could be used as a sensor element for detecting protein analytes. Interestingly, closing linear PEG molecules into a circular "crown" substantially modifies their dynamics in the $\alpha \mathrm{HL}$ pore [212]. In contrast to the linear PEGs, the blockage efficiency of the crown exhibits a strong dependence on both the sign and magnitude of the applied voltage (voltage asymmetry). The authors suggest that the charged rigid crown $/ \mathrm{K}^{+}$complex is responsible for the blockage. The closing of a linear polymer molecule into a circle changes its pore translocation because the complex of this cyclic molecule with a $\mathrm{K}^{+}$ion faces an effective barrier in the channel. The capture and release of single PEG molecules by the $\alpha \mathrm{HL}$ channel were detected as time-resolved reversible current-fluctuation events when extreme $\mathrm{KCl}$ concentrations (4 M) were used [213]. Remarkably, the capture on-rate, or fluctuation frequency, decreased monotonically with the PEG size, whereas the residence time of the polymer inside the channel showed a crossover behavior, initially increasing but then decreasing with molecular weight of the polymers. The authors suggest that the $\alpha \mathrm{HL}$ channel is not spacious enough to accommodate larger PEG molecules and that the out-of-pore portion of the polymer molecule acts as an entropic spring pulling on the trapped part and thereby decreasing the residence time of the proteins in the channel.

Furthermore, the $\alpha \mathrm{HL}$ variants carrying different point cysteine mutations were probed with small water-soluble sulfhydryl-specific reagents of different charge and mass [74,214]. These polymers bind to the cysteine side chains exposed into the aqueous phase in the $\alpha \mathrm{HL}$ lumen by forming disulfide linkages at different locations. This allowed one to determine the location of a constriction at the midpoint of the pore lumen [74]. The results also suggested that the net charge of an $\alpha \mathrm{HL}$ channel lumen defines the weak anionic selectivity of the channel and that the charge at the pore entrances determines the shape of the conductance-voltage dependencies [214]. Muthukumar's group investigated 
the molecular mechanisms responsible for the two-level ionic current blockages produced by single poly(styrene sulfonate) molecules passing a single $\alpha H L$ pore under an electric field [215]. The authors showed that only the current reduction sub-events with deep current blockages were successful translocations. However, changing the $\mathrm{pH}$ on the trans-side of the pore allowed for tuning the effective charge of the $\beta$-barrel and for dramatic increase in frequency of the successful translocation events. The authors also developed a stochastic theory with a pairwise free energy profile with polymer/pore interaction, that was qualitatively consistent with the experimental results [215]. A capture of single molecules of sodium poly(styrene sulfonate) by $\alpha \mathrm{HL}$ was also studied under varying transmembrane voltage, $\mathrm{pH}$, and salt concentration asymmetry conditions [216]. The study reports that the electrophoretic capture of single polymer molecules by a $\alpha \mathrm{HL}$ pore under salt concentration gradients is controlled by a combination of pore/polymer electrostatic interaction and induced drift force due to the salt concentration asymmetry. Besides, at higher $\mathrm{pH}$, the polymer/pore interaction is repulsive and lowering the cis compartment salt concentration increases the effect. At lower $\mathrm{pH}$, the polymer/pore interaction becomes attractive and the effect is stronger at lower cis compartment salt concentrations. The authors propose a hypothesis of an antagonistic/synergistic coupling between the pore/polymer interaction and induced drift by salt concentration asymmetry [216].

The interactions between the $\alpha H L$ 's $\beta$-barrel pore and positively charged signal $\alpha$-helical peptides were also examined [138]. The transport of the specifically designed peptides with a central lysine residue within the repeat unit (Ac-(AAKAA) ${ }_{m} \mathrm{Y}-\mathrm{NH}_{2}, m=2-7$ ) was investigated with a focus on the contribution of peptide charge and length to the free energy barrier for the translocation. The authors found that the kinetic parameters of the peptide/pore binding reaction were strongly dependent on transmembrane voltage and peptide length. In particular, a rise in event frequency with the increasing of the applied transmembrane voltage and a reduction in event frequency for longer peptides were reported. The collagen-like peptides existing as mixtures of single, double, and triple helices were also distinguished and identified by comparing their characteristic translocation parameters through $\alpha H L$ [217]. $\alpha \mathrm{HL}$, together with aerolysin of Aeromonas hydrophila, was used to analyze transport of several $\alpha$-helical peptides of the sequence fluorenylmethoxycarbonyl (Fmoc) $-\mathrm{D}_{n} \mathrm{~A}_{\mathrm{x}} \mathrm{K}_{\mathrm{y}}$ [218]. A net negative charge of these peptides has allowed them to be driven through the pores by the applied voltage.

Several studies were designed to use biological nanopores to probe protein folding. Thus, Auvray and collaborators investigated the transport of partially folded and unfolded maltose-binding proteins through $\alpha \mathrm{HL}$ under conditions that favored protein denaturation [219]. Movileanu and collaborators reported related effects when polypeptides with various $\beta$-hairpin structures produced longer ion current blockages by comparison with no-hairpin containing peptides [220]. The unfolding of the protein was shown to be important in facilitating its translocation through $\alpha \mathrm{HL}$ pore, and, apparently, is the rate-limiting step for nanopore-mediated protein translocation in many systems. More recently, a technique that allowed proteins to be unfolded for processive translocation was described [221]. The authors investigate controlled unfolding and translocation of proteins through $\alpha \mathrm{HL}$ using the protein unfoldase ClpX, which is a component of the ClpXP proteasome-like complex responsible for the targeted degradation of numerous protein substrates in E. coli and other organisms. ClpX acts by forming a homohexameric ring that uses ATP hydrolysis to unfold and translocate proteins through its central pore and generates sufficient mechanical force to denature stable protein folds. To examine co-translational unfolding of individual protein molecules, the protein substrates were tagged with 
oligonucleotides to enable potential-driven unidirectional movement through $\alpha \mathrm{HL}$ [222]. The kinetics of the co-translocational unfolding of thioredoxin, which is a model protein of 108 amino acids was then tested at the single-molecule single $\alpha \mathrm{HL}$ level. The study revealed a four-step mechanism that includes two separate unfolding events with a detectable, partly unfolded intermediate. A molecular description for each step is provided [222]. Interestingly the authors suggest that the general mechanism for the co-translocational protein unfolding that they describe is broadly similar the one proposed by Krantz and colleagues for the $\mathrm{PA}_{63}$-mediated uptake of lethal toxin of anthrax [223] (discussed in detail in the Section 5.2). The thioredoxin translocation through $\alpha \mathrm{HL}$ was recently presented as proof-of-principle system for detection of protein phosphorylation [224].

Another important factor in protein transport is the ability of the protein to interact with the binding sites within the pore lumen. To understand how this interaction alters the underlying kinetics of polypeptide translocation, $\alpha \mathrm{HL}$ variants with acidic binding sites composed of rings of negatively charged aspartic acid residues placed at the strategic positions within the $\beta$-barrel were engineered [225]. These mutations resulted in a significantly enhanced transport of cationic polypeptides across the membrane. For instance, when the entry and exit of the $\beta$-barrel were modified with the electrostatic binding sites, both the on- and off-rate of the polypeptide/channel binding reaction were significantly increased because of decrease in the free energy barrier for translocation. At the same time, hydrophobic polypeptides faced a greater energetic barrier and translocated at a considerably lower rate compared with the positively charged hydrophilic polypeptides [225]. To determine the sensitivity of the single-molecule pore recordings to the changes in biophysical features of the pore lumen or the interacting polypeptide, Mohammad and Movileanu used electrical recordings on a single $\alpha \mathrm{HL}$ pore probed with short ( $\sim 25$ residues) cationic polypeptides and small folded $\mathrm{pb}_{2}$-Ba proteins consisted of positively charged precytochrome $b_{2}$ fragments fused into the small ( 110 residues) ribonuclease barnase [226]. The $\alpha H L$ pore contained negatively charged electrostatic traps and the kinetics of the polypeptide/pore interaction was shown to be dependent on the trap location. At the same time, the positive charge carried by the pb2-Ba proteins was not sufficient to allow the protein to undergo a substantial partition into the pore lumen. The authors followed these studies $[225,226]$ with a simple model to describe nanopore-mediated translocation of the semi-flexible polypeptides, whose contour length is comparable with the length of the protein pore [227]. The impact of charge reversals of the $\alpha H L$ 's residues was also investigated with the pore variants where lysines were replaced with aspartic acids [228]. The study showed that charge-reversal mutations that disrupted ion-pair interactions on the cis opening of the $\beta$-barrel produced rather quiet electrical signals with reduced single-pore conductance, whereas disruption of an ion-pair interaction on the solvent-exposed trans opening of the $\beta$-barrel led to a significant gating activity, larger amplitude, and frequent current fluctuations in the pore. At the same time, the combination of the two charge-reversal mutations resulted in the irreversible collapse of the $\beta$-barrel detected as a large-amplitude permanent blockage of the channel current. The authors suggest that these distant charge reversals are energetically coupled and have different impacts on the ionic transport, conductance, and probability of the open state of the $\alpha \mathrm{HL}$ channel [228]. The model allowed for calculation of the relative and absolute exit frequencies of the short cationic polypeptides through the cis and trans openings of the pore and for quantitative assessment of the polypeptide translocation kinetics. The kinetics of peptide/pore interactions was also investigated with peptides containing mainly aromatic amino acids in $\alpha \mathrm{HL}$ pores engineered with 
aromatic binding sites [229]. The authors reported that with an increase in the peptide length, both the event mean dwell time and the amplitude of current blockage increases whereas the events frequency shows only slow increase, indicating that the binding affinities of the peptides are mainly dependent on the off-rate constants rather than on the on-rate constants. Besides, with more aromatic binding sites engineered in the pore lumen, a stronger binding affinity between peptides and the pore was detected [229].

Nanopore analysis was also suggested for studying the misfolding of certain proteins, for instance amyloids, $\alpha$-synucleins and prions [230,231]. The $\alpha \mathrm{HL}$ pores were used to probe the different aggregation transition of $\beta$-Amyloid 42 (A $\beta 42$ ) (Figure 9a) [231].

Figure 9. Detecting intrinsically disordered amyloid peptides, Ab42 [231] and $\alpha$-synuclein [232] with $\alpha \mathrm{HL}$ nanopore. (a) $\mathrm{A} \beta 42$ in the presence and absence of $\beta$-cyclodextrin (A $\beta 42-\mathrm{CD})$ or Congo Red (A $\beta 42-\mathrm{CR})$ added from the cis-side chamber (top). Representation of the blockage behavior of the translocation event of A $\beta 42-\mathrm{CR}$ (bottom); "i" is equal to the difference between the open pore current and the average amplitude of the blockage current, " $t$ " is the duration time of the blockage [231]; (b) Schematic model of $\alpha$-synuclein interaction with the $\alpha \mathrm{HL}$ channel pore [232]. While the membrane-bound helical part of $\alpha$-synuclein stays on one side of the membrane, the highly negatively charged C-terminal tail of the protein ( $\mathrm{red} /$ solid line) enters the $\alpha \mathrm{HL}$ pore from the trans-side and goes past the channel constriction under the externally applied electric field. Reprinted with permission from references [231,232].

a

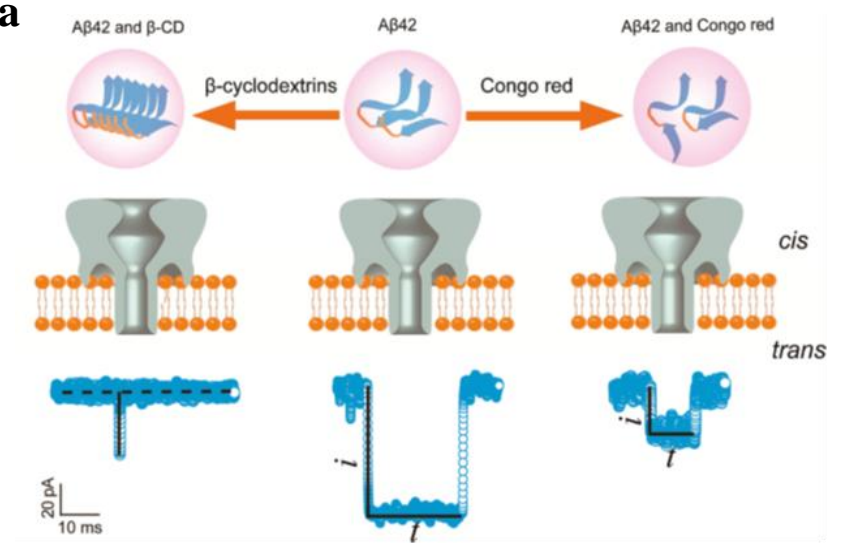

b

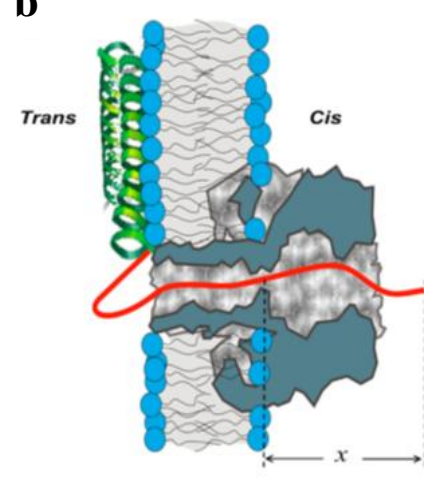

$\mathrm{A} \beta 42$ is the predominant form of the amyloid peptide, which is found in the plaques of the brains of Alzheimer's patients and is an abundant component in amyloid aggregates. The peptide was studied in the presence of $\beta$-cyclodextrin, which promotes $A \beta 42$ aggregation, and in the presence of Congo red, which inhibits the aggregation. These induced differences in the A $\beta 42$ aggregation states were analyzed by monitoring the corresponding characteristic blockage events where $\beta$-cyclodextrin and Congo red were used to promote or inhibit A $\beta 42$ aggregation, respectively. More recently, $\alpha \mathrm{HL}$ was utilized to investigate the elongation of wild type $\alpha$-synuclein and A53T $\alpha$-synuclein monomers [230,233]. $\alpha$-synuclein is a neuronal water-soluble protein involved in the etiology of Parkinson disease and other neurodegenerative dementias through formation of the $\alpha$-synuclein fibrils. Gurnev et al., observed 95\% blockage of the current by $\alpha$-synuclein when the compound was added from the membrane side where the shorter stem part of the channel was exposed [232] (Figure 9b). The applied potential was more 
negative on the side of $\alpha$-synuclein addition. The binding reaction on-rate was reported to depend strongly on the membrane lipid composition. In particular, in diphytanoylphosphocholine membranes $\alpha$-synuclein binding was about two orders of magnitude stronger compared with membranes made with dioleyl lipids. The turnover dependence of the dwell time on the applied transmembrane voltage strongly suggested the $\alpha$-synuclein translocation. Besides, when the unstructured C-terminal domain of $\alpha$-synuclein had the last 25 amino-acid residues, including nine carboxylates, removed, the compound's binding affinity dramatically decreased. At the same time, measurements of the binding/translocation reaction parameters in $4 \mathrm{M} \mathrm{KCl}$ solutions showed impressive increase in the pore-protein attraction, possibly reflecting the osmotic and crowding effects in $\alpha$-synuclein/pore interaction.

Investigation of $\alpha \mathrm{HL}$ pores for the stochastic sensing applications often involves substantial reengineering of the wild type channel. Thus, a new type of stochastic sensor based on a $\alpha \mathrm{HL}$ pore modified with an aptamer was recently reported [234]. The aptamer was bound to the channel by hybridization to an oligonucleotide that is attached covalently to a single cysteine residue through a disulfide bond near an entrance of the pore. In this way, the oligonucleotide acts as an adapter to which various nucleic acid ligands can be coupled by duplex formation. The authors demonstrate that thrombin was interacting with a 15-mer DNA aptamer at nM concentrations forming a cation-stabilized quadruplex.

\subsection{Studying Protein Transport with $P A_{63}$}

The substantial progress in understanding the physical principles governing anthrax toxin uptake is due to the pioneering lipid bilayer measurements performed by Finkelstein and Collier's groups and, more recently, by Krantz's group (reviewed in refs. [100,235,236]). The very first study investigating protein transport using the anthrax toxin was designed to answer the following two questions: (1) can LF and EF be translocated across a planar bilayer membranes in the absence of any cellular components; and (2) does the $\mathrm{PA}_{63}$ channel act as a conduit for this process [117]? Earlier studies with single-chain diphtheria (DT) and botulinum toxins (BT) showed that the A portion of the protein can be transported across a planar lipid membrane without the aid of any cellular components and, therefore, all of the translocation machinery for DT and BT is built into their B fragments [237,238]. At the same time, binary anthrax toxin has a significant advantage over the single-chain AB-type DT and BT toxins [117]. In particular, the channel incorporation and protein translocation events are separated in binary toxins, meaning that in the model studies of multiple or single $\mathrm{PA}_{63}$ channels could be reconstituted first and LF and EF added later. The authors believe that, if under these conditions translocation is captured, then the channel is not just a "discarded wrapper" [117]. An electrophysiological system for studying translocation across planar bilayer membrane is shown in Figure 10.

In contrast to the majority of publications where protein translocation through $\alpha \mathrm{HL}$ was investigated, the authors chose to focus on the multi $\mathrm{PA}_{63}$ channel membranes. In a typical experiment, the preactivated $\mathrm{PA}_{63}$ was added to the cis compartments of the bilayer chamber at $20 \mathrm{mV}$ cis side positive transmembrane voltage until channel formation reached steady state, which was indicated by stabilization of the ion current [117,239]. The substrates $\left(\mathrm{LF}_{\mathrm{N}}, \mathrm{LF}, \mathrm{EF}\right.$ or their variants) were then added to the cis compartment at the concentration that allows blockage of $95 \%$ of current. The unbound substrate was removed by perfusion from the cis compartment solution. The protein translocation leading to channel lumen unblocking was recorded as the increase in conductance vs. time. 
This process was triggered by either increase in the applied voltage to $\Delta \psi \geq 40 \mathrm{mV}$ (Figure 10b) or by creating $\mathrm{pH}$ gradient, $\mathrm{pH}_{\text {trans }}>\mathrm{pH}_{\mathrm{cis}}$ (Figure 10c) $[117,239,240]$. At the same time, the $\Delta \mathrm{pH}$ that the authors used to mimic a proton gradient across an endosomal membrane was more efficient in stimulating protein transport, allowing translocation not only $\mathrm{LF}_{\mathrm{N}}$ but also full-length $\mathrm{LF}$ and $\mathrm{EF}$. The conductance rise was S-shaped, and its rate increased systematically both with increasing of $\Delta \psi$ and $\Delta \mathrm{pH}$. With the minimum $\mathrm{PA}_{63}$-binding translocation component domain of $\mathrm{LF}, \mathrm{LF}_{\mathrm{N}}$, it was shown that, under small $\Delta \psi$, the $\mathrm{N}$ terminus of bound $\mathrm{LF}_{\mathrm{N}}$ enters the oligomeric channel and initiates the threading of the substrate across the bilayer membrane [116].

Figure 10. The interaction of $\mathrm{LF}_{\mathrm{N}}$ with the $\mathrm{PA}_{63}$ multichannel membrane [239]. (a) After the macroscopic $\mathrm{PA}_{63}$-induced current had reached a steady state at $+20 \mathrm{mV}, \sim 3 \mathrm{nM} \mathrm{LF}_{\mathrm{N}}$ was added to the cis compartment of the chamber, which resulted in a rapid fall in current. The cis compartment was then perfused of unbound $\mathrm{LF}_{\mathrm{N}}$. At time zero, the voltage was increased to $+50 \mathrm{mV}$, and $\mathrm{LF}_{\mathrm{N}}$ translocation kinetics through the $\mathrm{PA}_{63}$ channels was indicated by the increase in conductance $v s$. time; (b) Kinetic transients for $\mathrm{LF}_{\mathrm{N}}$ translocation at $+60 \mathrm{mV}$ and the indicated symmetrical $\mathrm{pH}$ values; (c) The rate of $\mathrm{LF}_{\mathrm{N}}$ translocation is controlled by the magnitude and sign of the transmembrane $\Delta \mathrm{pH}$ $\left(\mathrm{pH}_{\text {trans }}>\mathrm{pH}_{\text {cis }}\right)$; (d) A schematic illustration of the tandem Brownian ratchet translocation mechanism shows a model of several partially unfolded intermediates of $\mathrm{LF}_{\mathrm{N}}$ during translocation [239]. The scheme demonstrates how the hydrophobic, $\phi$-clamp ratchet and the protonation-state ratchet may work together facilitating translocation of $\mathrm{LF}_{\mathrm{N}}$. Reprinted with permission from reference [239].

a
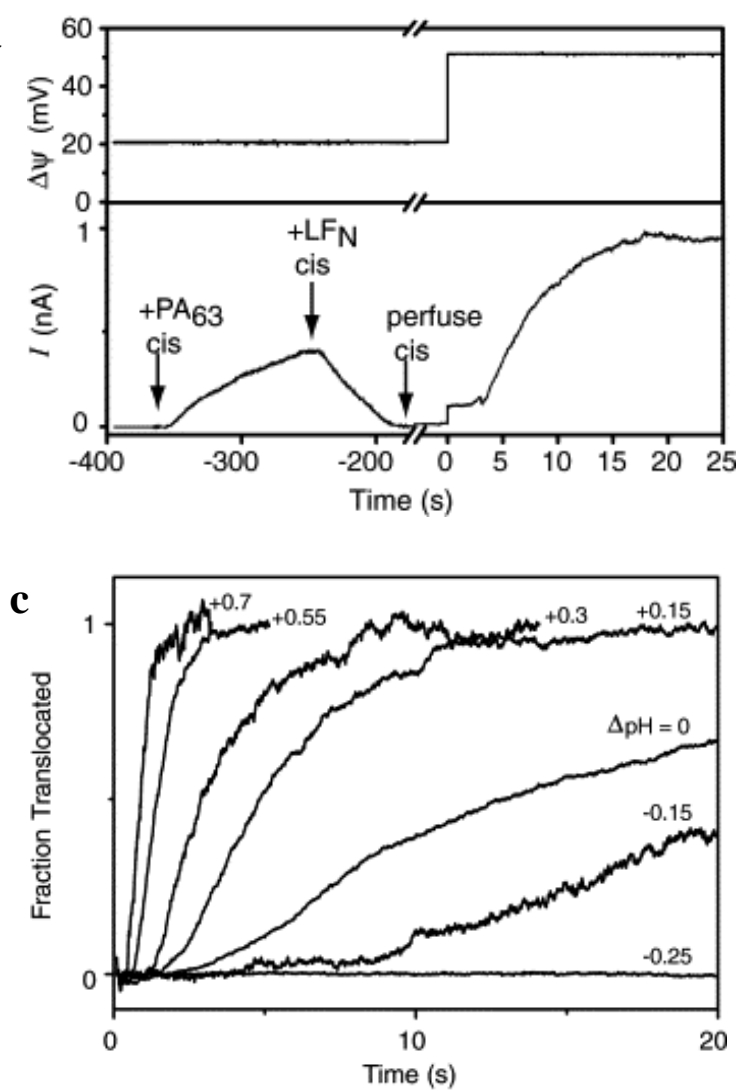

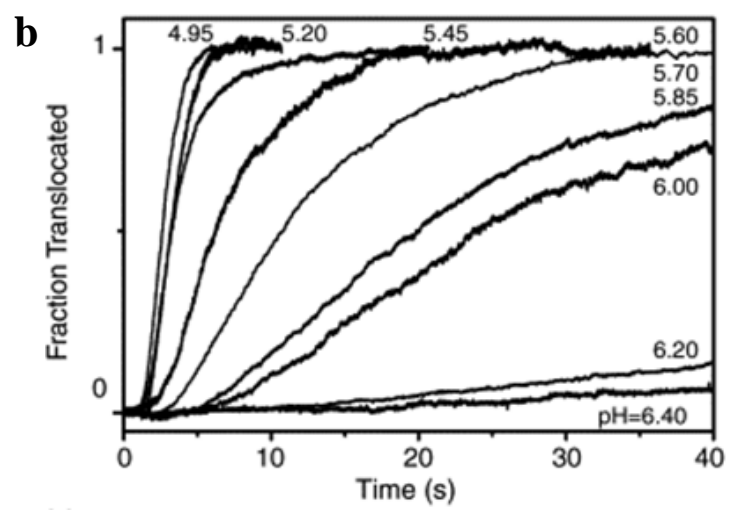

d

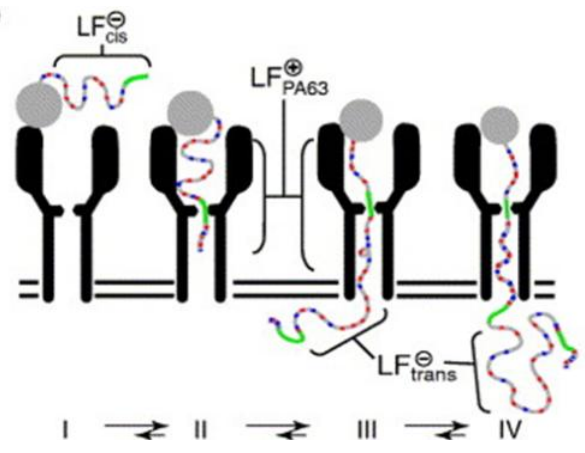


In order to identify residues in the $\mathrm{PA}_{63}$ lumen important for the channel-mediated transport of a substrate, the authors used cysteine-scanning mutagenesis coupled to [2-(trimethylammonium ethyl] methanethiosulfonate (MTS-ET) modifications [241]. The channels were the most significantly affected by Phe427/Cys427 modifications, and Phe427 (named $\phi$-clamp is the most hydrophobic residue in the otherwise hydrophilic pore lining [118]. In particular, when the bulky 427 phenylalanine residue was replaced by the small alanine, the single-channel conductance expectably increased but the rate of $\mathrm{LF}_{\mathrm{N}}$ translocation reduced by a factor of six [239]. Based on the fact that the $\phi$-clamp mutation blocked LF translocation in cell assays [242] or significantly slowed it in vitro [118], a chaperone model was suggested in which the $\phi$-clamp's phenyl rings directly interacted with the translocating polypeptide. According to the model [118], the $\phi$-clamp recognizes substrates through the hydrophobic effects, enhanced by aromatic-aromatic, $\pi-\pi$, and cation- $\pi$ interactions, and stabilizes the fragments it an unfolded state. This study for the first time provided evidence that $\mathrm{PA}_{63}$ was not a passive tunnel through which proteins electrophorese but rather an active player in facilitating the transport of a substrate molecule. At the same time, the lumen of a 14-strand $\beta$-barrel $\mathrm{PA}_{63}$ is believed to be as narrow as $12-15 \AA[101,174,243]$, which would allow the pore to accommodate secondary structure only as large as an $\alpha$-helix [244]. Therefore, translocation through $\mathrm{PA}_{63}$ would require the enzymatic substrates to unfold. If so, what are the factors that cause the folded LF and EF with tertiary structures to unfold? The authors show that one critical factor is low endosomal $\mathrm{pH}$. Thus, the acidic conditions in the endosome are sufficient to destabilize the native structure of $\mathrm{LF}_{\mathrm{N}}$ and $\mathrm{EF}_{\mathrm{N}}$ proteins [244]. In vitro experiments have also revealed that the translocation process is driven by cis positive voltages [117] and that the $\mathrm{PA}_{63}$ channel is selective to cations [175]. Paradoxically, $\mathrm{LF}_{\mathrm{N}}$ bears a net negative charge (about six negative charges) even at $\mathrm{pH}$ values as low as 5.5 [240]. To explain this finding, the authors developed a model describing $\mathrm{PA}_{63}$ channel as a protein translocase rather than anselective long tunnel. The easiest way for the substrates to achieve a net positive charge, which is thermodynamically and electrostatically required for the translocation, would be to get their aspartic and glutamic residues neutralized, for instance protonated [239]. Under $\Delta \mathrm{pH}$, the substrate molecule would get protons from the cis compartment solution (or an endosome) and discharge them into the trans compartment solution (or cytosol) following translocation. At the same time, the portion of LF/EF located inside the pore lumen would carry a net positive charge and $\mathrm{PA}_{63}$ would work as a proton-protein symporter [119].

To address the fundamental question of the translocation driving force, the authors developed a novel charge state-dependent Brownian-ratchet model for the $\Delta \mathrm{pH}$-driven translocation, which is based on the chemical asymmetry created by $\Delta \mathrm{pH}$ [239]. The probability of an aspartate or glutamate being in the protonated form is greater in the more acidic cis side compared to the more basic trans side, and, therefore, the rate of their entry is higher from the cis side than that from the trans side [240]. After the protonated aspartate and glutamate groups reach the cytosolic part of the membrane, they deprotonate, becoming negatively charged again, resulting in the electrostatic repulsion of the negatively charged chain fragment from the channel lined with the negatively charged residues. This electrostatic repulsion drives the translocation per se and enforces its directionality [100,239]. Therefore, the random Brownian motion of the substrate inside $\mathrm{PA}_{63}$ is biased toward the more basic trans compartment. Based on the experimental evidence, the authors suggest that the $\mathrm{PA}_{63}$ symporter achieves protein translocation using a tandem of two synergistic Brownian ratchets: the $\phi$-clamp 
ratchet, promoting the substrate unfolding, and the charge-state ratchet, which biases the entry rates of the substrates into the pore (Figure 10d).

Remarkably, further experiments with planar lipid bilayers have imparted support to this model using essentially non-titratable negatively charged $\mathrm{SO}_{3}{ }^{-}$groups introduced at most positions in $\mathrm{LF}_{\mathrm{N}}$ [119]. The voltage-driven translocation of the resulting $\mathrm{LF}_{\mathrm{N}}$ variants was dramatically reduced and the $\phi$-clamp was determined as a significant factor in the exclusion of $\mathrm{SO}_{3}{ }^{-}$from the channel. In another study, semisynthetic variants of $\mathrm{LF}_{\mathrm{N}}$ (12-263) in which selected acidic residues were replaced with the unnatural amino acid, cysteic acid, were examined [245]. The cysteic acid has a negatively charged side chain protonated only at $\mathrm{pH}$ values below the physiological range. Depending on the number of acidic residues replaced, transport of these mutants was either significantly suppressed or completely inhibited, whereas their binding and channel-blocking properties were comparable with those of wild type $\mathrm{LF}_{\mathrm{N}}$. To determine if the substrate's secondary structure is preserved during the pore-facilitated translocation, a method of trapping the polypeptide chain of the translocating protein within a pore was developed [121]. In order to determine the minimum number of residues that could traverse the $\mathrm{PA}_{63}$ oligomeric pore, the authors attached biotin to the $\mathrm{N}$ terminus of $\mathrm{LF}_{\mathrm{N}}$ and used molecular stoppers at the different positions. The trans-side streptavidin addition was used to determine whether the $\mathrm{N}$ terminus has reached the trans compartment solution. If the $\mathrm{N}$ terminus-stopper distance was long enough to allow for $\mathrm{LF}_{\mathrm{N}}$ to appear from the pore, streptavidin was able to bind the biotin. Otherwise, no biotin binding was recorded. The authors showed that an $\mathrm{LF}_{\mathrm{N}}$ polypeptide chain adopts a fully extended conformation, because it is being translocated through the channel's stem.

A typical characteristic of $\mathrm{LF}_{\mathrm{N}}$ translocation is its non-exponential S-shaped kinetics. At the same time, in most of the experiments the substrate translocation was investigated under conditions where two or three $\mathrm{LF}_{\mathrm{N}}$ molecules were bound to $\mathrm{PA}_{63}$ channels. To understand whether the S-shaped kinetics is an intrinsic characteristic of translocation kinetics or a consequence of the translocation in a tandem of two or three $\mathrm{LF}_{\mathrm{N}}$ molecules, a kinetic analysis of protein transport via the macroscopic and single-channel $\mathrm{PA}_{63}$ channels was performed [120]. The study showed that even with one $\mathrm{LF}_{\mathrm{N}}$ bound to $\mathrm{PA}_{63}$, the translocation kinetics is S-shaped, being, however, slower, with more than one $\mathrm{LF}_{\mathrm{N}}$ bound. The authors also propose a simple drift-diffusion model of $\mathrm{LF}_{\mathrm{N}}$ transport, where $\mathrm{LF}_{\mathrm{N}}$ is represented as a charged rod that moves subject to both Brownian motion and an applied electric field across the membrane [120].

A dramatically different model of anthrax toxin transmembrane uptake was recently suggested by Kasianowicz and colleagues [18]. The new model suggests that instead of LF and EF being threaded through the pore, anthrax toxin complexes (i.e., $\mathrm{LF}$ or $\mathrm{EF}$ bound to the $\mathrm{PA}_{63}$ channel) rupture membranes (Figure 11). 
Figure 11. (a) A schematic illustration of two proposed mechanisms for $\mathrm{PA}_{63}$ channel-mediated lethal factor (LF) and edema factor (EF) transport into the cytoplasm. The channel-mediated translocation model suggests that LF and EF pass through the pore $[118,239]$. The recent membrane rupturing model suggests that the enzymatically active anthrax toxin complexes (namely, LF or EF bound to the $\mathrm{PA}_{63}$ channel) rupture membranes [18]. Time course of the $\mathrm{PA}_{63}$ channel conductance with (b) LF removed before or (c) maintained at $1 \mathrm{nM}$ during cis-side acidification. (Top rows) $\sim 60 \mathrm{PA}_{63}$ channels were reconstituted into a planar bilayer membrane at $\mathrm{pH}$ cis|trans 7.2|7.2 (black) and, $1 \mathrm{nM} \mathrm{LF}$ was added to the cis chamber (blue). (Middle rows) The $\mathrm{pH}$ cis|trans 5.5|7.2 gradient was formed by perfusing the cis chamber with $\mathrm{pH} 5.5$ buffer that contained either $[\mathrm{LF}]=0$ (red) or $[\mathrm{LF}]=1 \mathrm{nM}$ (green). (Bottom rows) The neutral $\mathrm{pH}$ condition (pHcis|trans 7.2|7.2) (black) was restored by perfusing the cis chamber with $\mathrm{pH} 7.2$ buffer. If LF was present, the cis chamber was first perfused with $\mathrm{pH} 5.5$ buffer (red) then $\mathrm{pH} 7.2$ buffer (black). Reprinted with permission from reference [18].

a

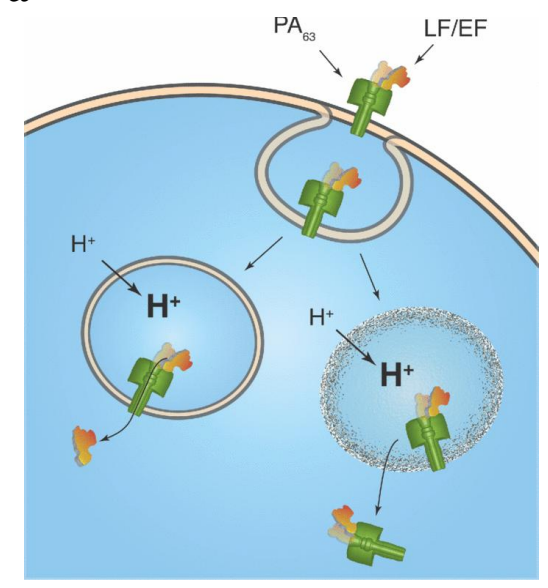

b

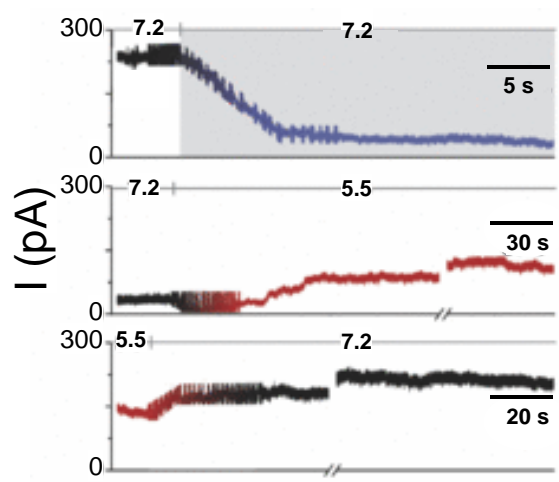

c

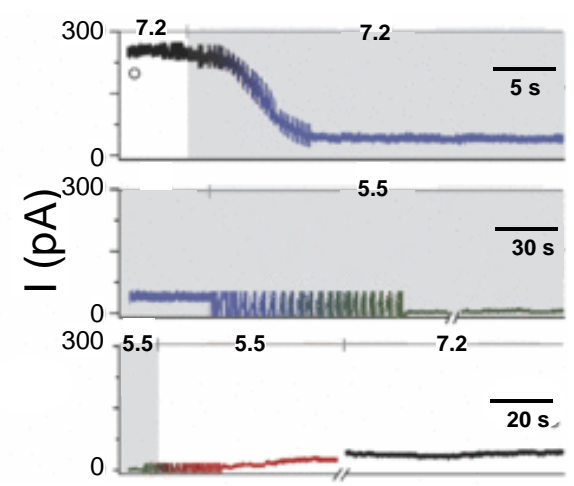

Kasianowicz et al., question the translocation model, noting that the in vitro $\mathrm{pH}$ gradient formation used in the previous translocation studies is precisely opposite to what occurs in vivo [18]. The translocation, manifested by $\mathrm{PA}_{63}$ ion current recovery (Figure 10), was observed either in static low $\mathrm{pH}$ conditions on both sites of the membrane (mostly with $\mathrm{LF}_{\mathrm{N}}$ ) or starting with the symmetrical acid conditions and forming a $\mathrm{pH}$ gradient by raising the trans solution $\mathrm{pH}$ (both with $\mathrm{LF}_{\mathrm{N}}, \mathrm{EF}_{\mathrm{N}}$, $\mathrm{LF}$, and EF). In the real in vivo systems, $\mathrm{PA}_{63}$ oligomeric prepore complexes would first bind the $\mathrm{LF}$ and/or $\mathrm{EF}$ subunits on the cell surface, then undergo endocytosis, and, after that, under $\mathrm{pH}_{\text {endosome }}<\mathrm{pH}_{\text {cytosol }}$ conditions, the prepore/pore transition would occur. To support the alternative anthrax toxin uptake model, the authors show that anthrax toxin complexes can rupture both the planar bilayer and the droplet membranes [18]. Moreover, the transmembrane $\mathrm{pH}$ gradients alter the ion conducting properties of the $\mathrm{PA}_{63}$ pores and $\mathrm{LF} / \mathrm{PA}_{63}$ interaction. In particular, under conditions that mimic those across the endosomal membrane, the strength of $\mathrm{LF}_{\mathrm{PA}} \mathrm{P}_{63}$ interaction in the absence of LF excess in the solution is relatively weak. However the LF binding is irreversible when LF is present in bulk during acidification [18]. To understand the binding of LF/EF to the channel, the authors designed an experiment starting from essentially different experimental conditions (Figure 11b) compared with those used for the translocation experiments. $\mathrm{PA}_{63}$ channels were incorporated into the planar bilayer 
membranes under symmetrical $\mathrm{pH}_{\mathrm{cis}}=\mathrm{pH}_{\text {trans }}=7.2$ conditions (Figure $11 \mathrm{~b}$, top). Following channel formation, LF was added to the cis compartment solution and the remaining unbound LF was flushed from the chamber. Lowering the $\mathrm{pH}$ cis solution to 5.5 led to a slow current increase (Figure 11b, middle) explained by dissociation of LF from the channel; the current continued to increase when $\mathrm{pH}$ was increased to 7.2 (Figure 11b, bottom). About $90 \%$ of current recovery was observed after $30 \mathrm{~min}$ [18]. To show that acidification promotes the LF dissociation from the channel, the authors repeated the experiment (Figure 11c) maintaining the bulk cis-solution LF concentration at constant during the acidification. For that purpose, the cis solution was perfused with the LF containing $\mathrm{pH} 5.5$ buffer (Figure 11c, middle). After that, the solution was additionally perfused with LF-less pH 5.5 buffer (Figure 11c, middle). The described procedure led to only minor increase in the current even after $\mathrm{pH}$ was return to 7.2 (Figure $11 \mathrm{c}$, bottom). Thus, about $90 \mathrm{~min}$ after returning to initial $\mathrm{pH}_{\text {cis }}=\mathrm{pH}_{\text {trans }}=7.2$ conditions, only $17 \%$ of the initial $\mathrm{PA}_{63}$ current was recorded, indicating strong, nearly irreversible $\mathrm{LF} / \mathrm{PA}_{63}$ interaction when $[\mathrm{LF}]_{\text {bulk }}=1 \mathrm{nM}$ during acidification. The authors also showed that when LF or EF were in the bulk during acidification of the cis side, the formation of the essentially irreversibly bound LF:PA 63 and EF:PA 63 complexes led to membrane rupture.

In addition, the article contains interesting suggestions about a possible alternative mechanism of the anthrax toxin uptake, which the authors support with carefully designed experiments and detailed discussion [18]. We believe these data must be addressed in the future. On the other hand, it is important to emphasize that the earlier studies showed nearly ideal positive correlation between the translocation rate measured for different $\mathrm{LF}, \mathrm{EF}$, and $\mathrm{PA}_{63}$ variants in vitro and cytotoxicity of the complexes in cell assays and in vivo. Moreover, a variety of available and rationally designed small molecule and polyvalent compounds aimed to specifically obstruct the $\mathrm{PA}_{63}$ 's translocation pathway were shown to be very effective in inhibiting anthrax toxin $[111,118,163,165,167,176,246]$. The positive correlation between binding activity of these blockers to the $\mathrm{PA}_{63}$ channel in vitro and their protective action in vivo was reported. The dominant-negative PA mutants that co-assemble with the wild-type $\mathrm{PA}_{63}$ and block its ability to translocate the LF and EF components have been also described [247-250].

\section{Channel-Forming Bacterial Toxins for Cancer Therapy}

Many traditional anticancer agents, while being highly effective, also show their well-known toxic properties toward normal fast proliferating cells. These drugs were often discovered in cellular screens of extracts from natural sources, or in in vivo screens using a leukemic P388 mouse model, and entered the clinical studies and market before the exact mechanism of their action was understood [251]. In contrast, emergent next-generation strategies of the anticancer drug discovery focus on targeted therapies, where the agents are designed rationally to target the unique features of malignant cells. Thus, cancer cells overexpress specific tumor antigens, carbohydrate structures, and growth factor receptors on their surface or they express cancer specific proteases [252]. Targeting these factors is a widespread strategy under development for a selective killing of cancer cell using small molecules, monoclonal antibodies, modified bacterial, plant and fungal toxins, viral nanoparticles, and any other inhibitors, which follow the principles required to selectively destroy cancer cells. 
The bacterial toxins are naturally cytotoxic: a property that makes them attractive to use in the targeted therapies. Thus, only one molecule of diphtheria toxin fragment A introduced into a cell can kill the cell [253]. The major task is to direct the cell-binding properties of the bacterial toxins for selective action on cancer cells while minimizing their ability to destroy healthy cells. At first, the targeted toxin research focused on design of so-called "immunotoxins", molecules consisting of a protein toxin fused to a tumor cell-specific antibody or antibody fragments. This approach afterwards expanded to include other target-specific ligands, such as growth factors or cytokines. These proteins are often referred to as "targeted toxins" (TTs). Pseudomonas exotoxin A of Pseudomonas aeruginosa and diphtheria toxin of Corynebacterium diphtheria, which enzymatically inhibit protein synthesis, are commonly used for the immunotoxin construction. The Clostridium and Bacillus binary toxins are also considered excellent candidates for the targeted toxin design. Being composed of two (or three in the case of anthrax toxin) nontoxic proteins, the binary toxins offer a significant advantage over the single-chain AB-type toxins, because activities of their binding and enzymatic components can be redirected independently towards targeted cancer cells. The membrane-perforating bacterial toxins and pore-forming antimicrobial peptides have also served as excellent tools for the targeted toxin research. For the specific aim of the current review, here we highlight examples of the therapeutic strategies that are focused on a targeted modification of the membrane-perforating bacterial toxins, such as $\alpha \mathrm{HL}$, and on the channel-forming components of the binary toxins, such as $\mathrm{PA}_{63}$. For examples of other targeted toxin applications and for a general overview of the field, we direct the reader to a series of recent reviews [254-264].

Anthrax toxin is an excellent choice for targeted toxin research [265]. The Bacillus anthracis infections are rare and currently only a limited number of people have been immunized against anthrax. According to the CDC, only laboratory workers who work with anthrax, some veterinarians, and some members of the US army are routinely vaccinated. Therefore, in contrast to diphtheria toxin (childhood immunization) and Pseudomonas exotoxin (earlier infections), most people lack pre-existing immunity for anthrax. Besides, the tripartite nature of the anthrax toxin offers a variety of tuning strategies for targeted modifications of the non-linked toxin components. Moreover, substantial recent progress made in the understanding of anthrax toxin protein structures and uptake mechanisms facilitates design of tailored antitumor agents.

Targeted anthrax toxin research progresses in at least three different directions, which are often combined. First, because PA binding to the CMG2 and TEM8 cell surface receptors is the first event in the multistep anthrax toxin's intracellular transit, redirecting the protein towards alternate tumor cell specific receptors was investigated. To demonstrate the feasibility of this approach, it was shown that tailor-made PA can be targeted towards the human p62 (c-Myc)-specific hybridoma cell line 9E10 [266,267]. The C-terminus of wild-type PA was fused to the amino acid residues 410-419 of the human $\mathrm{p} 62^{\mathrm{c}-\mathrm{Myc}}$ epitope via a $\left(\mathrm{G}_{2} \mathrm{~S}\right)_{2}$ linker; ac-Myc IgG was proven to act as alternate receptor. The PA-c-Myc fusion protein was shown to kill RAW cells, which do not express the c-Myc receptor. The addition of the c-Myc epitope to the C-terminus of PA did not interfere with the ability of the fusion protein to bind to the PA TEM8 receptor. Therefore, the presence of competitive inhibitor PA SNKE $\triangle F F$ (a non-toxic receptor-binding mutant) and the fusion protein FP59 (amino acid residues 1-254 of LF and the ADP-ribosylation domain of Pseudomonas exotoxin) was required to fully protect 9E10 cells from a challenge with PA-c-Myc and FP59. Another receptor-redirected approach is to disrupt the 
native receptor-binding function of the toxin and then to specifically link the mutated protein to a heterologous receptor-binding protein. Recently, the native receptor-binding activity of PA was ablated by introducing N682A and D683A mutations in domain 4 [268]. The resulting $\mathrm{C}$ terminus of the mutated protein was then fused to one of two heterologous receptor-binding proteins: human epidermal growth factor or the receptor-binding domain of diphtheria toxin (Figure 12). The resulting PA variants mediated the cell entry of the active components of the toxin. The developed approach was used to redirect toxin action to cells bearing the HER2 receptor [269,270].

Figure 12. The receptor-based approach to re-engineer PA by disrupting the native receptor-binding function of the toxin and specific linking of the mutated protein to a heterologous receptor-binding protein [268]. Composite representation of the heptameric prepore formed by $\mathrm{PA}_{63}$ (PDB: 1TZO) with EGF (PDB: 1JL9) linked to the C-terminus. An axial view of the heptameric prepore is shown, with domains 1,2,3, and 4 in a single subunit of $\mathrm{PA}_{63}$ colored magenta, green, gold, and purple, respectively. EGF is in red. Broken lines represent an 8-amino-acid linker (SPGHKTQP) connecting the $\mathrm{N}$ terminus of EGF to the $\mathrm{C}$ terminus of $\mathrm{PA}_{63}$. Reprinted with permission from reference [268].

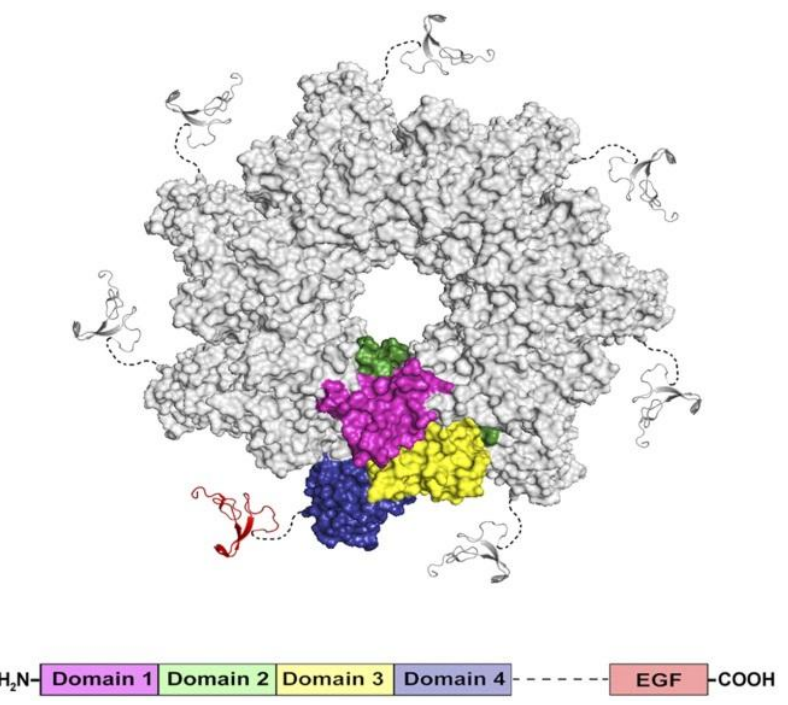

The unique requirement that certain toxins have to be active on the cell surface of the targeted cell provides strategies to tailor these toxins to make them dependent on the cancer cell-specific proteases. Therefore, a second approach to re-engineered PA is to replace the furin cleavage site with cleavage sites for proteases that are present on the surface of cancer cells. For the broad-spectrum TTs, it is practical to focus on the cell surface-associated proteases that are overexpressed in a variety of tumor tissues and tumor cell lines, namely on the matrix metalloproteases (MMPs) and urokinase plasminogen activator (uPA, not to be confused with PA, the binding/translocation subunit of anthrax toxin). To examine the role of MMPs in the design of TTs, two mutated PA proteins were constructed in which the furin protease recognition site RKKR was replaced by the GPLGMLSQ (PA-L1) and GPLGLWAQ (PA-L2) sequences [271]. These fusion proteins were designed to be susceptible to cleavage by MMP-2, MMP-9 and MT1-MMP and were rapidly and selectively activated on the surface of MMP-overexpressing cancel cells. The resulting PA-L1 and PA-L2 oligomers were used to internalize a recombinant FP59 fusion protein and these combinations were shown to be selectively 
toxic to MMP-overexpressing tumor cells, which included human fibrosarcoma, breast cancer, melanoma and thyroid carcinoma [267,271-275]. To examine the role of uPA in the design of TTs, a set of mutated PA proteins in which the furin activation site was replaced by uPA recognition sequences was also constructed [276]. The uPA substrate sequences, GSGRSA and GSGKSA were used to replace the furin RKKR sequence in PA, which yielded mutated PA proteins, PA-U2 and PA-U3 that were efficiently activated by uPA. PA-U2/FP59 was later investigated as a wide-range, highly selective, and highly potent chimeric toxin that specifically targets uPA-expressing tumors, independently of their tissue origin [277-280]. In an elegant study, Leppla and colleagues reengineered PA-constructing mutants with mutations affecting different LF-binding subsites and containing either uPA or MMP cleavage sites [281] (Figure 13a).

Figure 13. (a) Scheme for reengineering anthrax toxin protective antigen (PA) to modify its action towards two distinct proteolytic activities overexpressed by the cancer cells [281]; (b) Scheme for discovery of PA mutants that exclusively form octamers [282]; (c) EM images of heptameric and octameric PA species [282]. Reprinted with permission from references [281,282].

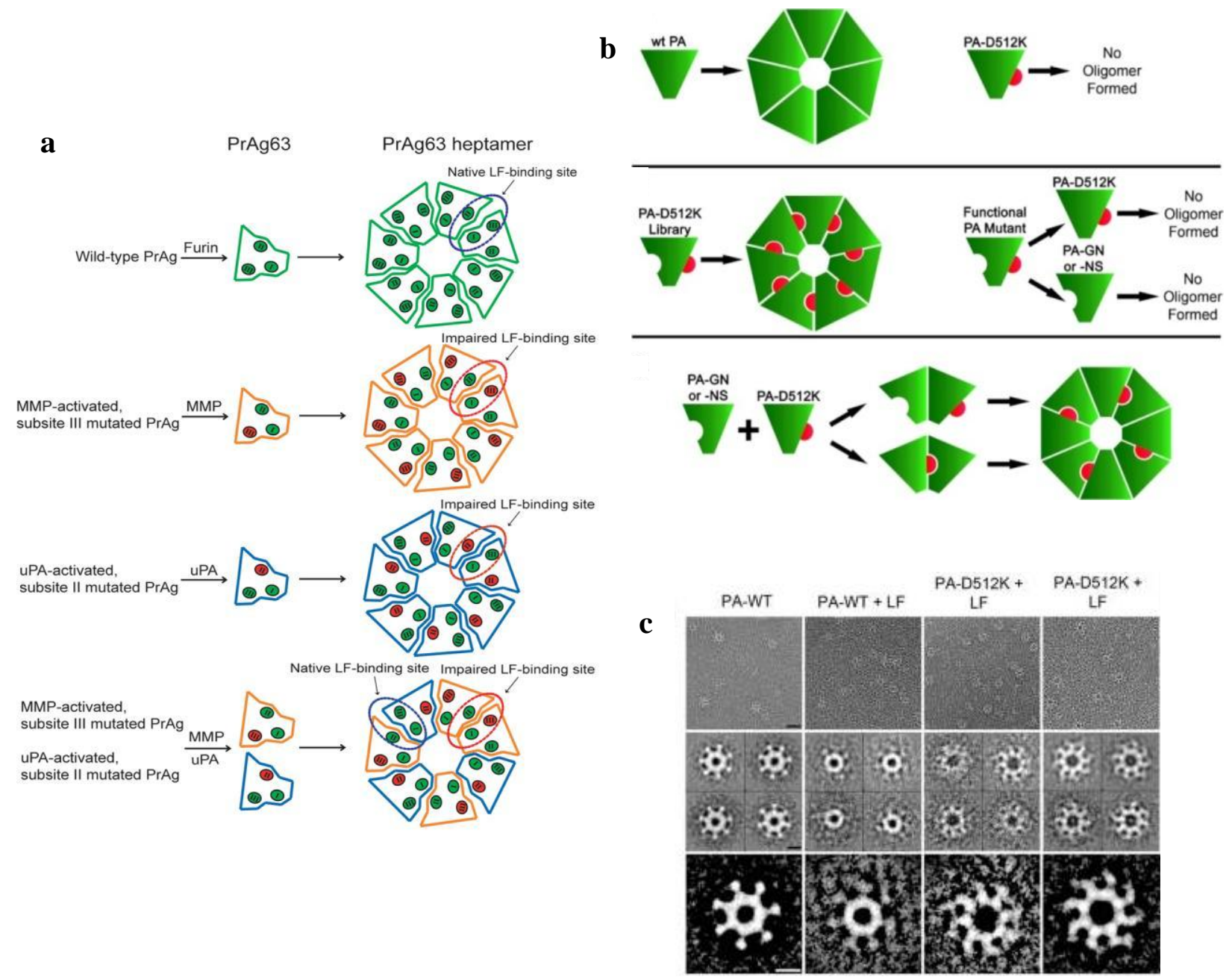

These proteins contained additional mutations so that PA-U2 and PA-L1 monomeric subunits had to be adjacent in an oligomer to form native LF binding sites. As a result, individually the constructed PA variants showed decreased toxicity due to the impaired LF binding; however, when administered 
together to uPA and MMP overexpressing cancer cells formed functional LF-binding heteroheptamers. The mixture of these two mutants was highly effective in vivo to treat diverse aggressive transplanted tumors. In this study, the authors established proof-of-principle that anthrax toxin can be re-engineered in a way so that its cytotoxicity relies on two distinct proteolytic activities overexpressed by the cancer cell [281]. This strategy was further examined in a study where the therapeutic window of the anthrax toxin-based TTs was enlarged with PA variants rationally designed to selectively and exclusively form oligomers [282] (Figure 13b).

The idea of this design was based on a finding made by Krantz and colleagues that PA, which for a long time was believed to form heptameric complexes, is also able to form octamers, and they are functional [107]. Moreover, conditions under which octameric oligomerization predominates were determined and heptamer/octamer structural comparison showed that there are two orientations of the receptor-binding PA domain 4, which alternate in the octamer. The molecular determinants that influence the stoichiometry of PA complexes were identified, e.g., the relative proportion of PA heptamers and octamers could be controlled by tethering domain 4 to domain 2 with two different length cross-links [283]. By screening a highly directed library of PA mutants, Leppla and colleagues identified variants that complemented each other to form octamers exclusively [282]. The authors started with the PA mutant D512K, which is incapable of forming oligomers (Figure 13b, top), and prepared a $<50,000$-members library of PA variants that have the D512K substitution together with random mutations in several residues on the complementary face of $\mathrm{PA}_{63}$ within the oligomers (Figure 13b, middle). The library was screened for regaining of oligomer-forming ability and then, after the sought variants were identified, D512K and new complementary mutations were placed into two separate PA proteins. As a result, the authors achieved formation of oligomers through the use of the two unique interfaces (wild type and mutated), which resulted in formation of even-numbered oligomers (Figure 13b, bottom), predominately octamers (Figure 13c). In particular, the authors focused on the transformants containing substitutions at residues 245 and 252. By combining PA-D512K with either PA K245G/R252N (abbreviated as PA-GN) or PA K245N/R252S (abbreviated as PA-NS) generated high toxicity comparable to that of wild type PA both in vitro and in vivo. However these variant were non-toxic when used individually [282].

The third strategy is based on the fact that the $\mathrm{PA}_{63}$-mediated protein uptake machinery is effective enough to deliver multiple engineered variants of the native anthrax toxin LF and EF components. To increase the therapeutic benefit of the TTs, the native LF and EF were replaced with a variety of fusion proteins containing the $\mathrm{PA}_{63}$ binding $\mathrm{N}$-terminal domain of $\mathrm{LF}\left(\mathrm{LF}_{\mathrm{N}}\right)$ or $\mathrm{EF}\left(\mathrm{EF}_{\mathrm{N}}\right)$ and different toxophores (the so called "cut and paste" approach [265]). The resulting chimeric variants included $\mathrm{LF}_{\mathrm{N}}$ fused to Pseudomonas exotoxin A enzymatic domain [284], Shiga toxin enzymatic domain, diphtheria toxin A chain [285,286], tetanus toxin light chain [287], Clostridia difficile B toxin glycosylating domain [288], Haemophilus ducreyi cytolethal distending toxin B subunit [289], Bcl-XL protein [290], ricin toxin A chain [269], flagellin [291], and beta-lactamase [292,293]. Many of these heterologous proteins have been successfully delivered by $\mathrm{PA}_{63}$ (native or mutated) into the cytosol. However, some proteins, apparently those that were not able to adopt a partially or fully unfolded state at the acidic endosomal pH, have failed [267,294]. Another factor that can limit the potency of TTs is the stability of the enzymatic domains in the cytosol [295]. Recently, this issue has been examined with $\mathrm{LF}_{\mathrm{N}}$-PEIII variants constructed with insertion of a ubiquitin domain (wild type and mutated) 
between the targeting domain $\left(\mathrm{LF}_{\mathrm{N}}\right)$ and the catalytic "payload" (PEIII) [295]. The variants were designed to address the previously described bias against the presence of lysine residues in enzymatic domains of several AB-type bacterial toxins [296]. Thus, the catalytic domains of cholera toxin, E. coli heat-labile toxin, Shiga-like toxin, and ricin have strong bias towards Arg relative to Lys. This characteristic is believed to limit the attachment of ubiquitin followed by the proteasomal degradation of the toxins [295,297]. Ubiquitin is a small eukaryotic regulatory protein, which, among its multiple functions, also has a signaling role in protein degradation. The cytosolic stability of LF and $\mathrm{LF}_{\mathrm{N}}$-based chimeric proteins was shown to follow the so-called N-end rule [294,298] described by Alexander Varshavsky in 1986 [299]. In accordance with the N-end rule, the specific destabilizing N-terminal amino acid of a protein controls the effectiveness with which side chain lysine residues are ubiquitinated for the following proteasomal degradation. Ubiquitin, after binding to a target protein, can be in its turn ubiquitinated, forming polyubiquitin chains on any of the seven lysine residues within ubiquitin. This process is controlled by deubiquitinating (DUBs) enzymes that allow for ubiquitin to be released from the protein. Interestingly, $\mathrm{LF}_{\mathrm{N}^{-}} \mathrm{Ub}$-PEIII fusion proteins, in which all seven lysines of the wild type ubiquitin were retained while the site cleaved by cytosolic DUBs was removed, were nontoxic, which the authors explain by a rapid ubiquitination and proteasomal degradation [295]. The authors also showed that the fusion protein, in which all seven lysines were substituted by arginine $\left(\mathrm{Ub}_{\mathrm{Knull}}\right)$, had high potency exceeding that of FP59. In general, the potency of these proteins was highly dependent on the number of lysines retained in the ubiquitin domain and on retention of the C-terminal ubiquitin sequences cleaved by DUBs [295]. The stability of LF $_{\mathrm{N}}$-PEIII fusion proteins was also significantly improved in a study where $\mathrm{N}$-terminal amino acids of $\mathrm{LF}_{\mathrm{N}}$ were mutated and all the lysines reductively dimethylated [300].

Besides the single chain and binary toxins, membrane-perforating bacterial toxins were also considered as potential candidates for the tailored modifications. Among the bacterial pore-forming toxins which were investigated for their cytolytic or cytocidal properties against tumorous cells were $\alpha$-hemolysin of Staphylococcus aureus [26,301-303], parasporin-4 of Bacillus thuringiensis [304-307], listeriolysin O of Listeria monocytogenes [308], aerolysin of Aeromonas hydrophila [309,310], the S component of Panton-Valentine lekocidin (LukS-PV) of Staphylococcus aureus [311] and epsilon toxin of Clostridium perfringens [312]. In particular, Bayley and colleagues explored $\alpha \mathrm{HL}$ mutants in which channel-forming activity can be triggered or switched on and off by biochemical, chemical, or physical stimuli [26,301,302]. The approach was based on earlier studies, which showed that the subunits of a functional $\alpha \mathrm{HL}$ with nicks near the midpoint of a central glycine-rich loop are supported by domain-domain interactions, whereas $\alpha \mathrm{HL}$ oligomers containing two truncated subunits that overlap in the central loop had greatly reduced channel-forming activity [313-315]. Based on these data, the group designed overlap $\alpha \mathrm{HL}$ mutants that were activated when redundant amino acids in the loop were removed by proteases that inactivate the wild-type protein [301]. The authors proposed that this strategy could be used to construct proimmunolysins, variants of $\alpha \mathrm{HL}$ that would be preferentially activated by the cancer cell surface proteases [301]. $\alpha \mathrm{HL}$ would then perforate and kill the tumor cell or permeabilize the cell membrane for the cytotoxic drugs that have no or low permeability [303]. Thus, combinatorial mutagenesis was used to obtain $\alpha \mathrm{HL}$ mutants that were rapidly and preferentially activated by cathepsin B [303]. Cathepsin B, normally an enzymatic protein, is involved in various 
pathologies and oncogenic processes in humans; its overexpression is correlated with invasive and metastatic phenotypes in cancer [316].

A series of tailor-made pore-forming bacterial toxins were generated for intracellular delivery of different types of macromolecules [317,318]. One of the main challenges drug designers face is poor bioavailability of the compounds as a result of poor membrane permeability. Loaded $\mathrm{pH}$-sensitive listeriolysin O-containing liposomes were developed [319-325] and tested both in vitro and in vivo (see refs. [19,317] for details). Targeted drug delivery to generate protective antiviral immunity was also examined using the anthrax toxin [266,326-328]. Interestingly, gramicidin, the first marketed natural antimicrobial agent (1939) [329], was also studied for inhibition of human immunodeficiency virus (HIV) infection [330-333].

\section{Concluding Remarks}

Promising new developments in nanopore biotechnology continually emerge [334]. Because of the overwhelming number of the reports in this popular field, the current review is not exhaustive. In this article, written for a special volume on "Intracellular Traffic and Transport of Bacterial Protein Toxins", we highlight many interesting applications of channel-forming bacterial toxins in small and macromolecule sensing and polymer transport. For clarity, instead of discussing all pore types previously investigated, we focus on three structurally and functionally different bacterial toxins: (1) peptide gramicidin A (GrA) of Bacillus brevis, which induces lesions in cell membranes forming small exclusively cation-permeable channels; (2) $\alpha$-hemolysin $(\alpha \mathrm{HL})$ of Staphylococcus aureus, which targets the host cell membranes by forming large $\beta$-barrel pores; and (3) protective antigen $\left(\mathrm{PA}_{63}\right)$, the pore-forming B component of the anthrax toxin, which mediates translocation of the toxin's enzymatic components inside the target cell. There is no doubt that the number of related publications on biotechnological applications of any of these toxins far exceeds all the residual reports in the bionanopore field. At the same time, the reasons why these particular molecules were chosen for development are mani-fold. Gramicidin A can serve as an ideal single molecule on/off switch reacting to different stimuli and as a sensor for lipid membranes properties. The $\alpha \mathrm{HL}$ channel is a structurally stable pore, which remains in the electrically low-noise open state over a wide range of experimental conditions, including extreme salt concentrations, $\mathrm{pH}$, and temperatures. The crystal structure of $\alpha \mathrm{HL}$ was solved at a $1.9-\AA$ resolution more than 15 years ago and the protein could be genetically or chemically modified in a number of ways. $\alpha \mathrm{HL}$ was recently reengineered to form a functional bottom-up dimeric pore than spans two adjacent lipid bilayers [335]. On the other hand, when $\alpha \mathrm{HL}$ was so severely truncated that the protein heptamer could not span a bilayer, the channel insertions were still observed, supporting the idea that membrane proteins could stabilize the toroidal lipid pores [336]. Interestingly, the channel-forming $\mathrm{B}$ component of the anthrax toxin, $\mathrm{PA}_{63}$ is often compared with the membrane pore of $\alpha \mathrm{HL}$. This is mostly because these channels were reported to form functional mushroom-shaped heptamers. However, electrical characteristics of $\mathrm{PA}_{63}$ differ dramatically from those of $\alpha \mathrm{HL}$. First, despite having comparable diameters at the most narrow constrictions, the $\alpha \mathrm{HL}$ conductance in $1 \mathrm{M} \mathrm{KCl}$ solution is $\sim 5$ times higher, which allows for a significant improvement of the signal-to-noise ratio at the single channel level. Second, since formation of the $\mathrm{PA}_{63}$ channels are triggered by the low endosomal $\mathrm{pH}$, the available $\mathrm{pH}$ range for the 
molecular sensing experiments is significantly limited for subacidic $\mathrm{pH}$. Finally, two types of gating were reported for the $\mathrm{PA}_{63}$ channels. The typical voltage gating, intrinsic to many $\beta$-barrel channels incorporated into the artificial bilayers [337,338], shows a pronounced voltage asymmetry in the case of $\mathrm{PA}_{63}$ pore, somewhat limiting the voltage range available for the statistically reliable measurements. More importantly, the current noise through the open $\mathrm{PA}_{63}$ channel is far from being electrically quiet, showing persistent $1 /$ f fluctuations between open and closed states. Similar to $\alpha \mathrm{HL}, \mathrm{PA}_{63}$ was shown to be able to accommodate $\beta C D$ molecules. However, the current blockage events were complete, which limits the possibilities to use $\beta C D$ as $\mathrm{PA}_{63}$-modifying adapters. Therefore, it was not the $\mathrm{PA}_{63}$ channel of being used as a biosensor per se, but rather an elevated interest in the anthrax toxin and several strong research groups working in the field that advanced biotechnological applications for the anthrax toxin. Attempting to understand the anthrax toxin uptake mechanism by investigating protein transport on the one hand, and the unique ability of reengineered $\mathrm{PA}_{63}$ to deliver enzymatic components inside the target tumor cell on the other hand, made this "noisy" channel a nanopore of choice for different studies. Some of these reports created directions for the rational modifications of $\mathrm{PA}_{63}$ that could significantly alter the pore properties. For instance, F427A PA 63 mutant was reported to have $\sim 3$-times higher conductance than the wild type pore and did not show the wild type $\mathrm{PA}_{63}$ 's $1 / \mathrm{f}$ noise current fluctuations [102,118]. A number of interesting dominant negative [247-250] and predominantly octameric $\mathrm{PA}_{63}$ mutants was reported [282]. The anthrax toxin-neutralizing antibodies reconfiguring PA into supercomplexes, which are yet to be tested in the bilayer membranes, were also described [339]. GrA, $\alpha H L$, and anthrax toxin's channel forming component PA $_{63}$ are available commercially and, in contrast to other toxins, for instance epsilon toxin and botulinum neurotoxin, there are no firm biosafety restrictions on the usage of small quantities of these proteins under regular laboratory conditions.

There is no doubt that the nanopore biotechnology is and will remain an exciting field of research. In the future, with the development of single-channel electrical recording techniques, X-ray crystallography, protein engineering, computational methods, and, importantly, human curiosity, we will see many interesting new pore types being explored. As an example, a group of peptide phytotoxins produced by Pseudomonas syringae, syringomycin E (SRE), and similar compounds were extensively studied by Schagina and colleagues [135,340]. Similarly to gramicidin A, SRE-produced pores can be used as sensitive probes of the membrane physical state, surface charge, orientation of membrane inner dipoles, and the interaction of membrane-active molecules.

A cytolytic pore-forming toxin aerolysin of Aeromonas hydrophila represents an interesting alterative to $\alpha \mathrm{HL}$. Recently, X-ray crystallography, cryo-EM, MD and computational modeling approaches have been used to resolve a near-atomistic structure of the aerolysin pore and to study intermediate states leading to the pore formation [341]. Both biosensing and protein translocation properties of the channel have been reported [342-345]. Another " $\alpha$ HL-like" oligomeric pore is formed by cholesterol-dependent Vibrio cholerae cytolysin [346-348]. Remarkably, the X-ray crystallography [349] revealed an interesting structural detail of cytolysin - a narrow constriction region formed by an unexpected aromatic tryptophan W318 ring of residues within the pore that is otherwise rich in charged amino acid residues. The authors compare this region with the $\phi$-clamp of the B component of the binary bacterial toxins, such as anthrax, where it is believed to be critical for the A component's translocation. At the same time, so far there is no evidence indicating that Vibrio cholerae cytolysin serves as a transmembrane protein translocase. We wonder if this structural property 
could be employed to mimic the Brownian ratchet mechanism of anthrax toxin translocation [239] with this significantly different protein in vitro.

Currently, one of the greatest problems hampering the study of polymer transport and nucleic acid pore-assisted sequencing is the high translocation rate of these molecules. Several approaches have been developed to slow down the single-molecule transport through a protein nanopore [192,350-352]. Thus, genetically optimized porin MspA of Myobacterium smegmatis is believed [19] to be a promising pore for biosensing and sequencing applications due to its conical shape providing a very narrow ( 10-£) sensing zone [194]. Interestingly, epsilon toxin of Clostridium perfringens (reviewed in refs. [353-355]) was reported to form slightly anion-selective stable low-noise pores with a single-channel conductance in the range of $440-640 \mathrm{pS}$ in $1 \mathrm{M} \mathrm{KCl}[356,357]$. The polymer-partitioning studies to access the epsilon toxin pore's functional shape and size suggested that the channel is highly asymmetric, i.e., conical with the tentative radii of openings of 0.4 and $1.0 \mathrm{~nm}$ on the cis and trans sides, respectively [358]. However the single channel studies on this channel are limited to three publications [356-358], which could be partially explained by lack of the epsilon toxin oligomer's crystal structure and by certain CDC regulations placed on use of this category B agent.

Besides, the channel-forming $\mathrm{B}$ components of the clostridial binary bacterial toxins show remarkable structural and functional similarities with $\mathrm{PA}_{63}$ [9,318]. Moreover, $\mathrm{PA}_{63}$ was shown to be effective in transporting the His-tagged enzymatic C2I component of the binary $\mathrm{C} 2$ toxin into the cytosol $[359,360]$. Along with the anthrax toxin, binary clostridial ADP-ribosylating toxins have been examined for their ability to deliver heterologous catalytic domains inside the tumor cells. Many of the reported examples, which mainly consist of the chimeric toxins constructed on the basis of the active component of C2 toxin, C2I are intensively reviewed elsewhere [9,318]. More recent reports describe genetically engineered chimeric C2IN-streptavidin complexes, which were designed to delivered biotin-labeled molecules into the cytosol of diverse eukaryotic cell lines by the binding/translocation subunit of the toxin [361-363]. The C2-streptavidin delivery system was used to internalize biotin-labeled p53 tumor suppressor into different mammalian cell lines, including human tumor cells [364]. The direct C2IN-p53 constructs were also investigated [365]. Chemical conjugation strategies as alternatives to engineering fusion proteins have also recently been explored resulting in the assembly of C2 toxin-based Janus-like supramolecular fusion proteins based on the iminobiotin-avidin linkage responding to external stimuli, such as $\mathrm{pH}$ [366]. Currently, it is unclear to what extent the channel-forming B components of the clostridial binary toxins serve as active translocase of their A components, similarly to what is suggested for $\mathrm{PA}_{63}$. On the one hand, the preserved $\phi$-clamp in position 428 was shown to be important for pore formation and for cytotoxicity and rounding up of cells by the enzymatic C2I subunits of the C2 toxin [367]. On the other hand, the host cell chaperones Hsp90 and the peptidyl-prolyl cis/trans isomerase cyclophilin A were reported to be critical for membrane translocation of the active moieties of clostridial C2, iota, and CDT toxins but not for LF of the anthrax toxin [368-370]. Provided that the corresponding bilayer measurements show successful translocation events similar to those described for the anthrax toxin, we believe these findings would add some useful arguments to the anthrax toxin uptake debate [18]. For that purpose, not only the native but also the $\mathrm{PA}_{63} / \mathrm{C} 2 \mathrm{I}$-His cross-combination of components could be tested. 


\section{Acknowledgments}

Philip A. Gurnev research is supported by the National Science Foundation EAGER award No. 1249199. Ekaterina M. Nestorovich research is supported by the startup funds from The Catholic University of America. The authors thank Adrian and Valerie Parsegian for their invaluable help with the manuscript proofreading.

\section{Author Contributions}

Ekaterina M. Nestorovich conceived and structured the review, she wrote major parts on Polymer sensing, Protein transport, and Cancer Therapy; Philip A. Gurnev wrote parts of Introduction, Molecular Sensing and Polynucleotide Sequencing.

\section{Conflicts of Interest}

The authors declare no conflict of interest.

\section{References}

1. Parker, M.W.; Feil, S.C. Pore-forming protein toxins: From structure to function. Prog. Biophys. Mol. Biol. 2005, 88, 91-142.

2. Geny, B.; Popoff, M.R. Bacterial protein toxins and lipids: Pore formation or toxin entry into cells. Biol. Cell 2006, 98, 667-678.

3. Van der Goot, G., Ed. Pore-Forming Toxins; Springer-Verlag: New York, NY, USA, 2001; p. 168.

4. Los, F.C.; Randis, T.M.; Aroian, R.V.; Ratner, A.J. Role of pore-forming toxins in bacterial infectious diseases. Microbiol. Mol. Biol. Rev. 2013, 77, 173-207.

5. Alouf, J.E. Pore-forming bacterial protein toxins: An overview. In Pore-Forming Toxins; Gisou van der Goot, F., Ed.; Springer-Verlag Berlin Heidelberg: Berlin, Germany, 2001; pp. 1-14.

6. Gilbert, R.J. Pore-forming toxins. Cell Mol. Life Sci. 2002, 59, 832-844.

7. Gouaux, E. Channel-forming toxins: Tales of transformation. Curr. Opin. Struct. Biol. 1997, 7, $566-573$.

8. Gonzalez, M.R.; Bischofberger, M.; Pernot, L.; van der Goot, F.G.; Freche, B. Bacterial pore-forming toxins: The (W)Hole story? Cell Mol. Life Sci. 2008, 65, 493-507.

9. Barth, H.; Aktories, K.; Popoff, M.R.; Stiles, B.G. Binary bacterial toxins: Biochemistry, biology, and applications of common clostridium and bacillus proteins. Microbiol. Mol. Biol. Rev. 2004, 68, 373-402.

10. Donovan, J.J.; Simon, M.I.; Draper, R.K.; Montal, M. Diphtheria toxin forms transmembrane channels in planar lipid bilayers. Proc. Natl. Acad. Sci. USA 1981, 78, 172-176.

11. Kagan, B.L.; Finkelstein, A.; Colombini, M. Diphtheria toxin fragment forms large pores in phospholipid bilayer membranes. Proc. Natl. Acad. Sci. USA 1981, 78, 4950-4954.

12. Deleers, M.; Beugnier, N.; Falmagne, P.; Cabiaux, V.; Ruysschaert, J.M. Localization in diphtheria toxin fragment $\mathrm{b}$ of a region that induces pore formation in planar lipid bilayers at low pH. FEBS Lett. 1983, 160, 82-86. 
13. Oblatt-Montal, M.; Yamazaki, M.; Nelson, R.; Montal, M. Formation of ion channels in lipid bilayers by a peptide with the predicted transmembrane sequence of botulinum neurotoxin A. Protein Sci. 1995, 4, 1490-1497.

14. Donovan, J.J.; Middlebrook, J.L. Ion-Conducting channels produced by botulinum toxin in planar lipid membranes. Biochemistry 1986, 25, 2872-2876.

15. Blaustein, R.O.; Koehler, T.M.; Collier, R.J.; Finkelstein, A. Anthrax toxin: Channel-Forming activity of protective antigen in planar phospholipid bilayers. Proc. Natl. Acad. Sci. USA 1989, 86, 2209-2213.

16. Schmid, A.; Benz, R.; Just, I.; Aktories, K. Interaction of clostridium botulinum C2 toxin with lipid bilayer membranes. Formation of cation-selective channels and inhibition of channel function by chloroquine. J. Biol. Chem. 1994, 269, 16706-16711.

17. Knapp, O.; Benz, R.; Gibert, M.; Marvaud, J.C.; Popoff, M.R. Interaction of clostridium perfringens iota-toxin with lipid bilayer membranes. Demonstration of channel formation by the activated binding component $\mathrm{Ib}$ and channel block by the enzyme component Ia. J. Biol. Chem. 2002, 277, 6143-6152.

18. Nablo, B.J.; Panchal, R.G.; Bavari, S.; Nguyen, T.L.; Gussio, R.; Ribot, W.; Friedlander, A.; Chabot, D.; Reiner, J.E.; Robertson, J.W.; et al. Anthrax toxin-induced rupture of artificial lipid bilayer membranes. J. Chem. Phys. 2013, 139, doi:10.1063/1.4816467.

19. Majd, S.; Yusko, E.C.; Billeh, Y.N.; Macrae, M.X.; Yang, J.; Mayer, M. Applications of biological pores in nanomedicine, sensing, and nanoelectronics. Curr. Opin. Biotechnol. 2010, 21, 439-476.

20. Panchal, R.G.; Smart, M.L.; Bowser, D.N.; Williams, D.A.; Petrou, S. Pore-forming proteins and their application in biotechnology. Curr. Pharm. Biotechnol. 2002, 3, 99-115.

21. Reiner, J.E.; Balijepalli, A.; Robertson, J.W.; Campbell, J.; Suehle, J.; Kasianowicz, J.J. Disease detection and management via single nanopore-based sensors. Chem. Rev. 2012, 112, 6431-6451.

22. Delcour, A.H. Electrophysiology of bacteria. Annu. Rev. Microbiol. 2013, 67, 179-197.

23. Steller, L.; Kreir, M.; Salzer, R. Natural and artificial ion channels for biosensing platforms. Anal. Bioanal Chem. 2012, 402, 209-230.

24. Bezrukov, S.M.; Kasianowicz, J.J. Current noise reveals protonation kinetics and number of ionizable sites in an open protein ion channel. Phys. Rev. Lett. 1993, 70, 2352-2355.

25. Kasianowicz, J.J.; Bezrukov, S.M. Protonation dynamics of the alpha-toxin ion channel from spectral analysis of pH-dependent current fluctuations. Biophys. J. 1995, 69, 94-105.

26. Bayley, H. Pore-forming proteins with built-in triggers and switches. Bioorg. Chem. 1995, 23, 340-354.

27. Coulter, H.W. Means for counting particles suspended in a fluid. U.S. Patent US2656508, 20 October 1953.

28. Hotchkiss, R.D. Gramicidin, tyrocidine, and tyrothricin. Adv. Enzymol. Relat. Areas Mol. Biol. 1944, 4, 153-199.

29. Ishii, S.I.; Witkop, B. Gramicidin, A. I. Determination of composition and amino acid configuration by enzymatic and gas chromatographic methods. J. Am. Chem. Soc. 1963, 85, 1832-1834. 
30. Ishii, S.I.; Witkop, B. Gramicidin, A. II. Preparation and properties of "seco-Gramicidin A". J. Am. Chem. Soc. 1964, 86, 1848-1853.

31. Sarges, R.; Witkop, B. Gramicidin, A. IV. Primary sequence of valine and isoleucine gramicidin A. J. Am. Chem. Soc. 1964, 86, 1862-1863.

32. Harold, F.M.; Baarda, J.R. Gramicidin, valinomycin, and cation permeability of streptococcus faecalis. J. Bacteriol. 1967, 94, 53-60.

33. Hladky, S.B.; Haydon, D.A. Discreteness of conductance change in bimolecular lipid membranes in the presence of certain antibiotics. Nature 1970, 225, 451-453.

34. Gurnev, P.A.; Bezrukov, S.M. Inversion of membrane surface charge by trivalent cations probed with a cation-selective channel. Langmuir 2012, 28, 15824-15830.

35. Urry, D.W. The gramicidin A transmembrane channel: A proposed Pi(L,D) helix. Proc. Natl. Acad. Sci. USA 1971, 68, 672-676.

36. Ketchem, R.R.; Hu, W.; Cross, T.A. High-resolution conformation of gramicidin A in a lipid bilayer by solid-state NMR. Science 1993, 261, 1457-1460.

37. Hladky, S.B.; Haydon, D.A. Ion transfer across lipid membranes in the presence of gramicidin A.I. Studies of the unit conductance channel. Biochim. Biophys. Acta 1972, 274, 294-312.

38. Myers, V.B.; Haydon, D.A. Ion transfer across lipid membranes in the presence of gramicidin A. II. the ion selectivity. Biochim. Biophys. Acta 1972, 274, 313-322.

39. Mazet, J.L.; Andersen, O.S.; Koeppe, R.E., 2nd. Single-Channel studies on linear gramicidins with altered amino acid sequences. A comparison of phenylalanine, tryptophane, and tyrosine substitutions at positions 1 and 11. Biophys. J. 1984, 45, 263-276.

40. Koeppe, R.E., 2nd; Mazet, J.L.; Andersen, O.S. Distinction between dipolar and inductive effects in modulating the conductance of gramicidin channels. Biochemistry 1990, 29, 512-520.

41. Schagina, L.V.; Grinfeldt, A.E.; Lev, A.A. Interaction of cation fluxes in gramicidin A channels in lipid bilayer membranes. Nature 1978, 273, 243-245.

42. Elliott, J.R.; Needham, D.; Dilger, J.P.; Haydon, D.A. The effects of bilayer thickness and tension on gramicidin single-channel lifetime. Biochim. Biophys. Acta 1983, 735, 95-103.

43. Lundbaek, J.A.; Birn, P.; Girshman, J.; Hansen, A.J.; Andersen, O.S. Membrane stiffness and channel function. Biochemistry 1996, 35, 3825-3830.

44. Helfrich, P.; Jakobsson, E. Calculation of deformation energies and conformations in lipid membranes containing gramicidin channels. Biophys. J. 1990, 57, 1075-1084.

45. Lundbaek, J.A.; Andersen, O.S. Spring constants for channel-induced lipid bilayer deformations. estimates using gramicidin channels. Biophys. J. 1999, 76, 889-895.

46. Killian, J.A. Gramicidin and gramicidin-lipid interactions. Biochim. Biophys. Acta 1992, 1113, $391-425$.

47. Lewis, J.C.; Dimick, K.P.; Feustel, I.C.; Fevold, H.L.; Olcott, H.S.; Fraenkel-Conrat, H. Modification of gramicidin through reaction with formaldehyde. Science 1945, 102, 274-275.

48. Lundbaek, J.A.; Collingwood, S.A.; Ingolfsson, H.I.; Kapoor, R.; Andersen, O.S. Lipid bilayer regulation of membrane protein function: Gramicidin channels as molecular force probes. J. R. Soc. Interface 2010, 7, 373-395. 
49. Rostovtseva, T.K.; Aguilella, V.M.; Vodyanoy, I.; Bezrukov, S.M.; Parsegian, V.A. Membrane surface-charge titration probed by gramicidin a channel conductance. Biophys. J. 1998, 75, 1783-1792.

50. Borisenko, V.; Zhang, Z.; Woolley, G.A. Gramicidin derivatives as membrane-based pH sensors. Biochim. Biophys. Acta 2002, 1558, 26-33.

51. Gurnev, P.A.; Yang, S.T.; Melikov, K.C.; Chernomordik, L.V.; Bezrukov, S.M. Cationic cell-penetrating peptide binds to planar lipid bilayers containing negatively charged lipids but does not induce conductive pores. Biophys. J. 2013, 104, 1933-1939.

52. Majd, S.; Yusko, E.C.; MacBriar, A.D.; Yang, J.; Mayer, M. Gramicidin pores report the activity of membrane-active enzymes. J. Am. Chem. Soc. 2009, 131, 16119-16126.

53. Macrae, M.X.; Blake, S.; Mayer, M.; Yang, J. Nanoscale ionic diodes with tunable and switchable rectifying behavior. J. Am. Chem. Soc. 2010, 132, 1766-1767.

54. Legendre, J.Y.; Szoka, F.C., Jr. Cyclic amphipathic peptide-DNA complexes mediate high-efficiency transfection of adherent mammalian cells. Proc. Natl. Acad. Sci. USA 1993, 90, 893-897.

55. Arbuthnott, J.P.; Freer, J.H.; Bernheimer, A.W. Physical states of staphylococcal alpha-toxin. J. Bacteriol. 1967, 94, 1170-1177.

56. Bhakdi, S.; Fussle, R.; Tranum-Jensen, J. Staphylococcal alpha-toxin: Oligomerization of hydrophilic monomers to form amphiphilic hexamers induced through contact with deoxycholate detergent micelles. Proc. Natl. Acad. Sci. USA 1981, 78, 5475-5479.

57. Cassidy, P.; Harshman, S. Studies on the binding of staphylococcal 125I-Labeled alpha-toxin to rabbit erythrocytes. Biochemistry 1976, 15, 2348-2355.

58. Wilke, G.A.; Bubeck Wardenburg, J. Role of a disintegrin and metalloprotease 10 in staphylococcus aureus alpha-hemolysin-mediated cellular injury. Proc. Natl. Acad. Sci. USA 2010, 107, 13473-13478.

59. Valeva, A.; Hellmann, N.; Walev, I.; Strand, D.; Plate, M.; Boukhallouk, F.; Brack, A.; Hanada, K.; Decker, H.; Bhakdi, S. Evidence that clustered phosphocholine head groups serve as sites for binding and assembly of an oligomeric protein pore. J. Biol. Chem. 2006, 281, 26014-26021.

60. Schwiering, M.; Brack, A.; Stork, R.; Hellmann, N. Lipid and phase specificity of alpha-toxin from S. Aureus. Biochim. Biophys. Acta 2013, 1828, 1962-1972.

61. Fussle, R.; Bhakdi, S.; Sziegoleit, A.; Tranum-Jensen, J.; Kranz, T.; Wellensiek, H.J. On the mechanism of membrane damage by staphylococcus aureus alpha-toxin. J. Cell Biol. 1981, 91, 83-94.

62. Bhakdi, S.; Tranum-Jensen, J. Alpha-Toxin of staphylococcus aureus. Microbiol. Rev. 1991, 55, 733-751.

63. Berube, B.J.; Bubeck Wardenburg, J. Staphylococcus aureus alpha-toxin: Nearly a century of intrigue. Toxins 2013, 5, 1140-1166.

64. Inoshima, I.; Inoshima, N.; Wilke, G.A.; Powers, M.E.; Frank, K.M.; Wang, Y.; Bubeck Wardenburg, J. A staphylococcus aureus pore-forming toxin subverts the activity of ADAM10 to cause lethal infection in mice. Nat. Med. 2011, 17, 1310-1314. 
65. Krasilnikov, O.; Ternovsky, V.I.; Musaev, Y.M.; Tashmukhamedov, B. Influence of staphylotoxin on conductance of bilayer phospholipid membranes. Dokl. Akad. Nauk UzSSR 1980, 7, 66-68.

66. Menestrina, G. Ionic channels formed by staphylococcus aureus alpha-toxin: Voltage-Dependent inhibition by divalent and trivalent cations. J. Membr. Biol. 1986, 90, 177-190.

67. Belmonte, G.; Cescatti, L.; Ferrari, B.; Nicolussi, T.; Ropele, M.; Menestrina, G. Pore formation by staphylococcus aureus alpha-toxin in lipid bilayers. Dependence upon temperature and toxin concentration. Eur. Biophys. J. 1987, 14, 349-358.

68. Krasilnikov, O.V.; Merzliak, P.G.; Sabirov, R.Z.; Tashmuk-Hamedov, B.A. Memory is a property of an ion channels pool: Ion channels formed by staphylococcus aureus alpha-toxin. Gen. Physiol. Biophys. 1990, 9, 569-575.

69. Korchev, Y.E.; Alder, G.M.; Bakhramov, A.; Bashford, C.L.; Joomun, B.S.; Sviderskaya, E.V.; Usherwood, P.N.; Pasternak, C.A. Staphylococcus aureus alpha-toxin-induced pores: Channel-Like Behavior in lipid bilayers and patch clamped cells. J. Membr. Biol. 1995, 143, 143-151.

70. Bezrukov, S.; Vodyanoy, I.; Kasianowicz, J. Dynamics and free energy of polymers partitioning into a nanoscale pore. Macromolecules 1996, 29, 8517-8522.

71. Merzlyak, P.G.; Yuldasheva, L.N.; Rodrigues, C.G.; Carneiro, C.M.; Krasilnikov, O.V.; Bezrukov, S.M. Polymeric nonelectrolytes to probe pore geometry: Application to the alpha-toxin transmembrane channel. Biophys. J. 1999, 77, 3023-3033.

72. Krasilnikov, O.V.; Merzlyak, P.G.; Yuldasheva, L.N.; Rodrigues, C.G.; Bhakdi, S.; Valeva, A. Electrophysiological Evidence for heptameric stoichiometry of ion channels formed by staphylococcus aureus alpha-toxin in planar lipid bilayers. Mol. Microbiol. 2000, 37, 1372-1378.

73. Gu, L.Q.; Bayley, H. Interaction of the noncovalent molecular adapter, beta-cyclodextrin, with the staphylococcal alpha-hemolysin pore. Biophys. J. 2000, 79, 1967-1975.

74. Movileanu, L.; Cheley, S.; Howorka, S.; Braha, O.; Bayley, H. Location of a constriction in the lumen of a transmembrane pore by targeted covalent attachment of polymer molecules. J. Gen. Physiol. 2001, 117, 239-252.

75. Menestrina, G.; Dalla Serra, M.; Comai, M.; Coraiola, M.; Viero, G.; Werner, S.; Colin, D.A.; Monteil, H.; Prevost, G. Ion channels and bacterial infection: The Case of beta-barrel pore-forming protein toxins of staphylococcus aureus. FEBS Lett. 2003, 552, 54-60.

76. Gu, L.Q.; Cheley, S.; Bayley, H. Electroosmotic enhancement of the binding of a neutral molecule to a transmembrane pore. Proc. Natl. Acad. Sci. USA 2003, 100, 15498-15503.

77. Movileanu, L.; Cheley, S.; Bayley, H. Partitioning of individual flexible polymers into a nanoscopic protein pore. Biophys. J. 2003, 85, 897-910.

78. Song, L.; Hobaugh, M.R.; Shustak, C.; Cheley, S.; Bayley, H.; Gouaux, J.E. Structure of staphylococcal alpha-hemolysin, a heptameric transmembrane pore. Science 1996, 274, 1859-1866.

79. Aksimentiev, A.; Schulten, K. Imaging alpha-hemolysin with molecular dynamics: Ionic conductance, osmotic permeability, and the electrostatic potential map. Biophys. J. 2005, 88, 3745-3761.

80. Young, J.A.; Collier, R.J. Anthrax toxin: Receptor Binding, internalization, pore formation, and translocation. Annu. Rev. Biochem. 2007, 76, 243-265.

81. Moayeri, M.; Leppla, S.H. Cellular and systemic effects of anthrax lethal toxin and edema toxin. Mol. Aspects Med. 2009, 30, 439-455. 
82. Fouet, A. The surface of bacillus anthracis. Mol. Aspects Med. 2009, 30, 374-385.

83. Bouzianas, D.G. Medical countermeasures to protect humans from anthrax bioterrorism. Trends Microbiol. 2009, 17, 522-528.

84. Brook, I.; Elliott, T.B.; Pryor, H.I., 2nd; Sautter, T.E.; Gnade, B.T.; Thakar, J.H.; Knudson, G.B. In vitro resistance of bacillus anthracis sterne to doxycycline, macrolides and quinolones. Int. J. Antimicrob. Agents 2001, 18, 559-562.

85. Athamna, A.; Athamna, M.; Abu-Rashed, N.; Medlej, B.; Bast, D.J.; Rubinstein, E. Selection of bacillus anthracis isolates resistant to antibiotics. J. Antimicrob. Chemother. 2004, 54, 424-428.

86. Nestorovich, E.M.; Bezrukov, S.M. Designing inhibitors of anthrax toxin. Expert Opin. Drug Discov. 2014, 9, 299-318.

87. Bartlett, J.G.; Inglesby, T.V., Jr.; Borio, L. Management of anthrax. Clin. Infect. Dis. 2002, 35, 851-858.

88. Bull, J.J.; Parrish, C.R. Microbiology. A binding contract for anthrax. Science 2002, 297, 201-202.

89. Mock, M.; Fouet, A. Anthrax. Annu. Rev. Microbiol. 2001, 55, 647-671.

90. Bann, J.G. Anthrax toxin protective antigen-Insights into molecular switching from prepore to pore. Protein Sci. 2012, 21, 1-12.

91. Frankel, A.E.; Kuo, S.R.; Dostal, D.; Watson, L.; Duesbery, N.S.; Cheng, C.P.; Cheng, H.J.; Leppla, S.H. Pathophysiology of anthrax. Front. Biosci. Landmark Ed. 2009, 14, 4516-4524.

92. Guichard, A.; Nizet, V.; Bier, E. New insights into the biological effects of anthrax toxins: Linking cellular to organismal responses. Microbes Infect. 2012, 14, 97-118.

93. Hicks, C.W.; Sweeney, D.A.; Cui, X.; Li, Y.; Eichacker, P.Q. An overview of anthrax infection including the recently identified form of disease in injection drug users. Intensive Care Med. 2012, 38, 1092-1104.

94. Lowe, D.E.; Glomski, I.J. Cellular and physiological effects of anthrax exotoxin and its relevance to disease. Front. Cell. Infect. Microbiol. 2012, 2, doi:10.3389/fcimb.2012.00076.

95. Moayeri, M.; Sastalla, I.; Leppla, S.H. Anthrax and the inflammasome. Microbes Infect. 2012, 14, 392-400.

96. Sweeney, D.A.; Hicks, C.W.; Cui, X.; Li, Y.; Eichacker, P.Q. Anthrax infection. Am. J. Respir. Crit. Care Med. 2011, 184, 1333-1341.

97. Van der Goot, G.; Young, J.A. Receptors of anthrax toxin and cell entry. Mol. Aspects Med. 2009, 30, 406-412.

98. Xie, T.; Auth, R.D.; Frucht, D.M. The effects of anthrax lethal toxin on host barrier function. Toxins 2011, 3, 591-607.

99. Zakowska, D.; Bartoszcze, M.; Niemcewicz, M.; Bielawska-Drozd, A.; Kocik, J. New aspects of the infection mechanisms of bacillus anthracis. Ann. Agric. Environ. Med. 2012, 19, 613-618.

100. Thoren, K.L.; Krantz, B.A. The unfolding story of anthrax toxin translocation. Mol. Microbiol. 2011, 80, 588-595.

101. Lee, K.I.; Jo, S.; Rui, H.; Egwolf, B.; Roux, B.; Pastor, R.W.; Im, W. Web interface for brownian dynamics simulation of ion transport and its applications to beta-barrel pores. J. Comput. Chem. 2012, 33, 331-339. 
102. Bezrukov, S.M.; Liu, X.; Karginov, V.A.; Wein, A.N.; Leppla, S.H.; Popoff, M.R.; Barth, H.; Nestorovich, E.M. Interactions of high-affinity cationic blockers with the translocation pores of B. Anthracis, C. Botulinum, and C. Perfringens binary toxins. Biophys. J. 2012, 103, 1208-1217.

103. Bradley, K.A.; Mogridge, J.; Mourez, M.; Collier, R.J.; Young, J.A. Identification of the cellular receptor for anthrax toxin. Nature 2001, 414, 225-229.

104. Scobie, H.M.; Rainey, G.J.; Bradley, K.A.; Young, J.A. Human capillary morphogenesis protein 2 functions as an anthrax toxin receptor. Proc. Natl. Acad. Sci. USA 2003, 100, 5170-5174.

105. Klimpel, K.R.; Molloy, S.S.; Thomas, G.; Leppla, S.H. Anthrax toxin protective antigen is activated by a cell surface protease with the sequence specificity and catalytic properties of furin. Proc. Natl. Acad. Sci. USA 1992, 89, 10277-10281.

106. Petosa, C.; Collier, R.J.; Klimpel, K.R.; Leppla, S.H.; Liddington, R.C. Crystal structure of the anthrax toxin protective antigen. Nature 1997, 385, 833-838.

107. Kintzer, A.F.; Thoren, K.L.; Sterling, H.J.; Dong, K.C.; Feld, G.K.; Tang, I.I.; Zhang, T.T.; Williams, E.R.; Berger, J.M.; Krantz, B.A. The protective antigen component of anthrax toxin forms functional octameric complexes. J. Mol. Biol. 2009, 392, 614-629.

108. Mogridge, J.; Cunningham, K.; Collier, R.J. Stoichiometry of anthrax toxin complexes. Biochemistry 2002, 41, 1079-1082.

109. Pilpa, R.M.; Bayrhuber, M.; Marlett, J.M.; Riek, R.; Young, J.A. A receptor-based switch that regulates anthrax toxin pore formation. PLoS Pathog. 2011, 7, doi:10.1371/journal.ppat.1002354.

110. Katayama, H.; Janowiak, B.E.; Brzozowski, M.; Juryck, J.; Falke, S.; Gogol, E.P.; Collier, R.J.; Fisher, M.T. GroEL as a molecular scaffold for structural analysis of the anthrax toxin pore. Nat. Struct. Mol. Biol. 2008, 15, 754-760.

111. Orlik, F.; Schiffler, B.; Benz, R. Anthrax toxin protective antigen: Inhibition of channel function by chloroquine and related compounds and study of binding kinetics using the current noise analysis. Biophys. J. 2005, 88, 1715-1724.

112. Panchal, R.G.; Halverson, K.M.; Ribot, W.; Lane, D.; Kenny, T.; Abshire, T.G.; Ezzell, J.W.; Hoover, T.A.; Powell, B.; Little, S.; et al. Purified bacillus anthracis lethal toxin complex formed in vitro and during infection exhibits functional and biological activity. J. Biol. Chem. 2005, 280, 10834-10839.

113. Blaustein, R.O.; Lea, E.J.; Finkelstein, A. Voltage-Dependent block of anthrax toxin channels in planar phospholipid bilayer membranes by symmetric tetraalkylammonium ions. Single-Channel analysis. J. Gen. Physiol. 1990, 96, 921-942.

114. Nestorovich, E.M.; Karginov, V.A.; Berezhkovskii, A.M.; Bezrukov, S.M. Blockage of anthrax PA63 pore by a multicharged high-affinity toxin inhibitor. Biophys. J. 2010, 99, 134-143.

115. Nestorovich, E.M.; Bezrukov, S.M. Obstructing Toxin pathways by targeted pore blockage. Chem. Rev. 2012, 112, 6388-6430.

116. Zhang, S.; Finkelstein, A.; Collier, R.J. Evidence that translocation of anthrax Toxin's lethal factor is initiated by entry of its $\mathrm{N}$ terminus into the protective antigen channel. Proc. Natl. Acad. Sci. USA 2004, 101, 16756-16761.

117. Zhang, S.; Udho, E.; Wu, Z.; Collier, R.J.; Finkelstein, A. Protein translocation through anthrax toxin channels formed in planar lipid bilayers. Biophys. J. 2004, 87, 3842-3849. 
118. Krantz, B.A.; Melnyk, R.A.; Zhang, S.; Juris, S.J.; Lacy, D.B.; Wu, Z.; Finkelstein, A.; Collier, R.J. A phenylalanine clamp catalyzes protein translocation through the anthrax toxin pore. Science 2005, 309, 777-781.

119. Basilio, D.; Juris, S.J.; Collier, R.J.; Finkelstein, A. Evidence for a proton-protein symport mechanism in the anthrax toxin channel. J. Gen. Physiol. 2009, 133, 307-314.

120. Basilio, D.; Kienker, P.K.; Briggs, S.W.; Finkelstein, A. A kinetic analysis of protein transport through the anthrax toxin channel. J. Gen. Physiol. 2011, 137, 521-531.

121. Basilio, D.; Jennings-Antipov, L.D.; Jakes, K.S.; Finkelstein, A. Trapping a translocating protein within the anthrax toxin channel: Implications for the secondary structure of permeating proteins. J. Gen. Physiol. 2011, 137, 343-356.

122. Duesbery, N.S.; Webb, C.P.; Leppla, S.H.; Gordon, V.M.; Klimpel, K.R.; Copeland, T.D.; Ahn, N.G.; Oskarsson, M.K.; Fukasawa, K.; Paull, K.D.; et al. Proteolytic inactivation of MAP-Kinase-Kinase by anthrax lethal factor. Science 1998, 280, 734-737.

123. Vitale, G.; Bernardi, L.; Napolitani, G.; Mock, M.; Montecucco, C. Susceptibility of mitogen-activated protein kinase kinase family members to proteolysis by anthrax lethal factor. Biochem. J. 2000, 352, 739-745.

124. Levinsohn, J.L.; Newman, Z.L.; Hellmich, K.A.; Fattah, R.; Getz, M.A.; Liu, S.; Sastalla, I.; Leppla, S.H.; Moayeri, M. Anthrax lethal factor cleavage of Nlrp1 is required for activation of the inflammasome. PLoS Pathog. 2012, 8, doi:10.1371/journal.ppat.1002638.

125. Dumetz, F.; Jouvion, G.; Khun, H.; Glomski, I.J.; Corre, J.P.; Rougeaux, C.; Tang, W.J.; Mock, M.; Huerre, M.; Goossens, P.L. Noninvasive imaging technologies reveal edema toxin as a key virulence factor in anthrax. Am. J. Pathol. 2011, 178, 2523-2535.

126. Liu, S.; Zhang, Y.; Moayeri, M.; Liu, J.; Crown, D.; Fattah, R.J.; Wein, A.N.; Yu, Z.X.; Finkel, T.; Leppla, S.H. Key tissue targets responsible for anthrax-toxin-induced lethality. Nature 2013, 501, 63-68.

127. Gruner, S.M. Intrinsic curvature hypothesis for biomembrane lipid composition: A role for nonbilayer lipids. Proc. Natl. Acad. Sci. USA 1985, 82, 3665-3669.

128. Andersen, O.S.; Koeppe, R.E., 2nd. Bilayer thickness and membrane protein function: An energetic perspective. Annu. Rev. Biophys. Biomol. Struct. 2007, 36, 107-130.

129. McLaughlin, S.G.; Szabo, G.; Eisenman, G.; Ciani, S.M. Surface charge and the conductance of phospholipid membranes. Proc. Natl. Acad. Sci. USA 1970, 67, 1268-1275.

130. McLaughlin, S. The electrostatic properties of membranes. Annu. Rev. Biophys. Biophys. Chem. 1989, 18, 113-136.

131. Apell, H.J.; Bamberg, E.; Lauger, P. Effects of surface charge on the conductance of the gramicidin channel. Biochim. Biophys. Acta 1979, 552, 369-378.

132. Franklin, J.C.; Cafiso, D.S.; Flewelling, R.F.; Hubbell, W.L. Probes of membrane electrostatics: Synthesis and voltage-dependent partitioning of negative hydrophobic ion spin labels in lipid vesicles. Biophys. J. 1993, 64, 642-653.

133. Rokitskaya, T.I.; Sorochkina, A.I.; Kovalchuk, S.I.; Egorova, N.S.; Kotova, E.A.; Sychev, S.V.; Antonenko, Y.N. The pH-Dependent induction of lipid membrane ionic permeability by n-terminally lysine-substituted analogs of gramicidin A. Eur. Biophys. J. 2012, 41, 129-138. 
134. Macrae, M.X.; Blake, S.; Jiang, X.; Capone, R.; Estes, D.J.; Mayer, M.; Yang, J. A semi-synthetic ion channel platform for detection of phosphatase and protease activity. ACS Nano 2009, 3, 3567-3580.

135. Malev, V.V.; Schagina, L.V.; Gurnev, P.A.; Takemoto, J.Y.; Nestorovich, E.M.; Bezrukov, S.M. Syringomycin E channel: A lipidic pore stabilized by lipopeptide? Biophys. J. 2002, 82, 1985-1994.

136. Bessonov, A.; Takemoto, J.Y.; Simmel, F.C. Probing DNA-Lipid membrane interactions with a lipopeptide nanopore. ACS Nano 2012, 6, 3356-3363.

137. Kasianowicz, J.J.; Brandin, E.; Branton, D.; Deamer, D.W. Characterization of individual polynucleotide molecules using a membrane channel. Proc. Natl. Acad. Sci. USA 1996, 93, 13770-13773.

138. Movileanu, L.; Schmittschmitt, J.P.; Scholtz, J.M.; Bayley, H. Interactions of peptides with a protein pore. Biophys. J. 2005, 89, 1030-1045.

139. Gu, L.Q.; Braha, O.; Conlan, S.; Cheley, S.; Bayley, H. Stochastic sensing of organic analytes by a pore-forming protein containing a molecular adapter. Nature 1999, 398, 686-690.

140. Gu, L.Q.; Dalla Serra, M.; Vincent, J.B.; Vigh, G.; Cheley, S.; Braha, O.; Bayley, H. Reversal of charge selectivity in transmembrane protein pores by using noncovalent molecular adapters. Proc. Natl. Acad. Sci. USA 2000, 97, 3959-3964.

141. Braha, O.; Walker, B.; Cheley, S.; Kasianowicz, J.J.; Song, L.; Gouaux, J.E.; Bayley, H. Designed protein pores as components for biosensors. Chem. Biol. 1997, 4, 497-505.

142. Braha, O.; Gu, L.Q.; Zhou, L.; Lu, X.; Cheley, S.; Bayley, H. Simultaneous stochastic sensing of divalent metal ions. Nat. Biotechnol. 2000, 18, 1005-1007.

143. Choi, L.S.; Mach, T.; Bayley, H. Rates and stoichiometries of metal ion probes of cysteine residues within ion channels. Biophys. J. 2013, 105, 356-364.

144. Cheley, S.; Gu, L.Q.; Bayley, H. Stochastic sensing of nanomolar inositol 1,4,5-trisphosphate with an engineered pore. Chem. Biol. 2002, 9, 829-838.

145. Guan, X.; Gu, L.Q.; Cheley, S.; Braha, O.; Bayley, H. Stochastic sensing of TNT with a genetically engineered pore. Chembiochem 2005, 6, 1875-1881.

146. Wu, Y.; Ma, L.; Cheley, S.; Bayley, H.; Cui, Q.; Chapman, E.R. Permeation of styryl dyes through nanometer-scale pores in membranes. Biochemistry 2011, 50, 7493-7502.

147. Asandei, A.; Mereuta, L.; Luchian, T. The kinetics of ampicillin complexation by gamma-cyclodextrins. A single molecule approach. J. Phys. Chem. B 2011, 115, 10173-10181.

148. Asandei, A.; Apetrei, A.; Luchian, T. Uni-Molecular detection and quantification of selected beta-lactam antibiotics with a hybrid alpha-hemolysin protein pore. J. Mol. Recognit. 2011, 24, 199-207.

149. Teixeira, L.R.; Merzlyak, P.G.; Valeva, A.; Krasilnikov, O.V. Interaction of heparins and dextran sulfates with a mesoscopic protein nanopore. Biophys. J. 2009, 97, 2894-2903.

150. Wu, H.C.; Bayley, H. Single-Molecule detection of nitrogen mustards by covalent reaction within a protein nanopore. J. Am. Chem. Soc. 2008, 130, 6813-6819.

151. Bacri, L.; Oukhaled, A.; Hemon, E.; Bassafoula, F.B.; Auvray, L.; Daniel, R. Discrimination of neutral oligosaccharides through a nanopore. Biochem. Biophys. Res. Commun. 2011, 412, 561-564. 
152. Luo, Y.; Egwolf, B.; Walters, D.E.; Roux, B. Ion selectivity of alpha-hemolysin with a beta-cyclodextrin adapter. I. Single ion potential of mean force and diffusion coefficient. J. Phys. Chem. B 2010, 114, 952-958.

153. Egwolf, B.; Luo, Y.; Walters, D.E.; Roux, B. Ion selectivity of alpha-hemolysin with beta-cyclodextrin adapter. II. Multi-Ion effects studied with grand canonical monte carlo/brownian dynamics simulations. J. Phys. Chem. B 2010, 114, 2901-2909.

154. Banerjee, A.; Mikhailova, E.; Cheley, S.; Gu, L.Q.; Montoya, M.; Nagaoka, Y.; Gouaux, E.; Bayley, H. Molecular bases of cyclodextrin adapter interactions with engineered protein nanopores. Proc. Natl. Acad. Sci. USA 2010, 107, 8165-8170.

155. Gu, L.Q.; Cheley, S.; Bayley, H. Prolonged residence time of a noncovalent molecular adapter, beta-cyclodextrin, within the lumen of mutant alpha-hemolysin pores. J. Gen. Physiol. 2001, 118, 481-494.

156. Wu, H.C.; Astier, Y.; Maglia, G.; Mikhailova, E.; Bayley, H. Protein nanopores with covalently attached molecular adapters. J. Am. Chem. Soc. 2007, 129, 16142-16148.

157. Li, W.W.; Claridge, T.D.; Li, Q.; Wormald, M.R.; Davis, B.G.; Bayley, H. Tuning the cavity of cyclodextrins: Altered sugar adaptors in protein pores. J. Am. Chem. Soc. 2011, 133, 1987-2001.

158. Gu, L.Q.; Cheley, S.; Bayley, H. Capture of a single molecule in a nanocavity. Science 2001, 291, 636-640.

159. Gurnev, P.A.; Harries, D.; Parsegian, V.A.; Bezrukov, S.M. The dynamic side of the hofmeister effect: A single-molecule nanopore study of specific complex formation. Chem. Phys. Chem. 2009, 10, 1445-1449.

160. Kang, X.F.; Cheley, S.; Guan, X.; Bayley, H. Stochastic detection of enantiomers. J. Am. Chem. Soc. 2006, 128, 10684-10685.

161. Karginov, V.A.; Nestorovich, E.M.; Schmidtmann, F.; Robinson, T.M.; Yohannes, A.; Fahmi, N.E.; Bezrukov, S.M.; Hecht, S.M. Inhibition of S. Aureus alpha-hemolysin and B. anthracis lethal toxin by beta-cyclodextrin derivatives. Bioorg. Med. Chem. 2007, 15, 5424-5431.

162. Ragle, B.E.; Karginov, V.A.; Bubeck Wardenburg, J. Prevention and treatment of staphylococcus aureus pneumonia with a beta-cyclodextrin derivative. Antimicrob. Agents Chemother. 2010, 54, 298-304.

163. Karginov, V.A.; Nestorovich, E.M.; Moayeri, M.; Leppla, S.H.; Bezrukov, S.M. Blocking anthrax lethal toxin at the protective antigen channel by using structure-inspired drug design. Proc. Natl. Acad. Sci. USA 2005, 102, 15075-15080.

164. Karginov, V.A.; Yohannes, A.; Robinson, T.M.; Fahmi, N.E.; Alibek, K.; Hecht, S.M. Beta-Cyclodextrin Derivatives that inhibit anthrax lethal toxin. bioorg. Med. Chem. 2006, 14, 33-40.

165. Karginov, V.A.; Nestorovich, E.M.; Yohannes, A.; Robinson, T.M.; Fahmi, N.E.; Schmidtmann, F.; Hecht, S.M.; Bezrukov, S.M. Search for cyclodextrin-based inhibitors of anthrax toxins: synthesis, structural features, and relative activities. Antimicrob. Agents Chemother. 2006, 50, 3740-3753.

166. Backer, M.V.; Patel, V.; Jehning, B.T.; Claffey, K.P.; Karginov, V.A.; Backer, J.M. Inhibition of Anthrax protective antigen outside and inside the cell. Antimicrob. Agents Chemother. 2007, 51, 245-251. 
167. Moayeri, M.; Robinson, T.M.; Leppla, S.H.; Karginov, V.A. In vivo efficacy of beta-cyclodextrin derivatives against anthrax lethal toxin. Antimicrob. Agents Chemother. 2008, 52, 2239-2241.

168. Nestorovich, E.M.; Karginov, V.A.; Popoff, M.R.; Bezrukov, S.M.; Barth, H. Tailored Ss-Cyclodextrin blocks the translocation pores of binary exotoxins from C. Botulinum and C. Perfringens and protects cells from intoxication. PLoS One 2011, 6, doi:10.1371/journal.pone.0023927.

169. Yannakopoulou, K.; Jicsinszky, L.; Aggelidou, C.; Mourtzis, N.; Robinson, T.M.; Yohannes, A.; Nestorovich, E.M.; Bezrukov, S.M.; Karginov, V.A. Symmetry requirements for effective blocking of pore-forming toxins: Comparative study with alpha-, beta-, and gamma-cyclodextrin derivatives. Antimicrob. Agents Chemother. 2011, 55, 3594-3597.

170. Nestorovich, E.M.; Karginov, V.A.; Berezhkovskii, A.M.; Parsegian, V.A.; Bezrukov, S.M. Kinetics and thermodynamics of binding reactions as exemplified by anthrax toxin channel blockage with a cationic cyclodextrin derivative. Proc. Natl. Acad. Sci. USA 2012, 109, 18453-18458.

171. Karginov, V.A. Cyclodextrin derivatives as anti-infectives. Curr. Opin. Pharmacol. 2013, 13, 717-725.

172. Berezhkovskii, A.; Bezrukov, S. Channel-facilitated membrane transport: Constructive role of particle attraction to the channel pore. Chem. Phys. 2005, 319, 342-349.

173. Berezhkovskii, A.M.; Bezrukov, S.M. Optimizing transport of metabolites through large channels: Molecular sieves with and without binding. Biophys. J. 2005, 88, L17-L19.

174. Blaustein, R.O.; Finkelstein, A. Diffusion limitation in the block by symmetric tetraalkylammonium ions of anthrax toxin channels in planar phospholipid bilayer membranes. J. Gen. Physiol. 1990, 96, 943-957.

175. Blaustein, R.O.; Finkelstein, A. Voltage-dependent block of anthrax toxin channels in planar phospholipid bilayer membranes by symmetric tetraalkylammonium ions. Effects on macroscopic conductance. J. Gen. Physiol. 1990, 96, 905-919.

176. Beitzinger, C.; Bronnhuber, A.; Duscha, K.; Riedl, Z.; Huber-Lang, M.; Benz, R.; Hajos, G.; Barth, H. Designed azolopyridinium salts block protective antigen pores in vitro and protect cells from anthrax toxin. PLoS One 2013, 8, doi:10.1371/journal.pone.0066099.

177. Halverson, K.M.; Panchal, R.G.; Nguyen, T.L.; Gussio, R.; Little, S.F.; Misakian, M.; Bavari, S.; Kasianowicz, J.J. Anthrax Biosensor, protective antigen ion channel asymmetric blockade. J. Biol. Chem. 2005, 280, 34056-34062.

178. Cornell, B.A.; Braach-Maksvytis, V.L.; King, L.G.; Osman, P.D.; Raguse, B.; Wieczorek, L.; Pace, R.J. A biosensor that uses ion-channel switches. Nature 1997, 387, 580-583.

179. Oh, S.Y.; Cornell, B.; Smith, D.; Higgins, G.; Burrell, C.J.; Kok, T.W. Rapid detection of influenza a virus in clinical samples using an ion channel switch biosensor. Biosens. Bioelectron. 2008, 23, 1161-1165.

180. Krishnamurthy, V.; Monfared, S.M.; Cornell, B. Ion-Channel Biosensors-Part I: Construction, operation, and clinical studies. Nanotechnol. IEEE Trans. 2010, 9, 303-312.

181. Krishnamurthy, V.; Monfared, S.M.; Cornell, B. Ion channel biosensors-Part II: Dynamic modeling, analysis, and statistical signal processing. Nanotechnol. IEEE Trans. 2010, 9, 313-321. 
182. Church, G.; Deamer, D.W.; Branton, D.; Baldarelli, R.; Kasianowicz, J. Characterization of individual polymer molecules based on monomer-interface interactions. U.S. Patent US5795782, 18 August 1998.

183. Akeson, M.; Branton, D.; Kasianowicz, J.J.; Brandin, E.; Deamer, D.W. Microsecond time-scale discrimination among polycytidylic acid, polyadenylic acid, and polyuridylic acid as homopolymers or as segments within single RNA molecules. Biophys. J. 1999, 77, 3227-3233.

184. Deamer, D.W.; Akeson, M. Nanopores and nucleic acids: Prospects for ultrarapid sequencing. Trends Biotechnol. 2000, 18, 147-151.

185. Bayley, H. Sequencing single molecules of DNA. Curr. Opin. Chem. Biol. 2006, 10, 628-637.

186. Branton, D.; Deamer, D.W.; Marziali, A.; Bayley, H.; Benner, S.A.; Butler, T.; di Ventra, M.; Garaj, S.; Hibbs, A.; Huang, X.; et al. The potential and challenges of nanopore sequencing. Nat. Biotechnol. 2008, 26, 1146-1153.

187. Meller, A.; Nivon, L.; Branton, D. Voltage-Driven DNA translocations through a nanopore. Phys. Rev. Lett. 2001, 86, 3435-3438.

188. Meller, A.; Branton, D. Single molecule measurements of DNA transport through a nanopore. Electrophoresis 2002, 23, 2583-2591.

189. Aksimentiev, A.; Heng, J.B.; Timp, G.; Schulten, K. Microscopic kinetics of DNA translocation through synthetic nanopores. Biophys. J. 2004, 87, 2086-2097.

190. Muthukumar, M.; Kong, C.Y. Simulation of polymer translocation through protein channels. Proc. Natl. Acad. Sci. USA 2006, 103, 5273-5278.

191. Saenger, W.; Riecke, J.; Suck, D. A structural model for the polyadenylic acid single helix. J. Mol. Biol. 1975, 93, 529-534.

192. Meller, A.; Nivon, L.; Brandin, E.; Golovchenko, J.; Branton, D. Rapid nanopore discrimination between single polynucleotide molecules. Proc. Natl. Acad. Sci. USA 2000, 97, 1079-1084.

193. Wiggin, M.; Tropini, C.; Tabard-Cossa, V.; Jetha, N.N.; Marziali, A. Nonexponential kinetics of DNA escape from alpha-hemolysin nanopores. Biophys. J. 2008, 95, 5317-5323.

194. Butler, T.Z.; Pavlenok, M.; Derrington, I.M.; Niederweis, M.; Gundlach, J.H. Single-Molecule DNA detection with an engineered mspa protein nanopore. Proc. Natl. Acad. Sci. USA 2008, 105, 20647-20652.

195. Howorka, S.; Siwy, Z. Nanopore analytics: Sensing of single molecules. Chem. Soc. Rev. 2009, 38, 2360-2384.

196. Wanunu, M. Nanopores: A journey towards DNA sequencing. Phys. Life. Rev. 2012, 9, 125-158.

197. Ashkenasy, N.; Sanchez-Quesada, J.; Bayley, H.; Ghadiri, M.R. Recognizing a single base in an individual DNA strand: A step toward DNA sequencing in nanopores. Angew. Chem. Int. Ed. Engl. 2005, 44, 1401-1404.

198. Purnell, R.F.; Schmidt, J.J. Discrimination of single base substitutions in a DNA strand immobilized in a biological nanopore. ACS Nano 2009, 3, 2533-2538.

199. Stoddart, D.; Heron, A.J.; Mikhailova, E.; Maglia, G.; Bayley, H. Single-Nucleotide discrimination in immobilized DNA oligonucleotides with a biological nanopore. Proc. Natl. Acad. Sci. USA 2009, 106, 7702-7707.

200. Cockroft, S.L.; Chu, J.; Amorin, M.; Ghadiri, M.R. A single-molecule nanopore device detects DNA polymerase activity with single-nucleotide resolution. J. Am. Chem. Soc. 2008, 130, 818-820. 
201. Chu, J.; Gonzalez-Lopez, M.; Cockroft, S.L.; Amorin, M.; Ghadiri, M.R. Real-Time monitoring of DNA polymerase function and stepwise single-nucleotide DNA strand translocation through a protein nanopore. Angew. Chem. Int. Ed. Engl. 2010, 49, 10106-10109.

202. Lieberman, K.R.; Cherf, G.M.; Doody, M.J.; Olasagasti, F.; Kolodji, Y.; Akeson, M. Processive replication of single DNA molecules in a nanopore catalyzed by phi29 DNA polymerase. J. Am. Chem. Soc. 2010, 132, 17961-17972.

203. Cherf, G.M.; Lieberman, K.R.; Rashid, H.; Lam, C.E.; Karplus, K.; Akeson, M. Automated forward and reverse ratcheting of DNA in a nanopore at 5-A precision. Nat. Biotechnol. 2012, 30, 344-348.

204. Astier, Y.; Braha, O.; Bayley, H. Toward single molecule DNA sequencing: Direct identification of ribonucleoside and deoxyribonucleoside 5'-Monophosphates by using an engineered protein nanopore equipped with a molecular adapter. J. Am. Chem. Soc. 2006, 128, 1705-1710.

205. Ayub, M.; Hardwick, S.W.; Luisi, B.F.; Bayley, H. Nanopore-based identification of individual nucleotides for direct RNA sequencing. Nano Lett. 2013, 13, 6144-6150.

206. Muthukumar, M. Polymer Translocation; CRC Press: New York, NY, USA, 2011.

207. Movileanu, L. Interrogating single proteins through nanopores: Challenges and opportunities. Trends Biotechnol. 2009, 27, 333-341.

208. Krasilnikov, O.V.; Sabirov, R.Z.; Ternovsky, V.I.; Merzliak, P.G.; Muratkhodjaev, J.N. A simple method for the determination of the pore radius of ion channels in planar lipid bilayer membranes. FEMS Microbiol. Immunol. 1992, 5, 93-100.

209. Nablo, B.J.; Halverson, K.M.; Robertson, J.W.; Nguyen, T.L.; Panchal, R.G.; Gussio, R.; Bavari, S.; Krasilnikov, O.V.; Kasianowicz, J.J. Sizing the bacillus anthracis PA63 channel with nonelectrolyte Poly(Ethylene Glycols). Biophys. J. 2008, 95, 1157-1164.

210. Howorka, S.; Movileanu, L.; Lu, X.; Magnon, M.; Cheley, S.; Braha, O.; Bayley, H. A protein pore with a single polymer chain tethered within the lumen. J. Am. Chem. Soc. 2000, 122, 2411-2416.

211. Movileanu, L.; Howorka, S.; Braha, O.; Bayley, H. Detecting protein analytes that modulate transmembrane movement of a polymer chain within a single protein pore. Nat. Biotechnol. 2000, 18, 1091-1095.

212. Bezrukov, S.M.; Krasilnikov, O.V.; Yuldasheva, L.N.; Berezhkovskii, A.M.; Rodrigues, C.G. Field-Dependent effect of crown ether (18-Crown-6) on ionic conductance of alpha-hemolysin channels. Biophys. J. 2004, 87, 3162-3171.

213. Krasilnikov, O.V.; Rodrigues, C.G.; Bezrukov, S.M. Single polymer molecules in a protein nanopore in the limit of a strong polymer-pore attraction. Phys. Rev. Lett. 2006, 97, doi:10.1103/PhysRevLett.97.018301.

214. Merzlyak, P.G.; Capistrano, M.F.; Valeva, A.; Kasianowicz, J.J.; Krasilnikov, O.V. Conductance and ion selectivity of a mesoscopic protein nanopore probed with cysteine scanning mutagenesis. Biophys. J. 2005, 89, 3059-3070.

215. Wong, C.T.; Muthukumar, M. Polymer translocation through alpha-hemolysin pore with tunable polymer-pore electrostatic interaction. J. Chem. Phys. 2010, 133, doi: 10.1063/1.3464333.

216. Jeon, B.J.; Muthukumar, M. Polymer capture by alpha-hemolysin pore upon salt concentration gradient. J. Chem. Phys. 2014, 140, doi:10.1063/1.4855075. 
217. Sutherland, T.C.; Long, Y.-T.; Stefureac, R.-L.; Bediako-Amoa, I.; Kraatz, H.-B.; Lee, J.S. Structure of peptides investigated by nanopore analysis. Nano Lett. 2004, 4, 1273-1277.

218. Stefureac, R.; Long, Y.T.; Kraatz, H.B.; Howard, P.; Lee, J.S. Transport of alpha-helical peptides through alpha-hemolysin and aerolysin pores. Biochemistry 2006, 45, 9172-9179.

219. Oukhaled, G.; Mathe, J.; Biance, A.L.; Bacri, L.; Betton, J.M.; Lairez, D.; Pelta, J.; Auvray, L. Unfolding of proteins and long transient conformations detected by single nanopore recording. Phys. Rev. Lett. 2007, 98, doi:10.1103/PhysRevLett.98.158101.

220. Goodrich, C.P.; Kirmizialtin, S.; Huyghues-Despointes, B.M.; Zhu, A.; Scholtz, J.M.; Makarov, D.E.; Movileanu, L. Single-Molecule electrophoresis of beta-hairpin peptides by electrical recordings and langevin dynamics simulations. J. Phys. Chem. B 2007, 111, 3332-3335.

221. Nivala, J.; Marks, D.B.; Akeson, M. Unfoldase-mediated protein translocation through an alpha-hemolysin nanopore. Nat. Biotechnol. 2013, 31, 247-250.

222. Rodriguez-Larrea, D.; Bayley, H. Multistep protein unfolding during nanopore translocation. Nat. Nanotechnol. 2013, 8, 288-295.

223. Thoren, K.L.; Worden, E.J.; Yassif, J.M.; Krantz, B.A. Lethal factor unfolding is the most force-dependent step of anthrax toxin translocation. Proc. Natl. Acad. Sci. USA 2009, 106, 21555-21560.

224. Rosen, C.B.; Rodriguez-Larrea, D.; Bayley, H. Single-Molecule site-specific detection of protein phosphorylation with a nanopore. Nat. Biotechnol. 2014, 32, 179-181.

225. Wolfe, A.J.; Mohammad, M.M.; Cheley, S.; Bayley, H.; Movileanu, L. Catalyzing the translocation of polypeptides through attractive interactions. J. Am. Chem. Soc. 2007, 129, 14034-14041.

226. Mohammad, M.M.; Movileanu, L. Excursion of a single polypeptide into a protein pore: Simple physics, but complicated biology. Eur. Biophys. J. 2008, 37, 913-925.

227. Bikwemu, R.; Wolfe, A.J.; Xing, X.; Movileanu, L. Facilitated translocation of polypeptides through a single nanopore. J. Phys. Condens Matter 2010, 22, doi:10.1088/0953-8984/22/45/454117.

228. Mohammad, M.M.; Movileanu, L. Impact of distant charge reversals within a robust beta-barrel protein pore. J. Phys. Chem. B 2010, 114, 8750-8759.

229. Zhao, Q.; Jayawardhana, D.A.; Wang, D.; Guan, X. Study of peptide transport through engineered protein channels. J. Phys. Chem. B 2009, 113, 3572-3578.

230. Madampage, C.; Tavassoly, O.; Christensen, C.; Kumari, M.; Lee, J.S. Nanopore analysis: An emerging technique for studying the folding and misfolding of proteins. Prion 2012, 6, 116-123.

231. Wang, H.Y.; Ying, Y.L.; Li, Y.; Kraatz, H.B.; Long, Y.T. Nanopore analysis of beta-amyloid peptide aggregation transition induced by small molecules. Anal. Chem. 2011, 83, 1746-1752.

232. Gurnev, P.A.; Yap, T.L.; Pfefferkorn, C.M.; Rostovtseva, T.K.; Berezhkovskii, A.M.; Lee, J.C.; Parsegian, V.A.; Bezrukov, S.M. Alpha-Synuclein lipid-dependent membrane binding and translocation through the alpha-hemolysin channel. Biophys. J. 2014, 106, 556-565.

233. Wang, H.Y.; Gu, Z.; Cao, C.; Wang, J.; Long, Y.T. Analysis of a single alpha-synuclein fibrillation by the interaction with a protein nanopore. Anal. Chem. 2013, 85, 8254-8261.

234. Rotem, D.; Jayasinghe, L.; Salichou, M.; Bayley, H. Protein detection by nanopores equipped with aptamers. J. Am. Chem. Soc. 2012, 134, 2781-2787.

235. Collier, R.J. Membrane translocation by anthrax toxin. Mol. Aspects Med. 2009, 30, 413-422. 
236. Feld, G.K.; Brown, M.J.; Krantz, B.A. Ratcheting up protein translocation with anthrax toxin. Protein Sci. 2012, 21, 606-624.

237. Oh, K.J.; Senzel, L.; Collier, R.J.; Finkelstein, A. Translocation of the catalytic domain of diphtheria toxin across planar phospholipid bilayers by its own T domain. Proc. Natl. Acad. Sci. USA 1999, 96, 8467-8470.

238. Koriazova, L.K.; Montal, M. Translocation of botulinum neurotoxin light chain protease through the heavy chain channel. Nat. Struct. Biol. 2003, 10, 13-18.

239. Krantz, B.A.; Finkelstein, A.; Collier, R.J. Protein translocation through the anthrax toxin transmembrane pore is driven by a proton gradient. J. Mol. Biol. 2006, 355, 968-979.

240. Finkelstein, A. Proton-Coupled protein transport through the anthrax toxin channel. Philos. Trans. $R$. Soc. Lond. B Biol. Sci. 2009, 364, 209-215.

241. Benson, E.L.; Huynh, P.D.; Finkelstein, A.; Collier, R.J. Identification of residues lining the anthrax protective antigen channel. Biochemistry 1998, 37, 3941-3948.

242. Sellman, B.R.; Nassi, S.; Collier, R.J. Point mutations in anthrax protective antigen that block translocation. J. Biol. Chem. 2001, 276, 8371-8376.

243. Nguyen, T.L. Three-Dimensional model of the pore form of anthrax protective antigen. Structure and biological implications. J. Biomol. Struct. Dyn. 2004, 22, 253-265.

244. Krantz, B.A.; Trivedi, A.D.; Cunningham, K.; Christensen, K.A.; Collier, R.J. Acid-Induced unfolding of the amino-terminal domains of the lethal and edema factors of anthrax toxin. J. Mol. Biol. 2004, 344, 739-756.

245. Pentelute, B.L.; Sharma, O.; Collier, R.J. Chemical dissection of protein translocation through the anthrax toxin pore. Angew. Chem. Int. Ed. Engl. 2011, 50, 2294-2296.

246. Diaz-Moscoso, A.; Mendez-Ardoy, A.; Ortega-Caballero, F.; Benito, J.M.; Ortiz Mellet, C.; Defaye, J.; Robinson, T.M.; Yohannes, A.; Karginov, V.A.; Garcia Fernandez, J.M. Symmetry complementarity-guided design of anthrax toxin inhibitors based on beta-cyclodextrin: synthesis and relative activities of face-selective functionalized polycationic clusters. Chem. Med. Chem. 2011, 6, 181-192.

247. Sellman, B.R.; Mourez, M.; Collier, R.J. Dominant-Negative mutants of a toxin subunit: An approach to therapy of anthrax. Science 2001, 292, 695-697.

248. Singh, Y.; Khanna, H.; Chopra, A.P.; Mehra, V. A dominant negative mutant of bacillus anthracis protective antigen inhibits anthrax toxin action in vivo. J. Biol. Chem. 2001, 276, 22090-22094.

249. Yan, M.; Collier, R.J. Characterization of dominant-negative forms of anthrax protective antigen. Mol. Med. 2003, 9, 46-51.

250. Cao, S.; Guo, A.; Liu, Z.; Tan, Y.; Wu, G.; Zhang, C.; Zhao, Y.; Chen, H. Investigation of new dominant-negative inhibitors of anthrax protective antigen mutants for use in therapy and vaccination. Infect. Immun. 2009, 77, 4679-4687.

251. Krogsgaard-Larsen, P.; Strømgaard, K.; Madsen, U. Textbook of Drug Design and Discovery; CRC Press LLC, Taylor \& Francis Group: New York, NY, USA, 2010.

252. Panchal, R.G. Novel therapeutic strategies to selectively kill cancer cells. Biochem. Pharmacol. 1998, 55, 247-252. 
253. Yamaizumi, M.; Mekada, E.; Uchida, T.; Okada, Y. One molecule of diphtheria toxin fragment A introduced into a cell can kill the cell. Cell 1978, 15, 245-250.

254. Mathew, M.; Verma, R.S. Humanized immunotoxins: A new generation of immunotoxins for targeted cancer therapy. Cancer Sci. 2009, 100, 1359-1365.

255. Li, Y.M.; Hall, W.A. Targeted toxins in brain tumor therapy. Toxins 2010, 2, 2645-2662.

256. Shapira, A.; Benhar, I. Toxin-Based therapeutic approaches. Toxins 2010, 2, 2519-2583.

257. Iyer, U.; Kadambi, V.J. Antibody drug conjugates-Trojan horses in the war on cancer. J. Pharmacol. Toxicol. Methods 2011, 64, 207-212.

258. Choudhary, S.; Mathew, M.; Verma, R.S. Therapeutic potential of anticancer immunotoxins. Drug Discov. Today 2011, 16, 495-503.

259. Weldon, J.E.; Pastan, I. A guide to taming a toxin-Recombinant immunotoxins constructed from pseudomonas exotoxin A for the treatment of cancer. FEBS J. 2011, 278, 4683-4700.

260. Adkins, I.; Holubova, J.; Kosova, M.; Sadilkova, L. Bacteria and their toxins tamed for immunotherapy. Curr. Pharm. Biotechnol. 2012, 13, 1446-1473.

261. Li, Y.M.; Vallera, D.A.; Hall, W.A. Diphtheria toxin-based targeted toxin therapy for brain tumors. J. Neurooncol. 2013, 114, 155-164.

262. Antignani, A.; Fitzgerald, D. Immunotoxins: The role of the toxin. Toxins 2013, 5, 1486-1502.

263. Dosio, F.; Stella, B.; Cerioni, S.; Gastaldi, D.; Arpicco, S. Advances in anticancer antibody-drug conjugates and immunotoxins. Recent. Pat. Anticancer Drug Discov. 2014, 9, 35-65.

264. Weidle, U.H.; Tiefenthaler, G.; Schiller, C.; Weiss, E.H.; Georges, G.; Brinkmann, U. Prospects of bacterial and plant protein-based immunotoxins for treatment of cancer. Cancer Genomics Proteomics 2014, 11, 25-38.

265. Frankel, A.E.; Powell, B.L.; Duesbery, N.S.; Vande Woude, G.F.; Leppla, S.H. Anthrax fusion protein therapy of cancer. Curr. Protein Pept. Sci. 2002, 3, 399-407.

266. Varughese, M.; Chi, A.; Teixeira, A.V.; Nicholls, P.J.; Keith, J.M.; Leppla, S.H. Internalization of a bacillus anthracis protective Antigen-C-Myc fusion protein mediated by cell surface Anti-C-Myc antibodies. Mol. Med. 1998, 4, 87-95.

267. Liu, S.; Schubert, R.L.; Bugge, T.H.; Leppla, S.H. Anthrax toxin: Structures, functions and tumour targeting. Expert Opin. Biol. Ther. 2003, 3, 843-853.

268. Mechaly, A.; McCluskey, A.J.; Collier, R.J. Changing the receptor specificity of anthrax toxin. MBio 2012, 3, doi:10.1128/mBio.00088-12.

269. McCluskey, A.J.; Olive, A.J.; Starnbach, M.N.; Collier, R.J. Targeting HER2-Positive cancer cells with receptor-redirected anthrax protective antigen. Mol. Oncol. 2013, 7, 440-451.

270. McCluskey, A.J.; Collier, R.J. Receptor-Directed chimeric toxins created by sortase-mediated protein fusion. Mol. Cancer. Ther. 2013, 12, 2273-2281.

271. Liu, S.; Netzel-Arnett, S.; Birkedal-Hansen, H.; Leppla, S.H. Tumor cell-selective cytotoxicity of matrix metalloproteinase-activated anthrax toxin. Cancer Res. 2000, 60, 6061-6067.

272. Koo, H.M.; VanBrocklin, M.; McWilliams, M.J.; Leppla, S.H.; Duesbery, N.S.; Vande Woude, G.F. Apoptosis and melanogenesis in human melanoma cells induced by anthrax lethal factor inactivation of mitogen-activated protein kinase kinase. Proc. Natl. Acad. Sci. USA 2002, 99, $3052-3057$. 
273. Alfano, R.W.; Leppla, S.H.; Liu, S.; Bugge, T.H.; Duesbery, N.S.; Frankel, A.E. Potent inhibition of tumor angiogenesis by the matrix metalloproteinase-activated anthrax lethal toxin: Implications for broad anti-tumor efficacy. Cell Cycle 2008, 7, 745-749.

274. Alfano, R.W.; Leppla, S.H.; Liu, S.; Bugge, T.H.; Ortiz, J.M.; Lairmore, T.C.; Duesbery, N.S.; Mitchell, I.C.; Nwariaku, F.; Frankel, A.E. Inhibition of tumor angiogenesis by the matrix metalloproteinase-activated anthrax lethal toxin in an orthotopic model of anaplastic thyroid carcinoma. Mol. Cancer Ther. 2010, 9, 190-201.

275. Schafer, J.M.; Peters, D.E.; Morley, T.; Liu, S.; Molinolo, A.A.; Leppla, S.H.; Bugge, T.H. Efficient targeting of head and neck squamous cell carcinoma by systemic administration of a dual uPA and MMP-Activated engineered anthrax toxin. PLoS One 2011, 6, doi:10.1371/journal.pone.0020532.

276. Liu, S.; Bugge, T.H.; Leppla, S.H. Targeting of tumor cells by cell surface urokinase plasminogen activator-dependent anthrax toxin. J. Biol. Chem. 2001, 276, 17976-17984.

277. Liu, S.; Aaronson, H.; Mitola, D.J.; Leppla, S.H.; Bugge, T.H. Potent antitumor activity of a urokinase-activated engineered anthrax toxin. Proc. Natl. Acad. Sci. USA 2003, 100, 657-662.

278. Rono, B.; Romer, J.; Liu, S.; Bugge, T.H.; Leppla, S.H.; Kristjansen, P.E. Antitumor efficacy of a urokinase activation-dependent anthrax toxin. Mol. Cancer. Ther. 2006, 5, 89-96.

279. Su, Y.; Ortiz, J.; Liu, S.; Bugge, T.H.; Singh, R.; Leppla, S.H.; Frankel, A.E. Systematic urokinase-activated anthrax toxin therapy produces regressions of subcutaneous human non-small cell lung tumor in athymic nude mice. Cancer Res. 2007, 67, 3329-3336.

280. Wein, A.N.; Liu, S.; Zhang, Y.; McKenzie, A.T.; Leppla, S.H. Tumor therapy with a urokinase plasminogen activator-activated anthrax lethal toxin alone and in combination with paclitaxel. Invest. New Drugs 2013, 31, 206-212.

281. Liu, S.; Redeye, V.; Kuremsky, J.G.; Kuhnen, M.; Molinolo, A.; Bugge, T.H.; Leppla, S.H. Intermolecular complementation achieves high-specificity tumor targeting by anthrax toxin. Nat. Biotechnol. 2005, 23, 725-730.

282. Phillips, D.D.; Fattah, R.J.; Crown, D.; Zhang, Y.; Liu, S.; Moayeri, M.; Fischer, E.R.; Hansen, B.T.; Ghirlando, R.; Nestorovich, E.M.; et al. Engineering anthrax toxin variants that exclusively form octamers and their application to targeting tumors. J. Biol. Chem. 2013, 288, 9058-9065.

283. Feld, G.K.; Kintzer, A.F.; Tang, I.I.; Thoren, K.L.; Krantz, B.A. Domain flexibility modulates the heterogeneous assembly mechanism of anthrax toxin protective antigen. J. Mol. Biol. 2012, 415, 159-174.

284. Arora, N.; Klimpel, K.R.; Singh, Y.; Leppla, S.H. Fusions of anthrax toxin lethal factor to the ADP-Ribosylation domain of pseudomonas exotoxin A are potent cytotoxins which are translocated to the cytosol of mammalian cells. J. Biol. Chem. 1992, 267, 15542-15548.

285. Arora, N.; Leppla, S.H. Fusions of anthrax toxin lethal factor with shiga toxin and diphtheria toxin enzymatic domains are toxic to mammalian cells. Infect. Immun. 1994, 62, 4955-4961.

286. Milne, J.C.; Blanke, S.R.; Hanna, P.C.; Collier, R.J. Protective antigen-binding domain of anthrax lethal factor mediates translocation of a heterologous protein fused to its Amino- or carboxy-terminus. Mol. Microbiol. 1995, 15, 661-666. 
287. Arora, N.; Williamson, L.C.; Leppla, S.H.; Halpern, J.L. Cytotoxic effects of a chimeric protein consisting of tetanus toxin light chain and anthrax toxin lethal factor in non-neuronal cells. J. Biol. Chem. 1994, 269, 26165-26171.

288. Spyres, L.M.; Qa'Dan, M.; Meader, A.; Tomasek, J.J.; Howard, E.W.; Ballard, J.D. Cytosolic delivery and characterization of the TcdB glucosylating domain by using a heterologous protein fusion. Infect. Immun. 2001, 69, 599-601.

289. Bachran, C.; Hasikova, R.; Leysath, C.E.; Sastalla, I.; Zhang, Y.; Fattah, R.J.; Liu, S.; Leppla, S.H. Cytolethal distending toxin B as a cell-killing component of tumor-targeted anthrax toxin fusion proteins. Cell Death Dis. 2014, 5, doi:10.1038/cddis.2013.540.

290. Liu, X.H.; Collier, R.J.; Youle, R.J. Inhibition of axotomy-induced neuronal apoptosis by extracellular delivery of a Bcl-XL fusion protein. J. Biol. Chem. 2001, 276, 46326-46332.

291. Von Moltke, J.; Trinidad, N.J.; Moayeri, M.; Kintzer, A.F.; Wang, S.B.; van Rooijen, N.; Brown, C.R.; Krantz, B.A.; Leppla, S.H.; Gronert, K.; et al. Rapid induction of inflammatory lipid mediators by the inflammasome in vivo. Nature 2012, 490, 107-111.

292. Hobson, J.P.; Liu, S.; Rono, B.; Leppla, S.H.; Bugge, T.H. Imaging specific cell-surface proteolytic activity in single living cells. Nat. Methods 2006, 3, 259-261.

293. Hu, H.; Leppla, S.H. Anthrax toxin uptake by primary immune cells as determined with a lethal factor-beta-lactamase fusion protein. PLoS One 2009, 4, doi:10.1371/journal.pone.0007946.

294. Wesche, J.; Elliott, J.L.; Falnes, P.O.; Olsnes, S.; Collier, R.J. Characterization of membrane translocation by anthrax protective antigen. Biochemistry 1998, 37, 15737-15746.

295. Bachran, C.; Morley, T.; Abdelazim, S.; Fattah, R.J.; Liu, S.; Leppla, S.H. Anthrax toxin-mediated delivery of the pseudomonas exotoxin A enzymatic domain to the cytosol of tumor cells via cleavable ubiquitin fusions. MBio 2013, 4, doi:10.1128/mBio.00201-13.

296. London, E.; Luongo, C.L. Domain-Specific bias in arginine/lysine usage by protein toxins. Biochem. Biophys. Res. Commun. 1989, 160, 333-339.

297. Falnes, P.O.; Olsnes, S. Modulation of the intracellular stability and toxicity of diphtheria toxin through degradation by the N-End rule pathway. EMBO J. 1998, 17, 615-625.

298. Gupta, P.K.; Moayeri, M.; Crown, D.; Fattah, R.J.; Leppla, S.H. Role of N-Terminal amino acids in the potency of anthrax lethal factor. PLoS One 2008, 3, doi:10.1371/journal.pone.0003130.

299. Bachmair, A.; Finley, D.; Varshavsky, A. In vivo half-life of a protein is a function of its amino-terminal residue. Science 1986, 234, 179-186.

300. Bachran, C.; Gupta, P.K.; Bachran, S.; Leysath, C.E.; Hoover, B.; Fattah, R.J.; Leppla, S.H. Reductive methylation and mutation of an anthrax toxin fusion protein modulates its stability and cytotoxicity. Sci. Rep. 2014, 4, doi:10.1038/srep04754.

301. Walker, B.; Bayley, H. A pore-forming protein with a protease-activated trigger. Protein Eng. 1994, 7, 91-97.

302. Bayley, H. Triggers and switches in a self-assembling pore-forming protein. J. Cell. Biochem. 1994, 56, 177-182.

303. Panchal, R.G.; Cusack, E.; Cheley, S.; Bayley, H. Tumor protease-activated, pore-forming toxins from a combinatorial library. Nat. Biotechnol. 1996, 14, 852-856. 
304. Mizuki, E.; Park, Y.S.; Saitoh, H.; Yamashita, S.; Akao, T.; Higuchi, K.; Ohba, M. Parasporin, a human leukemic cell-recognizing parasporal protein of bacillus thuringiensis. Clin. Diagn. Lab. Immunol. 2000, 7, 625-634.

305. Chan, K.K.; Wong, R.S.; Mohamed, S.M.; Ibrahim, T.A.; Abdullah, M.; Nadarajah, V.D. Bacillus thuringiensis parasporal proteins induce cell-cycle arrest and caspase-dependant apoptotic cell death in leukemic cells. J. Environ. Pathol. Toxicol. Oncol. 2012, 31, 75-86.

306. Ohba, M.; Mizuki, E.; Uemori, A. Parasporin, a new anticancer protein group from bacillus thuringiensis. Anticancer Res. 2009, 29, 427-433.

307. Uemori, A.; Ohgushi, A.; Yasutake, K.; Maeda, M.; Mizuki, E.; Ohba, M. Parasporin-1Ab, a novel bacillus thuringiensis cytotoxin preferentially active on human cancer cells in vitro. Anticancer Res. 2008, 28, 91-95.

308. Bergelt, S.; Frost, S.; Lilie, H. Listeriolysin O as cytotoxic component of an immunotoxin. Protein Sci. 2009, 18, 1210-1220.

309. Williams, S.A.; Merchant, R.F.; Garrett-Mayer, E.; Isaacs, J.T.; Buckley, J.T.; Denmeade, S.R. A prostate-specific antigen-activated channel-forming toxin as therapy for prostatic disease. J. Natl. Cancer Inst. 2007, 99, 376-385.

310. Singh, R.; Browning, J.L.; Abi-Habib, R.; Wong, K.; Williams, S.A.; Merchant, R.; Denmeade, S.R.; Buckley, T.J.; Frankel, A.E. Recombinant prostate-specific antigen proaerolysin shows selective protease sensitivity and cell cytotoxicity. Anticancer Drugs 2007, 18, 809-816.

311. Bu, S.; Xie, Q.; Chang, W.; Huo, X.; Chen, F.; Ma, X. LukS-PV induces mitochondrial-mediated apoptosis and G0/G1 cell cycle arrest in human acute myeloid leukemia THP-1 cells. Int. J. Biochem. Cell Biol. 2013, 45, 1531-1537.

312. Shekarsaraei, A.G.; Hasannia, S.; Pirooznia, N.; Ataiee, F. The investigation of epsilon toxin effects on different cancerous cell lines and its synergism effect with methotrexate. J. Cancer Res. Ther. 2014, 10, 15-20.

313. Ward, R.J.; Palmer, M.; Leonard, K.; Bhakdi, S. Identification of a putative membrane-inserted segment in the alpha-toxin of staphylococcus aureus. Biochemistry 1994, 33, 7477-7484.

314. Walker, B.; Kasianowicz, J.; Krishnasastry, M.; Bayley, H. A pore-forming protein with a metal-actuated switch. Protein Eng. 1994, 7, 655-662.

315. Valeva, A.; Weisser, A.; Walker, B.; Kehoe, M.; Bayley, H.; Bhakdi, S.; Palmer, M. Molecular architecture of a toxin pore: A 15-Residue sequence lines the transmembrane channel of staphylococcal alpha-toxin. EMBO J. 1996, 15, 1857-1864.

316. Gondi, C.S.; Rao, J.S. Cathepsin B as a cancer target. Expert Opin. Ther. Targets 2013, 17, 281-291.

317. Provoda, C.J.; Lee, K.D. Bacterial pore-forming hemolysins and their use in the cytosolic delivery of macromolecules. Adv. Drug Deliv. Rev. 2000, 41, 209-221.

318. Barth, H.; Stiles, B.G. Binary Actin-ADP-Ribosylating toxins and their use as molecular trojan horses for drug delivery into eukaryotic cells. Curr. Med. Chem. 2008, 15, 459-469.

319. Lee, K.D.; Oh, Y.K.; Portnoy, D.A.; Swanson, J.A. Delivery of macromolecules into cytosol using liposomes containing hemolysin from listeria monocytogenes. J. Biol. Chem. 1996, 271, $7249-7252$. 
320. Mandal, M.; Lee, K.D. Listeriolysin O-Liposome-Mediated cytosolic delivery of macromolecule antigen in vivo: enhancement of antigen-specific cytotoxic T lymphocyte frequency, activity, and tumor protection. Biochim. Biophys. Acta 2002, 1563, 7-17.

321. Saito, G.; Amidon, G.L.; Lee, K.D. Enhanced cytosolic delivery of plasmid DNA by a sulfhydryl-activatable listeriolysin O/Protamine conjugate utilizing cellular reducing potential. Gene Ther. 2003, 10, 72-83.

322. Mathew, E.; Hardee, G.E.; Bennett, C.F.; Lee, K.D. Cytosolic delivery of antisense oligonucleotides by listeriolysin O-Containing liposomes. Gene Ther. 2003, 10, 1105-1115.

323. Provoda, C.J.; Stier, E.M.; Lee, K.D. Tumor cell killing enabled by listeriolysin O-LiposomeMediated delivery of the protein toxin gelonin. J. Biol. Chem. 2003, 278, 35102-35108.

324. Mandal, M.; Kawamura, K.S.; Wherry, E.J.; Ahmed, R.; Lee, K.D. Cytosolic delivery of viral nucleoprotein by listeriolysin O-Liposome induces enhanced specific cytotoxic T lymphocyte response and protective immunity. Mol. Pharm. 2004, 1, 2-8.

325. Walls, Z.F.; Goodell, S.; Andrews, C.D.; Mathis, J.; Lee, K.D. Mutants of listeriolysin O for enhanced liposomal delivery of macromolecules. J. Biotechnol. 2013, 164, 500-502.

326. Goletz, T.J.; Klimpel, K.R.; Leppla, S.H.; Keith, J.M.; Berzofsky, J.A. Delivery of antigens to the MHC class i pathway using bacterial toxins. Hum. Immunol. 1997, 54, 129-136.

327. Goletz, T.J.; Klimpel, K.R.; Arora, N.; Leppla, S.H.; Keith, J.M.; Berzofsky, J.A. Targeting HIV proteins to the major histocompatibility complex class I processing pathway with a novel gp120-Anthrax toxin fusion protein. Proc. Natl. Acad. Sci. USA 1997, 94, 12059-12064.

328. Leppla, S.H.; Arora, N.; Varughese, M. Anthrax toxin fusion proteins for intracellular delivery of macromolecules. J. Appl. Microbiol. 1999, 87, doi:10.1046/j.1365-2672.1999.00890.x.

329. Kelkar, D.A.; Chattopadhyay, A. The gramicidin ion channel: A model membrane protein. Biochim. Biophys. Acta 2007, 1768, 2011-2025.

330. Bourinbaiar, A.S.; Krasinski, K.; Borkowsky, W. Anti-HIV effect of gramicidin in vitro: Potential for spermicide use. Life Sci. 1994, 54, PL5-PL9.

331. Bourinbaiar, A.S.; Lee-Huang, S. Comparative in vitro study of contraceptive agents with Anti-HIV activity: Gramicidin, Nonoxynol-9, and gossypol. Contraception 1994, 49, 131-137.

332. Bourinbaiar, A.S.; Lee, C.H. Synergistic effect of gramicidin and EDTA in inhibiting sperm motility and cervical mucus penetration in vitro. Contraception 1996, 54, 367-372.

333. Bourinbaiar, A.S.; Coleman, C.F. The effect of gramicidin, a topical contraceptive and antimicrobial agent with Anti-HIV activity, against herpes simplex viruses Type 1 and 2 in vitro. Arch. Virol. 1997, 142, 2225-2235.

334. Stoloff, D.H.; Wanunu, M. Recent trends in nanopores for biotechnology. Curr. Opin. Biotechnol. 2013, 24, 699-704.

335. Mantri, S.; Sapra, K.T.; Cheley, S.; Sharp, T.H.; Bayley, H. An engineered dimeric protein pore that spans adjacent lipid bilayers. Nat. Commun. 2013, 4, doi:10.1038/ncomms2726.

336. Stoddart, D.; Ayub, M.; Hofler, L.; Raychaudhuri, P.; Klingelhoefer, J.W.; Maglia, G.; Heron, A.; Bayley, H. Functional truncated membrane pores. Proc. Natl. Acad. Sci. USA 2014, $111,2425-2430$.

337. Bainbridge, G.; Gokce, I.; Lakey, J.H. Voltage gating is a fundamental feature of porin and toxin beta-barrel membrane channels. FEBS Lett. 1998, 431, 305-308. 
338. Delcour, A.H. Structure and function of pore-forming beta-barrels from bacteria. J. Mol. Microbiol. Biotechnol. 2002, 4, 1-10.

339. Radjainia, M.; Hyun, J.K.; Leysath, C.E.; Leppla, S.H.; Mitra, A.K. Anthrax toxin-neutralizing antibody reconfigures the protective antigen heptamer into a supercomplex. Proc. Natl. Acad. Sci. USA 2010, 107, 14070-14074.

340. Ostroumova, O.S.; Kaulin, Y.A.; Gurnev, P.A.; Schagina, L.V. Effect of agents modifying the membrane dipole potential on properties of syringomycin E channels. Langmuir 2007, 23, 6889-6892.

341. Degiacomi, M.T.; Iacovache, I.; Pernot, L.; Chami, M.; Kudryashev, M.; Stahlberg, H.; van der Goot, F.G.; dal Peraro, M. Molecular assembly of the aerolysin pore reveals a swirling membrane-insertion mechanism. Nat. Chem. Biol. 2013, 9, 623-629.

342. Fennouri, A.; Przybylski, C.; Pastoriza-Gallego, M.; Bacri, L.; Auvray, L.; Daniel, R. Single molecule detection of glycosaminoglycan hyaluronic acid oligosaccharides and depolymerization enzyme activity using a protein nanopore. ACS Nano 2012, 6, 9672-9678.

343. Payet, L.; Martinho, M.; Pastoriza-Gallego, M.; Betton, J.M.; Auvray, L.; Pelta, J.; Mathe, J. Thermal unfolding of proteins probed at the single molecule level using nanopores. Anal. Chem. 2012, 84, 4071-4076.

344. Merstorf, C.; Cressiot, B.; Pastoriza-Gallego, M.; Oukhaled, A.; Betton, J.M.; Auvray, L.; Pelta, J. Wild type, mutant protein unfolding and phase transition detected by single-nanopore recording. ACS Chem. Biol. 2012, 7, 652-658.

345. Pastoriza-Gallego, M.; Rabah, L.; Gibrat, G.; Thiebot, B.; van der Goot, F.G.; Auvray, L.; Betton, J.M.; Pelta, J. Dynamics of unfolded protein transport through an aerolysin pore. J. Am. Chem. Soc. 2011, 133, 2923-2931.

346. Yuldasheva, L.N.; Merzlyak, P.G.; Zitzer, A.O.; Rodrigues, C.G.; Bhakdi, S.; Krasilnikov, O.V. Lumen geometry of ion channels formed by vibrio cholerae EL Tor cytolysin elucidated by nonelectrolyte exclusion. Biochim. Biophys. Acta 2001, 1512, 53-63.

347. Krasilnikov, O.V.; Merzlyak, P.G.; Lima, V.L.; Zitzer, A.O.; Valeva, A.; Yuldasheva, L.N. Pore formation by vibrio cholerae cytolysin requires cholesterol in both monolayers of the target membrane. Biochimie 2007, 89, 271-277.

348. Krasilnikov, O.V.; Yuldasheva, L.N. Transmembrane cholesterol migration in planar lipid membranes measured with vibrio cholerae cytolysin as molecular tool. Biochimie 2009, 91, 620-623.

349. De, S.; Olson, R. Crystal structure of the vibrio cholerae cytolysin heptamer reveals common features among disparate pore-forming toxins. Proc. Natl. Acad. Sci. USA 2011, 108, 7385-7390.

350. Mathe, J.; Aksimentiev, A.; Nelson, D.R.; Schulten, K.; Meller, A. Orientation discrimination of single-stranded DNA inside the alpha-hemolysin membrane channel. Proc. Natl. Acad. Sci. USA 2005, 102, 12377-12382.

351. Mereuta, L.; Roy, M.; Asandei, A.; Lee, J.K.; Park, Y.; Andricioaei, I.; Luchian, T. Slowing down single-molecule trafficking through a protein nanopore reveals intermediates for peptide translocation. Sci. Rep. 2014, 4, doi: 10.1038/srep03885.

352. Mahendran, K.R.; Singh, P.R.; Arning, J.; Stolte, S.; Kleinekathofer, U.; Winterhalter, M. Permeation through nanochannels: Revealing fast kinetics. J. Phys. Condens Matter 2010, 22, doi:10.1088/0953-8984/22/45/454131. 
353. Popoff, M.R. Epsilon toxin: A fascinating pore-forming toxin. FEBS J. 2011, 278, 4602-4615.

354. Bokori-Brown, M.; Savva, C.G.; Fernandes da Costa, S.P.; Naylor, C.E.; Basak, A.K.; Titball, R.W. Molecular basis of toxicity of clostridium perfringens epsilon toxin. FEBS J. 2011, 278, 4589-4601.

355. Stiles, B.G.; Barth, G.; Barth, H.; Popoff, M.R. Clostridium Perfringens epsilon toxin: A malevolent molecule for animals and man? Toxins 2013, 5, 2138-2160.

356. Petit, L.; Gibert, M.; Gourch, A.; Bens, M.; Vandewalle, A.; Popoff, M.R. Clostridium perfringens epsilon toxin rapidly decreases membrane barrier permeability of polarized MDCK cells. Cell. Microbiol. 2003, 5, 155-164.

357. Knapp, O.; Maier, E.; Benz, R.; Geny, B.; Popoff, M.R. Identification of the channel-forming domain of clostridium perfringens epsilon-toxin (ETX). Biochim. Biophys. Acta 2009, 1788, 2584-2593.

358. Nestorovich, E.M.; Karginov, V.A.; Bezrukov, S.M. Polymer partitioning and ion selectivity suggest asymmetrical shape for the membrane pore formed by epsilon toxin. Biophys. J. 2010, 99, 782-789.

359. Kronhardt, A.; Rolando, M.; Beitzinger, C.; Stefani, C.; Leuber, M.; Flatau, G.; Popoff, M.R.; Benz, R.; Lemichez, E. Cross-Reactivity of anthrax and C2 toxin: Protective antigen promotes the uptake of botulinum C2I toxin into human endothelial cells. PLoS One 2011, 6, doi:10.1371/journal.pone.0023133.

360. Beitzinger, C.; Stefani, C.; Kronhardt, A.; Rolando, M.; Flatau, G.; Lemichez, E.; Benz, R. Role of N-Terminal His6-Tags in binding and efficient translocation of polypeptides into cells using anthrax Protective Antigen (PA). PLoS One 2012, 7, doi:10.1371/journal.pone.0046964.

361. Fahrer, J.; Plunien, R.; Binder, U.; Langer, T.; Seliger, H.; Barth, H. Genetically engineered clostridial $\mathrm{C} 2$ toxin as a novel delivery system for living mammalian cells. Bioconjug. Chem. 2010, 21, 130-139.

362. Fahrer, J.; Rieger, J.; van Zandbergen, G.; Barth, H. The C2-Streptavidin delivery system promotes the uptake of biotinylated molecules in macrophages and T-Leukemia cells. Biol. Chem. 2010, 391, 1315-1325.

363. Fahrer, J.; Funk, J.; Lillich, M.; Barth, H. Internalization of biotinylated compounds into cancer cells is promoted by a molecular trojan horse based upon core streptavidin and clostridial C2 toxin. Naunyn Schmiedebergs Arch. Pharmacol. 2011, 383, 263-273.

364. Fahrer, J.; Schweitzer, B.; Fiedler, K.; Langer, T.; Gierschik, P.; Barth, H. C2-Streptavidin mediates the delivery of biotin-conjugated tumor suppressor protein p53 into tumor cells. Bioconjug. Chem. 2013, 24, 595-603.

365. Fahrer, J.; Rausch, J.; Barth, H. A cell-permeable fusion protein based on clostridium botulinum $\mathrm{C} 2$ toxin for delivery of p53 tumorsuppressor into cancer cells. PLoS One 2013, 8, doi:10.1371/journal.pone.0072455.

366. Kuan, S.L.; Ng, D.Y.; Wu, Y.; Fortsch, C.; Barth, H.; Doroshenko, M.; Koynov, K.; Meier, C.; Weil, T. pH responsive janus-like supramolecular fusion proteins for functional protein delivery. J. Am. Chem. Soc. 2013, 135, 17254-17257. 
367. Lang, A.E.; Neumeyer, T.; Sun, J.; Collier, R.J.; Benz, R.; Aktories, K. Amino acid residues involved in membrane insertion and pore formation of clostridium botulinum $\mathrm{C} 2$ toxin. Biochemistry 2008, 47, 8406-8413.

368. Kaiser, E.; Pust, S.; Kroll, C.; Barth, H. Cyclophilin A facilitates translocation of the clostridium botulinum $\mathrm{C} 2$ toxin across membranes of acidified endosomes into the cytosol of mammalian cells. Cell. Microbiol. 2009, 11, 780-795.

369. Dmochewitz, L.; Lillich, M.; Kaiser, E.; Jennings, L.D.; Lang, A.E.; Buchner, J.; Fischer, G.; Aktories, K.; Collier, R.J.; Barth, H. Role of CypA and Hsp90 in membrane translocation mediated by anthrax protective antigen. Cell. Microbiol. 2011, 13, 359-373.

370. Barth, H. Exploring the role of host cell chaperones/PPIases during cellular Up-Take of bacterial ADP-Ribosylating toxins as basis for novel pharmacological strategies to protect mammalian cells against these virulence factors. Naunyn Schmiedebergs Arch. Pharmacol. 2011, 383, 237-245.

(C) 2014 by the authors; licensee MDPI, Basel, Switzerland. This article is an open access article distributed under the terms and conditions of the Creative Commons Attribution license (http://creativecommons.org/licenses/by/3.0/). 